\title{
REGULATION OF THE NUCLEAR FACTOR OF ACTIVATED T CELL (NFAT) \\ FAMILY OF TRANSCRIPTION FACTORS IN THE FREEZE TOLERANT WOOD FROG, Rana sylvatica
}

By

Rasha Al-attar

B.SC HONOURS- UNIVERSITY OF OTTAWA, 2009

A THESIS SUBMITTED TO THE FACULTY OF GRADUATE AND POSTDOCTORAL AFFAIRS IN PARTIAL FULFILLMENT OF THE REQUIREMENTS FOR THE DEGREE OF MASTER OF SCIENCE

DEPARTMENT OF BIOLOGY

CARLETON UNIVERSITY

OTTAWA, ONTARIO, CANADA

C COPYRIGHT 2016

Rasha Al-attar 


\begin{abstract}
During winter, wood frogs (Rana sylvatica) can endure whole body freezing with $65-70 \%$ of total body water converted to extracellular ice. As a result, cells experience extensive dehydration when water exits as well as anoxia due to interruption of blood flow. Adapting to such challenges requires metabolic rearrangement, partially mediated by transcription factor control over gene expression. Here, involvement of the nuclear factor of activated T-cells (NFAT) transcription factors, isoforms c1-c4, was analyzed in liver and skeletal muscle over freeze/thaw and anoxia/re-oxygenation cycles. Freezing activated NFATc3 in liver, leading to increased osteopontin expression and glycogen synthase kinase $3 \beta$ repression (the latter potentially linked with glucose production as a cryoprotectant). Anoxia activated NFATc4 in liver, leading to increased atrial natriuretic peptide levels. Neither freezing nor anoxia significantly affected NFATs in skeletal muscle. Overall, the study indicates that NFATs have a crucial role to play in the natural cryoprotection of liver.
\end{abstract}




\section{Acknowledgement}

First, I would like to extend my sincerest thanks and appreciation to my supervisor Dr. Kenneth Storey who has taught many valuable lessons both in science and in life. His guidance and encouragement has driven me to work harder and grow to be the researcher that I aspire to be. It is because of him that I now have mice and a stronger antioxidant immune response that can deal with any stressful situation successfully. I am also thankful to Jan Storey who has always been helpful, encouraging and supportive during my stay at the Storey Lab. The Storey \& Storey duo is truly what every graduate student needs to have in order to succeed.

I would also like to thank my dear colleagues Hanane, Sanoji, Kama, Tony, Trong, Sam W, Sam L, Liam, Alex, Christie, Stuart, Bryan and Mike as well as all the undergraduate students for their support and for creating an environment full of laughter. My special thanks to Khuloud and Huda for always being there for me and encouraging me to become the scientist that I want to be. I am sorry if you had to listen to me talk about NFATs and frozen frogs over and over and over again.

I am also grateful to my parents for always being there for me and supporting me endlessly. I am truly lucky to have parents like you and I can't thank you enough for all the unconditional love that you have shown me.

Last but not least, I would like to thank the special little creatures, Rana sylvatica, for their sacrifices. If it wasn't for them, my work would have been purely theoretical.

Contribution statement: All of the data was collected by Rasha Al-attar. 
Table of Contents

Acknowledgement III

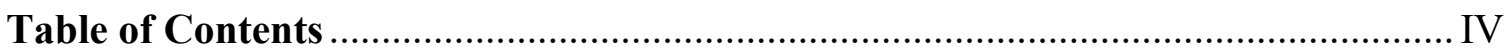

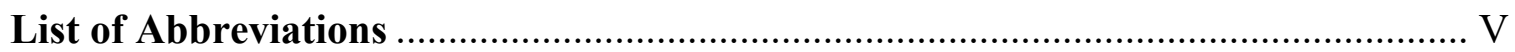

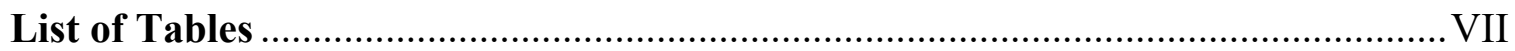

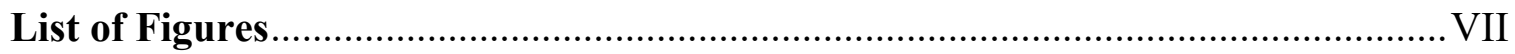

Chapter 1: General introduction....................................................................... 1

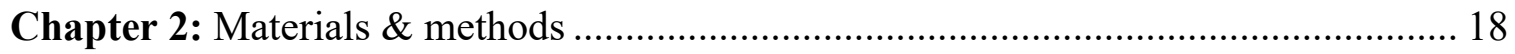

Chapter 3: Nuclear factor of activated T cell (NFAT) regulated glucose metabolism over

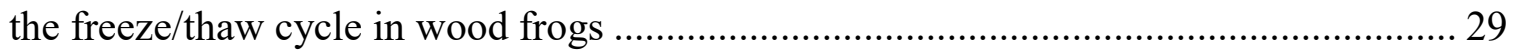

Chapter 4: Nuclear factor of activated T cell (NFAT) regulation over the anoxia/re-

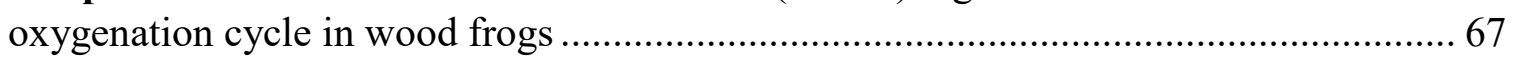

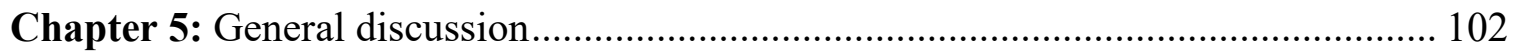

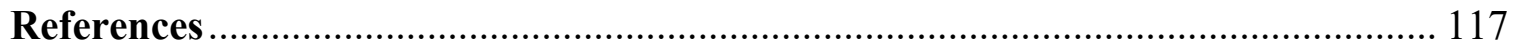

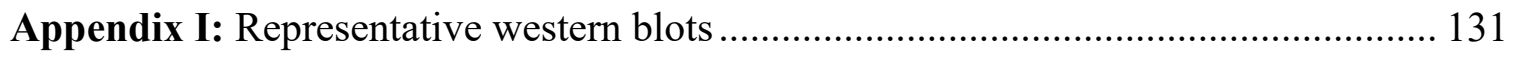




\section{List of Abbreviations}

AMPK

ANP

ATP

APS

ChIP-seq

CK1

CRAC

CREBP

DTT

EDTA

ELISA

ERK

ETC

GLUT

GRP

GSK3 $\beta$

HIF

HRP

HSP

IL-6

Iк $\beta$

JNK
AMP-activated protein kinase

Atrial natriuretic peptide

Adenosine triphosphate

Ammonium persulfate

Chromatin immunoprecipitation massive parallel sequencing

Casein kinase 1

Calcium released-activated channels

cAMP response element binding protein

Dithiothreitol

Ethylenediaminetetraacetic acid

Enzyme linked immunosorbent assay

Extracellular signal-regulated kinase

Electron transport chain

Glucose transporter

Glucose-regulated proteins

Glycogen synthase kinase $3 \beta$

Hypoxia inducible factor

Horse radish peroxidase

Heat shock proteins

Interleukin-6

Inhibitory factor kappa B

C-Jun N-terminal kinase 


\begin{tabular}{ll} 
MALDI-MS & matrix-assisted laser desorption/ionization mass spectrometry \\
MAPK & Mitogen-activated protein kinase \\
NaF & Sodium fluoride \\
NFAT & Nuclear factor of activated T cell \\
NFkB & Nuclear factor kappa B \\
PAH & pulmonary arterial hypertension \\
PMSF & Phenylmethyl-sulfonyl fluoride \\
PVDF & Polyvinylidene difuoride \\
qRT-PCR & quantitative reverse transcriptase polymerase chain reaction \\
ROS & Reactive oxygen species \\
SDS-PAGE & Sodium dodecyl sulfate polyacrylamide gel electrophoresis \\
STAT3 & signal transducer and activator of transcription 3 \\
TBST & Tris-buffered saline Tween-20 \\
TEMED & N,N,N',N'-Tetramethylethane-1,2-diamine \\
TF & Transcription factor \\
UTP & Uridine 5' triphosphate \\
VDCC & Voltage dependent calcium channel \\
\hline
\end{tabular}




\section{List of Tables}

Table 3.1: Summary of experimental conditions and antibodies used for western blotting for the freeze/thaw experiment. 35

Table 3.2: Summary of experimental conditions and antibodies used for TF-ELISAs for the freeze/thaw experiment. 36

Table 4.1: Summary of experimental conditions and antibodies used for western blotting used in the anoxia/re-oxygenation experiment. 75

Table 4.2: Summary of experimental conditions and antibodies used for TF-ELISAs used in the anoxia/re-oxygenation experiment. 76

\section{List of Figures}

Figure 1.1: Geographical distribution of $R$. sylvatica. 17

Figure 3.1: Western blot analysis on total protein extracts showing the effects of the freeze/thaw cycle on NFAT proteins in wood frog liver. 54

Figure 3.2: Western blot analysis on total protein extracts showing the effects of the freeze/thaw cycle on NFAT proteins in wood frog skeletal muscle.

Figure 3.3: TF-ELISA analysis on total protein extracts showing the effects of the freeze/thaw cycle on the DNA binding ability of NFATs in wood frog liver. 56

Figure 3.4: TF-ELISA analysis on total protein extracts showing the effects of the freeze/thaw cycle on the DNA binding ability of NFATs in wood frog skeletal muscle. 57

Figure 3.5: Environmental TF-ELISA analysis on total protein extracts showing the effect of glucose on NFATc3 DNA binding in wood frog liver.

Figure 3.6: Environmental TF-ELISA analysis on total protein extracts showing the effect of glucose on NFATc3 DNA binding in wood frog skeletal muscle.

Figure 3.7: Environmental TF-ELISA analysis on total protein extracts showing the effect of glucose and temperature on NFATc3 DNA binding in wood frog liver.....

Figure 3.8: Western blot analysis showing the effect of freezing on nuclear distribution of NFATc3 in wood frog liver.

Figure 3.9: Western blot analysis on total protein extracts showing the effect of the freeze/thaw cycle on calcineurin A protein levels in wood frog liver. 
Figure 3.10: Western blot analysis on total protein extracts showing the effect of the freeze/thaw cycle on GSK3 $\beta$ protein levels in wood frog liver and skeletal muscle.

Figure 3.11: Western blot analysis on total protein extracts showing the effect of the freeze/thaw cycle on osteopontin protein levels in wood frog liver and skeletal muscle. 64

Figure 3.12a: Western blot analysis on total protein extracts showing the effect of the freeze/thaw cycle on p-STAT3 (Tyr 705) protein levels in wood frog liver and skeletal muscle.

Figure 3.12b: Western blot analysis on total protein extracts showing the effect of the freeze/thaw cycle on p-STAT3 S727 protein levels in wood frog liver. 66

Figure 4.1: Western blot analysis on total protein extracts showing the effects of the anoxia/re-oxygenation cycle on NFAT proteins in wood frog liver.....

Figure 4.2: Western blot analysis on total protein extracts showing the effects of the anoxia/re-oxygenation cycle on NFAT proteins in wood frog skeletal muscle. 95

Figure 4.3: TF-ELISA analysis on total protein extracts showing the effects of the anoxia/re-oxygenation cycle on the DNA binding ability of NFATs in wood frog liver. 96

Figure 4.4: TF-ELISA analysis on total protein extracts showing the effects of the anoxia/re-oxygenation cycle on the DNA binding ability of NFATs in wood frog skeletal muscle.

Figure 4.5: Western blot analysis on total protein extracts showing the effect of the anoxia/re-oxygenation cycle on protein levels of GSK3 $\beta$ in wood frog liver and skeletal muscle.

Figure 4.6: Western blot analysis on total protein extracts showing the effect of the anoxia/re-oxygenation cycle on protein levels of calcineurin A in wood frog liver and skeletal muscle.

Figure 4.7: Western blot analysis on total protein extracts showing the effect of the anoxia/re-oxygenation cycle on protein levels of ANP in wood frog liver.

Figure 4.8: Western blot analysis on total protein extracts showing the effect of the anoxia/re-oxygenation cycle on protein levels of osteopontin in wood frog skeletal muscle. 


\section{Chapter 1: General introduction}


Extreme environmental conditions such as sub-zero temperatures, water loss, food availability, and prolonged exposure to low oxygen levels can impose challenges on organisms in the wild. Although the majority of animals cannot survive these abiotic stresses, a handful of organisms have developed coordinated physiological and biochemical strategies that aid survival. Studying how these organisms naturally withstand extreme conditions will better our understanding of their adaptive strategies at the molecular level, which in turn will help in creating a road map for finding novel medical therapeutics and treatments for conditions such as diabetes, ischemic stroke/reperfusion and organ cryopreservation.

\subsection{Adaptations to sub-zero temperatures}

Exposure to cold temperatures can be challenging for some organisms. While some organisms, such as the Monarch butterflies simply avoid cold temperatures by migrating to warmer climates, other organisms including most ectotherms use anhydrobiosis, vitrification, freeze avoidance or freeze tolerance to overcome cold temperatures (Storey \& Storey, 2004a). Anhydrobiosis is a defence mechanism that allows some species of prokaryotes (ex. cyanobacteria) and micro fauna (ex. Ditylenchus dipsaci nematodes) to go through periods of extreme dehydration to remove all available free water that could potentially freeze (Potts, 1994; Wharton, 1996; Storey \& Storey, 2004a). Other organisms such as poplar and birch trees use a vitrification strategy in which their free water is solidified into an amorphous sugar glass that incorporates both the extracellular and intracellular solutes (Storey \& Storey, 2004a). Insects, arthropods, and some invertebrates use two freeze avoidance strategies that rely on either the accumulation of high levels of

different solutes (ex glycerol, sorbitol, mannitol, ribitol, xylitol, erythritol, ethylene glycol, 
glucose, trehalose and sucrose) in order to lower the freezing point or they use a deep supercooling strategy where they activate mechanisms that enable their internal solutions to remain in a liquid state in freezing temperatures (Storey \& Storey, 2004a). On the other hand, in freeze tolerant organisms, freezing starts with a controlled ice nucleation event that forms ice crystals on the skin, in the extracellular matrix, and between the organs (Schmid, 1982; Storey \& Storey, 1988, 1992; Storey, 2006; Costanzo et al., 2008; Storey $\&$ Storey, 2012). Freeze-tolerance is an adaptive strategy used by some reptiles, insects, invertebrates, amphibians, and intertidal species such as bivalves, gastropods, and barnacles.

Freezing imposes several challenges including: (A) physical stress as a result of ice crystal formation in the extracellular matrix and between organs which may be damaging to the architectural integrity of the cells and capillaries, (B) anoxic/ischemic stress to organs as a result of decrease in oxygen delivery due to blood plasma being frozen (C) dehydration stress as a result of losing up to $\sim 60-70 \%$ of total body water to freezing resulting in organ dehydration and an increase in osmolality and ionic strength, and finally (D) physiological stress as a result of prolonged inactivity, complete cessation of heart beat, breathing, and brain activity (Storey, 1999; Storey \& Storey 2004a, 2004b). Furthermore, these organisms have to also deal with challenges associated with thawing such as a large influx of reactive oxygen species upon oxygen reperfusion, cellular rehydration, and disuse of skeletal muscles during prolonged periods of inactivity. Taking this into consideration, it is evident that freeze-tolerant organisms have adapted to these stresses both at the physiological and molecular level. These natural adaptations create a natural freezetolerant model system that allows scientists to gain a thorough understanding of the 
molecular underpinnings in efforts to help solve current medical problems such as organ cryopreservation for transplants, ischemic stroke, and diabetes (Storey \& Storey 2004a).

\subsection{Rana sylvatica as a natural freeze-tolerant model}

Rana sylvatica ( $R$. sylvatica), commonly known as the wood frog, is an excellent model organism used for studying vertebrate natural freeze-tolerance. The geographical range of $R$. sylvatica stretches from the Arctic circle, including Alaska (near Fairbanks), western Canada, Midwestern United States, and extends down to the Great Lakes and the Ohioan boarders (Martof \& Humphries, 1959; Middle and Barnes, 2001; Constanzo \& Lee, 2013; Constanzo et al., 2013) (Figure 1.1). Due to their large range, wood frogs from different zones are exposed to varying temperatures and have therefore adapted with different degrees of freeze tolerance. For example, wood frogs in the northern regions have shown to survive in temperatures below $-18^{\circ} \mathrm{C}$, whereas the wood frog population in the Great Lakes can only tolerate freezing at -3 to $-6^{\circ} \mathrm{C}$ (Middle \& Barnes, 2001; Costanzo \& Lee, 2013). Interestingly, a study by Costanzo \& Lee (2013) compared the physiological and biochemical response between Alaskan and Ohioan wood frogs and showed that Ohioan wood frogs have smaller glycogen stores, are less uremic and lack cryoprotective solutes compared to the Alaskan wood frogs. It is clear that the same species of wood frogs native to different geographical locations have a varying degree of freeze-tolerance. Examining the molecular responses to freezing among wood frogs native to different locations provides us with insights about the evolutionary origins of freeze-tolerance.

Wood frogs use their surroundings to cope with freezing. During winter, wood frogs burrow into the subnivean space, under multiple layers of leaves and snow on forest floors, to keep themselves insulated from the fluctuating winter conditions (Burroughs, 1914). 
Indeed, a study by Schmid (1986) has shown that the temperature of the hibernacula under layers of leaf and snow remained modestly low at $-1^{\circ} \mathrm{C}$ and decreased to only $-7^{\circ} \mathrm{C}$ in cold winter days. These hibernacula sites prevent further dehydration and help wood frogs conserve their latent heat of fusion which helps to maintain a stable body temperature close to the body's freezing point $\left(-0.5^{\circ} \mathrm{C}\right.$ for body fluids) (Storey \& Storey, 2013). Therefore, these hibernacula sites are vital in controlling the freezing process.

\subsection{Ice nucleation and total body freezing in wood frogs}

Wood frogs activate several adaptive mechanisms in response to freezing. The first step of freezing is ice nucleation whereby wood frogs initiate a slow and controlled ice crystallization process at temperatures slightly under the freezing point of their body fluids $\left(\sim-0.5^{\circ} \mathrm{C}\right)$ (Storey \& Storey, 2004b). Their moist hibernacula will form ice crystals at subzero temperatures which provides the ice contact needed to initiate ice nucleation on the surface of the skin typically happening at $-2.5^{\circ} \mathrm{C}$ to $-3^{\circ} \mathrm{C}$ (Storey \& Storey, 2004a). Interestingly, it has been shown that $\sim 98 \%$ of wood frogs kept in moist environments froze at $-2^{\circ} \mathrm{C}$ while only $\sim 20 \%$ froze when kept in dry environments (Constanzo et al., 1999). When frogs overwinter on a dry surface, ice nucleation usually happens through ice nucleating bacterial activity (Pseudomonas and Enterobacter species) that are present on the surface of the skin and/or in the gut, this occurs when the frog has cooled down to approximately $-2^{\circ} \mathrm{C}$ (Lee et al., 1995). Additionally, it has been shown that wood frog blood plasma contains ice nucleating proteins which upon activation mediate the formation of ice crystals within the vasculature (Storey \& Storey, 1988). The permeable skin of wood frogs allows ice formed on the surface to penetrate through and inoculate the internal body fluids thereby initiating an internal ice nucleation cascade (Storey \& Storey, 2004a, 2004b). 
Using proton magnetic resonance imaging (MRI), Rubinsky et al. (1994) showed that wood frogs freeze from the outside-in and ice propagates inwards through the body and fills the abdominal cavity, brain ventricles, bladder, eye lenses and forms sheets of ice between the skeletal muscle and the skin. Studies have shown that it would take between 12 to 24 hours for the wood frog to achieve maximum ice content of $60-70 \%$ (Storey \& Storey, 2004b).

\subsection{Freeze/thaw adaptations in wood frogs}

Freezing can cause serious damage to the integrity of the cell, therefore to survive freezing and maintain cellular function after thawing, various cryoprotective measures are required to facilitate extracellular freeze tolerance and intracellular freeze avoidance. Some of these cryoprotective measures include the stabilization of cell membranes by trehalose and prolines and production of large quantities of small molecular weight carbohydrates used as cryoprotectants (Storey \& Storey, 2004b). R. sylvatica use glucose and to a lesser degree glycerol as cryoprotectants during freezing (Layne \& Lee, 1995). As such, wood frogs accumulate extensive levels of glycogen ( $\sim 180 \mathrm{mg} / \mathrm{g}$ wet weight) in their liver during the fall (Storey \& Storey, 1984, 1992). Within 2-5 minutes of ice nucleation on the surface of the skin, molecular signals (involving thyroid hormones and $\beta$ adrenergic receptors) are sent to the liver to initiate the conversion of stored glycogen to glucose (via glycogenolysis) which is then distributed to other tissues via the blood (Storey \& Storey, 1984, 1985, 1988; Costanzo et al., 1993; Hemmings \& Storey, 1993). Studies have been shown that freezetolerant vertebrates such as $R$. sylvatica can increase their plasma glucose levels from 1-5 $\mathrm{mM}$ in control state to $\sim 300 \mathrm{mM}$ in frozen state, a level that well exceeds the plasma glucose levels in diabetic patients (Storey \& Storey, 1984; Duigliano et al., 2008). During freezing the heart (enters cardiac arrest after 15 hours of freezing) and the liver are saturated 
with high levels of glucose and freeze last. This saturation is important as it can cause the tissues to have a lower melting point and thereby increase the speed of thawing when temperatures rise (Layne et al., 1989; Storey \& Storey 2004b). The use of glucose as one of the main cryoprotectants is an excellent choice during freezing for several reasons: (a) glucose can be easily synthesized from liver glycogen, (b) it can easily move in and out of cells, (c) it can be easily removed and stored when no longer needed, (d) it can stabilize proteins under stress conditions, and (e) it is a compatible solute meaning that even when levels are high, it will not interfere with the kinetics of different enzymes such as the glycolytic enzymes (Storey \& Storey, 2004a, 2004b). These wood frogs can maintain their frozen state for months during the winter and only start to thaw when temperatures rise in the spring.

Thawing, similar to freezing has to occur in a controlled manner to avoid any damage to the cell. Unlike the inward propagation of ice during freezing, MRI scans by Rubinsky's group showed that thawing happens uniformly across all organs (Rubinsky et al., 1994). Interestingly, even though the heart and the liver were the last organs to freeze, they are the first ones to thaw due to the high levels of glucose present (Layne et al., 1989; Storey \& Storey, 2013). In fact, the first measurable vital sign of $R$. sylvatica during thawing is the heart beat which is detected even when some organs are still frozen (Layne et al., 1989). A study by Layne et al. (1989) on wood frogs collected from New York showed that heart beat resumes as early as one hour after thawing at $5^{\circ} \mathrm{C}(\sim 1$ beat $/ \mathrm{min})$, reaches 13.6 beat $/ \mathrm{min}$ six hours after thawing and returns to control levels ( 15 beats/min) after complete thawing. Furthermore, once regular respiratory conditions are established and oxygen delivery to anoxic organs is resumed, more physical signs such as hind leg movement are observed 
(Layne \& First, 1991). It is important to note that the length of full recovery from freezing is directly related to the length of the freezing; and the longer the frogs spend in the frozen state, the longer it would take to resume full metabolic functions (Layne et al., 1998).

Once thawed, it is important to restore glucose levels. A study by Storey and Storey (1986) showed that it could take over a week at $4{ }^{\circ} \mathrm{C}$ to fully clear excess glucose from the wood frog system. The slow up-take of glucose allows the wood frogs to be protected against fluctuating temperatures and allows them to be ready to increase their glucose concentrations should the temperatures decrease again. Due to the hyperglycemic state of the frog and the limit of renal glucose reabsorption, some of the glucose is excreted through urine; however, because glucose is extremely important for subsequent freeze/thaw cycles, it is reabsorbed from the bladder and is converted back to glycogen and stored in the liver (Storey \& Storey, 1986; Constanzo \& Lee, 1997).

\subsection{Anoxia and dehydration}

One of the main consequences of freezing is anoxia, which can be defined as inadequate delivery of oxygen to tissues. During freezing, oxygen delivery by blood to organs is interrupted due to the thickening of the blood plasma and due to blocked blood circulation (Storey \& Storey, 2004b). This blockage also interrupts communication between cells/organs and halts waste removal from cells, leaving each individual cell to survive on its own during freezing (Storey \& Storey, 2004b). Exposure to prolonged anoxic conditions causes a vast array of biochemical challenges that must be dealt with in order to survive. Challenges associated with long term anoxic exposure include the need for: a) large quantities of fermentable fuels, mainly glycogen, b) mechanisms to deal with storing and neutralization of the end products of anaerobic metabolism, c) mechanisms to adjust 
the rate of ATP consumption to match the rate of ATP synthesis and d) orchestrating a coordinated antioxidant response to protect the cell from oxidative damage as a result of anoxic exposure (Storey \& Storey, 2004c).

As a result of limited oxygen availability, the mitochondrial electron transport chain (ETC) will not have sufficient oxygen to accept electrons, therefore it becomes reduced (Krivoruchko \& Storey, 2010). The need for energy but the lack of oxygen directs ATP (adenosine triphosphate) synthesis toward anaerobic metabolism where carbohydrates (mainly glycogen) and a few amino acids (mainly aspartate but also asparagine, glutamate and glutamine) are used as fermentative fuels to make ATP (Storey \& Storey, 2004c). While glycolysis in normoxic conditions can produce up to 38 moles of ATP per one mole of glucose, during anoxic conditions catabolism of glucose to lactate and $\mathrm{H}^{+}$yields only 2 moles of ATP for each mole of glucose (Storey \& Storey, 2004c). This means that compared to aerobic ATP production, anaerobic ATP production requires 18 times more glucose to generate the same amount of energy. Although frozen frogs have large quantities of glucose available, its main role is to serve as a cryoprotectant in cells and not a fermentative energy source. Indeed, frozen wood frogs suppress the activity of three key glycolytic enzymes (hexokinase, glucose-6-phosphate dehydrogenase, 6phosphogluconate dehydrogenase) to prevent the use of cryoprotectant glucose as a source of fuel and instead they turn to endogenous glycogen stores to supply their fermentative energy demand (Storey \& Storey, 2004b; Cowan \& Storey, 2001). Moreover, even if there was an infinite supply of fermentable fuels, the end products lactate and $\mathrm{H}^{+}$would disturb the $\mathrm{pH}$ balance of the cells and would require the production of large quantities of buffering substrates to be neutralized (Jackson \& Ultsch, 2010). As a result, the demand for ATP 
exceeds the amount of ATP present during anoxia and cells are not able to provide energy for their normal metabolic rates. This disequilibrium invokes mechanisms that enable the cells to suppress their normal metabolic rates and restrict energy expenditure to processes that are crucial for survival (Storey \& Storey, 2004a, 2004b).

Some of these processes involve pro-survival pathways important for dealing with the effect of anoxia and production of reactive oxygen species (ROS). One of the main outcomes of long-term anoxia is the lethal flow of ROS during oxygen reperfusion. Since the ETC is reduced during anoxia, it becomes more susceptible to producing large quantities of ROS upon re-oxygenation (reperfusion) which can cause serious damage in the cell. Wood frogs have developed mechanisms that allow them to selectively and strategically modulate the levels and activities of specific enzymes. Studies have shown that wood frogs up-regulate the enzymatic activity of several different antioxidant enzymes such as superoxide dismutase, catalase, glutathione S-transferase, glutathione reductase, and total Se-dependent glutathione peroxidase in the majority of tissues in response to anoxia (Joanisse \& Storey, 1996; Storey \& Storey, 2004b). Moreover, levels of metabolite antioxidants such as glutathione also increase during the freeze/thaw cycle (Storey \& Storey, 2004b). Another challenge associated with anoxia is that it can damage protein structures and cause them to unfold. Heat shock proteins (HSPs) are extremely sensitive to the intracellular environment and can sense changes in intracellular $\mathrm{pH}$, ionic strength and the redox state (Krivoruchko \& Storey, 2010). They control various processes such as the cell cycle, DNA repair and stabilization, elimination of damaged proteins and guide the folding of nascent and misfolded proteins (Krivoruchko \& Storey, 2010; Storey \& Storey, 2011). Glucose-regulated proteins (GRPs) are another set of chaperone proteins that are 
induced after misfolded proteins accumulate in the endoplasmic reticulum and are markers of the unfolded protein response (Lee, 2001). Interestingly, a study by Zhenhong \& Storey (unpublished data) found that GRP78, GRP94, HSP110, Hsc 70, HSP60, HSP40 and HSP10 all increased significantly in liver during 24 hours freezing and showed tissue specific differential regulation in skeletal muscle, kidney and heart in the same condition. The same study found that HSPs also show differential regulation during anoxic exposure and recovery in these organs. Moreover, while GRP78 protein levels remained unaltered in liver and skeletal muscle after 24 hours of anoxia, GRP78 protein levels increased significantly in heart and skin (Zhenhong \& Storey, unpublished data). Protein levels of GRP78 decreased after aerobic recovery in heart and skin and kidney. Interestingly, the same study found that GRP94 protein levels increased significantly during anoxia in liver, skeletal muscle, brain, kidney and skin (Zhenhong \& Storey, unpublished data). The level of GRP94 proteins remained high in the heart during the aerobic recovery process but showed a significant decrease in kidney. The differential regulation of the chaperone proteins as well as the antioxidant response during the freeze/thaw and anoxia/reoxygenation cycle protect $R$. sylvatica and demonstrate that wood frogs have a wellorchestrated defence mechanism to protect themselves in such conditions (Joanisse \& Storey, 1996).

Another stress associated with freezing is dehydration. When wood frogs freeze, $\sim 65-70 \%$ of their total body water is withdrawn from the cells and is crystalized in the extracellular matrix (Lee et al., 1992). In fact, freezing at $-2.5^{\circ} \mathrm{C}$ caused a $58 \%$ water loss from liver and intestines and 23-36\% water loss from skeletal muscle (Lee et al., 1992). Moreover, regardless of their physiological state and whether they are at $-2^{\circ} \mathrm{C}$ or at $5^{\circ} \mathrm{C}$, 
due to their permeable skin, wood frogs rapidly loose water; which adds another layer of complication to freezing (Churchill \& Storey, 1993). To prevent further water loss as a result of evaporation, wood frogs crouch into a tight ball, known as the water-conserving position, and hibernate in damp hibernacula under layers of leaves and snow (Churchill \& Storey, 1993). In fact, the same study showed that wood frogs that hibernate in damp hibernacula lose only $2.5 \%$ of their total body water to evaporation while those that hibernate without covers will lose $\sim 50 \%$ of their total body water in the same period of freezing (Churchill \& Storey, 1993). Dehydration provides great benefits for wood frogs during freezing, it limits the amount of free water available and attenuates ice growth within the organs, thereby preventing intracellular ice formation (Storey, 1999). Wood frogs confine ice growth within the extra-organ space, abdominal cavity, the bladder, and/or between the skeletal muscle and the skin thus limiting cellular damage to tissues and capillaries (Storey, 1999). In addition, during dehydration water is withdrawn from inside the cell to the extracellular matrix resulting in the increase of cryoprotectant glucose concentration inside the cell which would allow for better cellular protection (Storey, 1999; Storey \& Storey, 2004a). Lastly, although extreme dehydration can disturb the balance in ionic strength and osmolality, the permeable nature of amphibian skin already has prepared the wood frogs to deal with such problems (Storey \& Storey, 2004b). Ultimately, although several defence mechanisms are in place to combat cellular stress as a result of freezing, anoxia and dehydration, the limited amount of energy available to spend on different metabolic processes makes it impossible for cells to survive for prolonged periods of time under these conditions. For this reason, wood frogs rearrange their metabolic processes in a well-organized manner and allocate the energy available to those metabolic pathways 
that mediate survival under stress conditions. This means wood frogs will go through a series of metabolic re-organization events before entering the hypometabolic frozen state.

\subsection{Metabolic rate depression in wood frogs}

There is a finite amount of ATP available for metabolic processes (as a result of anaerobic metabolism), therefore strict regulation of energy usage is extremely important for survival. For this reason, organisms that go through prolonged periods of freezing, dehydration or anoxia decrease their metabolic rate dramatically to restrict energy expenditure to those processes that enable survival (Storey \& Storey, 2004a; Storey, 2015). Some insects have been shown to decrease their metabolic rates to $<10 \%$ of their control state when kept in the same conditions (Storey \& Storey, 2004a). There are several requirements that must be met before wood frogs can survive in a hypometabolic state including: a) coordinating a global suppression of metabolic processes, b) maintaining available and adequate reservoir of glucose, and facilitate cellular mechanisms to dispose of accumulated waste and end products, c) coordinating communication between cells and organs d) strict regulation of ATP production and ATP consumption, e) reprioritizing energy allocation/restriction to specific cellular functions, and f) stabilizing cellular components during periods of stress in order to minimize/cut the amount of energy needed for restoration (Storey, 2015; Storey \& Storey, 2007).

These metabolic suppressions occur at various cellular levels including: transcription (i.e. epigenetic modifications such as histone phosphorylation, methylation \& acetylation, DNA methylation, acetylation and SUMOylation, etc.), post-transcription (i.e. microRNAs and stress granules), and post-translation (i.e. reversible protein phosphorylation, acetylation, methylation, ubiquitination) (Biggar \& Storey, 2011; Storey, 2015). The focus 
of this project will be on the nuclear factor of activated $\mathrm{T}$ cells transcription factor family (NFATs) and their role in mediating transcriptional regulation under freezing and anoxia in liver and skeletal muscle of wood frogs.

Transcription and translation are energy consuming processes and are subjected to tight regulation during metabolic rate depression. The accessibility of the DNA to the transcriptional machinery determines the rate and possibility of transcription. Several studies have thoroughly outlined the histone code and concluded that generally histone $\mathrm{H} 3$ methylation at lysine 4 (H3K4), lysine 36 (H3K36) and lysine 79 (H3K79) causes gene activation whereas di-and tri-methylation of histone H3 at lysine 9 (H3K9), lysine 27 (H3K27) and histone H4 lysine 20 (H4K20) causes gene repression (Zhang et al., 2012). Previous studies have shown that histone acetylation (Lys 23) and to some degree phosphorylation (Ser 10) promote transcription as they make the chromatin relaxed and open to the transcriptional machinery (Sterner \& Berger, 2000; Cheung et al., 2000). Interestingly, when comparing histone $\mathrm{H} 3$ during hibernation in 13-lined ground squirrels, (also a hypometabolic state), total levels of this protein did not change; however, there was a 38-39\% reduction in both histone $\mathrm{H} 3$ phosphorylation (Ser 10) and acetylation (Lys 23) during hibernation as compared to the euthermic group corresponding to the global suppression of transcription (Morin \& Storey, 2006). Moreover, total histone deacetylase activity (enzymes that remove acetyl groups from histones) increased by 1.82 folds during hibernation, indicating their role in suppressing transcription (Morin \& Storey, 2006).

Even when more than $80-95 \%$ of the global metabolic rates are suppressed, about $\sim 1-10 \%$ of the cellular energy is used by transcription (Rolfe \& Brown, 1997; Storey \& Storey, 2007). As mentioned earlier, to be able to withstand prolonged periods of stress (in this 
case freezing and anoxia), it is important to selectively express certain genes that will promote survival. In order to do that, there needs to be an increase in the activity and or levels of the corresponding transcription factor as well as easy accessibility to the DNA segments involved. For this thesis, the nuclear factor of activated $\mathrm{T}$ cells (NFATs) transcription factor family will be investigated under frozen and anoxic conditions in liver and skeletal muscle to assess whether NFATs may play a role in regulating freeze-tolerance in the wood frog.

\subsection{Nuclear Factor of Activated T cells (NFATs)}

Nuclear factor of activated T-cells (NFATs) are a family of five transcription factors that are associated with different signaling pathways. Studies have shown that NFATc1-4 share the same DNA binding sequence $(\mathrm{A} / \mathrm{T})$ GGAAA $(\mathrm{AN})(\mathrm{A} / \mathrm{T} / \mathrm{C}) \mathrm{N}$ and are regulated by calcium levels, whereas NFAT5 binds to a different DNA sequence and is activated by osmotic changes (Rao et al., 1997; Graef et al., 2001; Viola et al., 2005; Cheung \& Ko, 2013). Inactive NFATs are heavily phosphorylated and reside in the cytoplasm. Upon stimulation with intracellular calcium, NFATs are selectively dephosphorylated by calcineurin (calcium-calmodulin dependant phosphatase) and translocate into the nucleus (Rao et al., 1997; Rusnak \& Mertz, 2000). Once in the nucleus, NFATs will bind to their DNA consensus sequence either alone or with other co-factors and carry out the expression of target genes (i.e. osteopontin and atrial natriuretic peptide). When calcium levels decrease, several nuclear kinases including glycogen synthase kinase-3 $\beta$ (GSK3 $\beta$ ), p38, and c-Jun N-terminal kinase (JNK) will re-phosphorylate NFATs in the nucleus and mediate their translocation back to the cytoplasm (Lee \& Kim, 2007; Velden et al., 2008). NFATc1-c4 have been extensively studied in the immune system and are associated with 
inducing the expression of immune related genes (Rao et al., 1997; Iniguez et al., 2000). Emerging studies on NFATs have shown that they also regulate genes associated with the cell cycle, apoptosis, adipocyte differentiation, skeletal and cardiac muscle differentiation, intestinal cell differentiation, insulin homeostasis, and cardiac hypertrophy (Molkentin et al., 1998; Ho et al., 1998; Baksh et al, 2000; Delling et al., 2000; Wang et al., 2001; Baksh et al., 2002; Viola et al., 2005; Yang et al., 2006). Because of their involvement in several cellular processes, it was of interest to examine NFAT regulation and see how they are able to surpass several control points and remain active even during an extreme hypometabolic state in wood frogs. This study, is the first investigation into the role that NFAT signaling during the freeze/thaw and anoxia/re-oxygenation cycles in $R$. sylvatica liver and skeletal muscle. 
Figure 1.1: Geographical distribution of $R$. sylvatica. The geographical location of $R$. sylvatica from Alaska to the Ohioan boarders is shown by the shaded area.

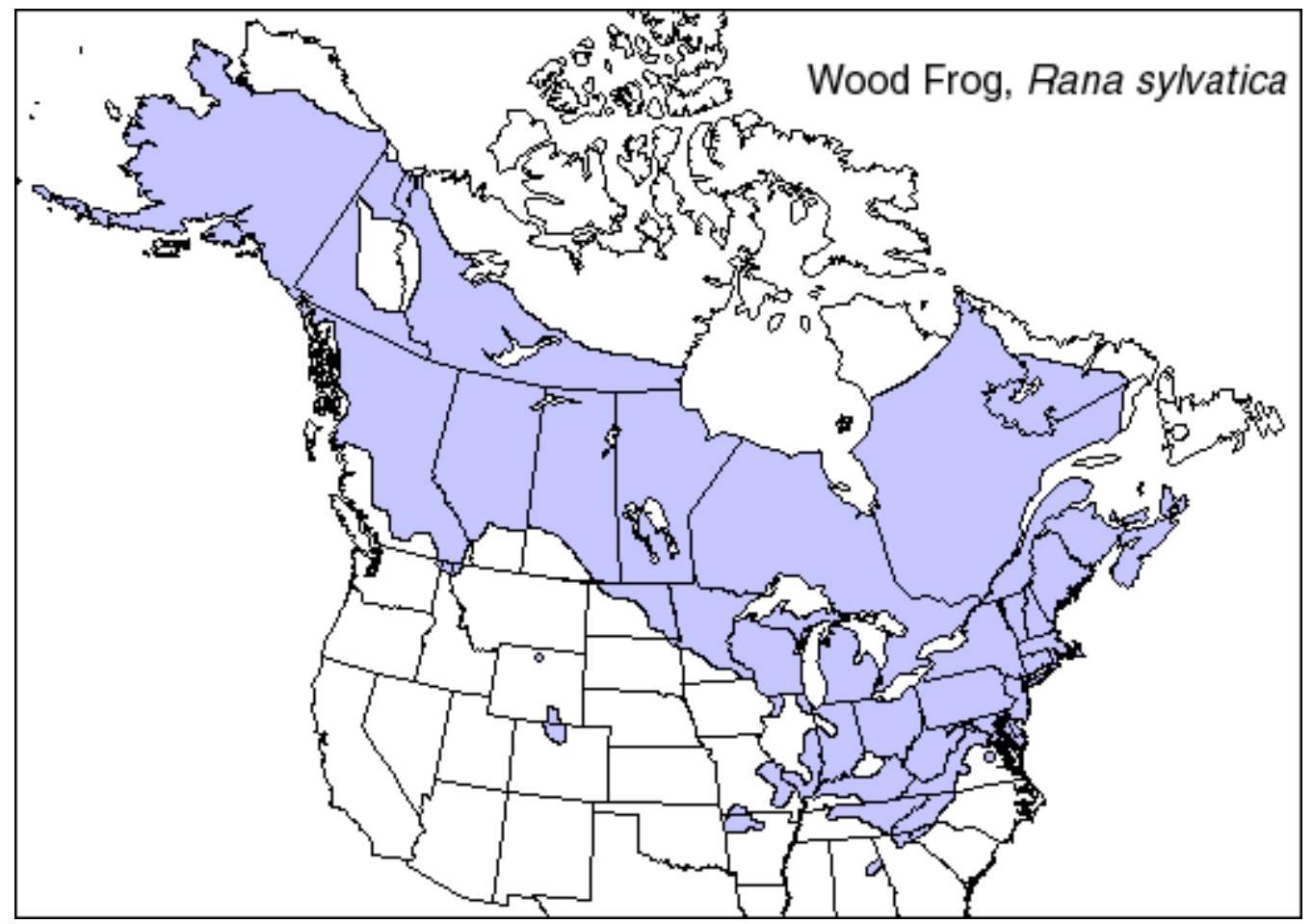

http://idahoherps.pbworks.com/f/1222831176/Rana-sylvatica_Range.gif 
Chapter 2: Materials \& methods 


\subsection{Animals}

A group of 250 adult male wood frogs (approximately 2 years old, between 5-7 grams) were captured from breeding ponds in the Limerick Forest near the Ottawa area during the spring and transported, on ice, to our animal care facility at Carleton University. Frogs were then washed in a tetracycline bath and held at $5^{\circ}$ in plastic containers containing sphagnum moss for two weeks prior to experimentation. The control group was sampled from this temperature and time.

\subsubsection{Freezing treatment}

A subset of wood frogs was placed in plastic containers lined with damp paper towel and kept at $-4^{\circ} \mathrm{C}$ incubators for 45 minutes to facilitate the cooling of their body temperatures and to allow for the initiation of ice nucleation. Immediately after the initial 45-minute cooling period, containers were placed in a $-2.5^{\circ} \mathrm{C}$ incubator for 24 hours. The frozen group was sampled at this time and temperature. The other group exposed to 24 hours of freezing was transferred to another incubator and allowed to thaw for 8 hours at $5^{\circ} \mathrm{C}$. The 8 hour thawed group was sampled from this temperature. All animals (25-30 wood frogs for each experimental condition) were sacrificed by pithing, and the dissected tissues were immediately flash frozen in liquid nitrogen and stored at $-80{ }^{\circ} \mathrm{C}$ for future use.

\subsubsection{Anoxic treatment}

Distilled water was bubbled with $100 \%$ nitrogen gas for approximately 30 minutes and was then used to damp paper towels. The damp paper towels were used to line the bottom of the plastic chambers in preparation for the experiment. The lid to the plastic chamber had two ports: one to allow nitrogen gas in and one to vent it out. Once the lid 
was secured, $100 \%$ nitrogen gas was introduced to the chamber for $15-20$ minutes. The $5^{\circ} \mathrm{C}$ acclimated frogs were then placed in these chambers (5-6 frogs/chamber) and the lid was tightened and sealed with parafilm. Nitrogen gas was then passed through the chambers for approximately 30 minutes and the chambers were placed at $5^{\circ} \mathrm{C}$ incubators for 24 hours.

After 24 hours of exposure, half of the chambers were placed on ice while still sealed. Nitrogen gas was reintroduced to the plastic chambers and frogs were quickly sampled with minimal air exposure. This group represented the 24 hour anoxic group. The remaining 24 hour anoxic frogs were transferred to new chambers where they were exposed to air and allowed to recover from their anaerobic episode for 4 hours at $5^{\circ} \mathrm{C}$. The 4 hour anoxic recovery group was sampled from this time and temperature. All animals (25-30 wood frogs for each experimental condition) were sacrificed by pithing, and the dissected tissues were immediately flash frozen in liquid nitrogen and stored at $-80{ }^{\circ} \mathrm{C}$ for future use.

All animal care, experimentation and euthanasia procedures were previously approved by the Carleton University Animal Care Committee in accordance to the guidelines set forth by the Canadian Council on Animal Care.

\subsection{Total soluble protein extraction for immunoblotting}

Total soluble protein extraction was done using the control, 24 hour frozen, 8 hour thawed, 24 hour anoxic and 4 hour aerobic recovered liver and skeletal muscle tissues. Frozen tissue samples ( $n=4$ independent biological replicates) were homogenized in 1:2 w/v of homogenization buffer containing $20 \mathrm{mM}$ Hepes, $\mathrm{pH}$ 7.4, $100 \mathrm{mM} \mathrm{NaCl}, 0.1 \mathrm{mM}$ EDTA, $10 \mathrm{mM} \mathrm{NaF}, 1.0 \mathrm{mM} \mathrm{Na} \mathrm{VO}_{4}, 10 \mathrm{mM} \beta$-glycerophosphate, a few crystals of 
phenylmethyl-sulfonyl fluoride (PMSF) and $1.0 \mu \mathrm{L}$ of Protease Inhibitor Cocktail (BioShop, Burlington, ON, Canada, cat. No. P1Coo1.1) using a Polytron homogenizer for $\sim 15-20$ seconds. All of the homogenates were then centrifuged at $12,000 \mathrm{xg}$ at $4^{\circ} \mathrm{C}$ for 15 minutes and the resulting supernatants containing the soluble proteins were collected. The concentrations of the supernatants were measured using a Bio-Rad protein assay (Bio-Rad, Mississauga, ON, Canada, cat. No. 500.006) and all of the liver as well as the control skeletal muscle samples were normalized to $10 \mu \mathrm{g} / \mu \mathrm{L}$ using homogenization buffer. The 24 hour frozen, 8 hour thawed, 24 hour anoxic and 8 hour recovered skeletal muscle samples were normalized to $5 \mu \mathrm{g} / \mu \mathrm{L}$ using homogenization buffer.

Equal volumes of the total soluble protein extracts and 2X SDS-PAGE (Sodium dodecyl sulfate polyacrylamide gel electrophoresis) sample buffer containing $100 \mathrm{mM}$ Tris-HCl, $4 \% \mathrm{w} / \mathrm{v}$ SDS, $20 \% \mathrm{v} / \mathrm{v}$ glycerol, $0.2 \% \mathrm{w} / \mathrm{v}$ bromophenol blue and $10 \% \mathrm{v} / \mathrm{v} 2$ mercaptoethanol were mixed to give the following final concentrations: $5 \mu \mathrm{g} / \mu \mathrm{L}$ for all of the liver and the control of skeletal muscle samples and $2.5 \mu \mathrm{g} / \mu \mathrm{L}$ for the 24 hour frozen, 8 hour thawed, 24 hour anoxic and 8 hour recovered skeletal muscle samples. All of the samples were then boiled in a water bath for $\sim 5$ minutes, cooled on ice for $\sim 5$ minutes and stored at $-80{ }^{\circ} \mathrm{C}$ until needed. To check for the integrity of the proteins extracted, all of the prepared samples were run on a $10 \%$ SDS-PAGE gel. The gel was then stained using Coomassie Brilliant Blue $(0.25 \% \mathrm{w} / \mathrm{v}$ Coomassie Brilliant Blue, $7.5 \% \mathrm{v} / \mathrm{v}$ acetic acid and $50 \%$ methanol) and visualized using the Chemi-Genius Bioimager (Syngene, MD, United States). 


\subsection{Cyto-nuclear protein extraction}

Frozen skeletal muscle and liver tissues from the control and 24 hour frozen groups ( 0.5-1.0 g) were homogenized in 1:2 w/v of homogenization buffer A containing $10 \mathrm{mM}$ HEPES, pH 7.9; $10 \mathrm{mM} \mathrm{KCl} ; 10$ mM EDTA; $20 \mathrm{mM} \beta$-glycerol phosphate, $10 \mu \mathrm{L}$ of Dithiotreitol (DTT) and $10 \mu \mathrm{L}$ of Protease Inhibitor Cocktail (BioShop, Burlington, ON, Canada, cat. No. P1Coo1.1) per one mL of buffer using a Dounce Pestle homogenizer for 3-10 strokes. The samples were then centrifuged at $10,000 \mathrm{xg}$ for 10 minutes at $4^{\circ} \mathrm{C}$. The resulting supernatants were removed and used as the cytoplasmic fraction. The remaining pellets were re-suspended in extraction buffer B containing 20 mM HEPES, pH 7.9; 400 $\mathrm{mM} \mathrm{NaCl} ; 1 \mathrm{mM}$ EDTA; $10 \% \mathrm{v} / \mathrm{v}$ glycerol; $20 \mathrm{mM} \beta$-glycerol phosphate and $1.5 \mu \mathrm{L}$ of DTT and $1.5 \mu \mathrm{L}$ of Protease Inhibitor Cocktail per $147 \mu \mathrm{L}$ of buffer. The samples were incubated on ice for one hour while rocking with intermittent vortexing and subsequently centrifuged at $10,000 \mathrm{xg}$ for 10 minutes at $4^{\circ} \mathrm{C}$. The resulting supernatants were removed and used as the nuclear extract. The concentration of each sample was measured using a Bio-Rad protein assay (Bio-Rad, Mississauga, ON, Canada, cat No. 500.006) and samples were normalized to $10 \mu \mathrm{g} / \mu \mathrm{L}$ using their respective extraction buffers. The samples were then mixed with equal volumes of 2x SDS-PAGE sample buffer, boiled in a water bath for $\sim 5$ minutes and chilled on ice for $\sim 5$ minutes. To test for the integrity of the cyto-nuclear extraction, equal concentrations of the cytoplasmic and the corresponding nuclear fractions

were run on an SDS-PAGE gel. The separated proteins were then electro-blotted to a polyvinylidene difluoride (PVDF) membrane (Millipore, Etobicoke, ON, Canada, cat No. IPVH07850, $45 \mu \mathrm{m}$ pore) and probed with an anti-histone H3 antibody (Cell Signaling, 
Dancers, MA, United States, cat No. 9715) which served as a nuclear marker. All of the samples were stored at $-80{ }^{\circ} \mathrm{C}$ until needed.

\subsection{SDS polyacrylamide gel electrophoresis and Western blotting}

All samples were run on SDS-PAGE gels with either $8 \%, 10 \%$, or $15 \%$ resolving and 5\% stacking gel compositions. The 5\% stacking gels contained 5\% acrylamide, $0.13 \mathrm{M}$ Tris $\mathrm{pH}$ 6.8, 0.10\% SDS, 0.10\% ammonium persulfate (APS), and $0.10 \%$ N,N,N',N'Tetramethylethane-1,2-diamine (TEMED) and the 10\% resolving gels contained $10 \% \mathrm{v} / \mathrm{v}$ of acrylamide, $0.4 \mathrm{M}$ Tris $\mathrm{pH} 8.8,0.10 \%$ SDS, $0.10 \%$ APS and $0.10 \%$ TEMED. Equal amounts $(\sim 25 \mu \mathrm{g})$ of all total soluble protein extracts were loaded on SDS-PAGE gels and run using the Bio-Rad mini-gel apparatus filled with running buffer (25mM Tris-base, 190 $\mathrm{mM}$ glycine, $0.1 \% \mathrm{w} / \mathrm{v}$ SDS with $\mathrm{pH}$ of $\sim 7.6$ ). The separated proteins were then transferred to PVDF membranes (Millipore, Etobicoke, ON, Canada, cat No. IPVH07850, $45 \mu \mathrm{m}$ pore), and electro-blotted at $160 \mathrm{~mA}$ for 60-100 minutes at room temperature using transfer buffer containing $25 \mathrm{mM}$ Tris $(\mathrm{pH} 8.5), 192 \mathrm{mM}$ glycine and 10\% v/v methanol. The membranes were then dried at room temperature for $\sim 5$ minutes, rehydrated with methanol for $\sim 1-2$ minutes and blocked with either $5-10 \% \mathrm{w} / \mathrm{v}$ milk in Tris buffered saline with Tween-20 (TBST: 20mM Tris base pH 7.6, $150 \mathrm{mM} \mathrm{NaCl}$, and 0.05\% v.v Tween-20) or high molecular weight $2 \mathrm{mg} / \mathrm{mL}$ polyvinyl alcohol in TBST (Sigma-Aldrich, Oakville, ON, Canada, cat No. P8136-250G). Membranes were then washed 2-3 times for $\sim 5$ minutes with TBST and probed with either 1:500 or 1:000 of primary antibodies diluted in TBST and incubated overnight at $4^{\circ} \mathrm{C}$. The membranes were then washed 3-4 times for $\sim 5$ minutes with TBST at room temperature while shaking and incubated with 1:5000 or 1:7000 of appropriate secondary antibodies conjugated to horse radish peroxidase (HRP) 
for $\sim 30$ minutes at room temperature while shaking. Membranes were then washed 3 times for 5 minutes at room temperature with TBST while shaking. Membranes were then visualized with chemiluminescence (ECL: $\mathrm{H}_{2} \mathrm{O}_{2}$ and luminol) and stained with Coomassie blue $(0.25 \% \mathrm{w} / \mathrm{v}$ Coomassie brilliant blue, $7.5 \% \mathrm{v} / \mathrm{v}$ acetic acid, and $50 \%$ methanol). The Chemi-Genius Bioimager system (Syngene, MD, US) was used to visualized ECL bands as well as the Coomassie stained membranes. Band intensities were analyzed using the Gene Tools software (Syngene, MD, US) and statistical analysis was done using the SigmaPlot software (SYSTAT, San Jose, CA, US).

\subsection{Total soluble protein isolation for transcription factor ELISA (TF-ELISA)}

Approximately $50 \mathrm{mg}$ of frozen liver and skeletal muscle samples from control, 24 hour frozen, 8 hour thawed, 24 hour anoxic and 4 hour aerobically recovered tissues $(n=4$ independent biological replicates) were homogenized with 1:5 w/v pre-chilled lysis buffer (Etobicoke, ON, Canada, cat. No. 43-040) with $1 \mathrm{mM} \mathrm{Na}_{3} \mathrm{VO}_{4}, 10 \mathrm{mmM} \mathrm{NaF}, 10 \mathrm{mM} \beta$ glycerophosphate and 1\% protease inhibitor cocktail (BioShop, Burlington, ON, Canada, cat. No. PIC001) using a Dounce Pestle Homogenizer. The homogenates were then incubated on ice for 30 minutes with intermittent vortexing and centrifuged at $14,000 \mathrm{xg}$ for 20 minutes at $4{ }^{\circ} \mathrm{C}$. The supernatants were collected and their concentrations were measured using the Bio-Rad protein assay. To evaluate the efficiency of the extraction, aliquots of $10 \mu \mathrm{L}$ of each sample was mixed with $2 x$ SDS-PAGE sample buffer and run on SDS-PAGE, as previously described. The gel was then stained with Coomassie blue and bands were visualized using the Chemi-Genius Bioimager system (Syngene, MD, United States). The total soluble protein extracts were stored at $-80^{\circ} \mathrm{C}$ until use. 


\subsubsection{TF-ELISA DNA binding activity}

Biotinylated-DNA oligonucleotides containing the NFAT binding element were synthesized by Sigma Genosys (Sigma-Aldrich, Oakville, ON, Canada). The biotinylated probe (5'-Biotin-CGCCCAAAGAGGAAAATTTGTTTCATA-3' and the complementary probe 3'GCGGGTTTCTCCTTTTAAACAAAGTAT-5') were diluted to a final concentration of $500 \mathrm{pmol} / \mu \mathrm{L}$ with $\mathrm{ddH}_{2} \mathrm{O}$. The two probes were then mixed in a 1:1 ratio and placed in a thermocycler for 10 minutes at $95^{\circ} \mathrm{C}$ and subsequently allowed to cool at room temperature. The double stranded probes were then diluted with 1x phosphate buffer

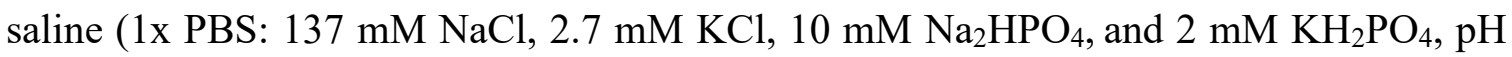
7.4), briefly vortexed and $50 \mu \mathrm{L}$ containing $40 \mathrm{pmol}$ of the double stranded probe was added to streptavidin coated micro-plate wells (R\&D Systems, Minneapolis, MB, Canada, Cat. No.CA73521-134,). Following a $~ 1$ hour incubation at room temperature, the unbound probes were discarded and the wells were washed three times with $200 \mu \mathrm{L}$ of wash buffer (1x PBS and 0.1\% Tween-20) and another time with 1x PBS buffer. Total soluble TFELISA protein extracts containing equal amounts of protein $(n=3-4$ biological replicates for control, 24 hour frozen, 8 hour thawed, 24 hour anoxic and 4 hour recovery) for liver and skeletal muscle were mixed with transcription binding buffer (10 mM HEPES, $50 \mathrm{mM}$ $\mathrm{KCl}, 0.5 \mathrm{mM}$ EDTA, 3mM MgCl $2,10 \%$ glycerol, $0.5 \mathrm{mg} / \mathrm{ml} \mathrm{BSA,} 0.05 \% \mathrm{NP}-40$ and 20 mM DTT, $\mathrm{pH} 7.9,1 \mu \mathrm{g}$ of Salmon sperm DNA), briefly vortexed and $50 \mu \mathrm{L}$ (containing 20-50 $\mu \mathrm{g}$ ) of each sample was added to the probed wells. For the negative control wells, the same lysis buffer (Etobicoke, ON, Canada, cat. No. 43-040) used for TF-ELISA protein extraction was added to the master mix instead of proteins. All the wells were incubated for 1-2 hours at room temperature while on the plate shaker (Denville Scientific, Holliston, 
MA, US, cat. No. S2125). After the incubation, the unbound transcription factors were discarded and the wells were washed three times with wash buffer. A volume of $60 \mu \mathrm{L}$ per well of the appropriate anti-NFAT antibody was then added to each well and the plate was incubated for $\sim 1-2$ hours at room temperature. Excess primary antibody was discarded and the wells were washed three times with wash buffer. Anti-rabbit IgG antibodies conjugated to HRP (Bio-Shop, Burlington, ON, cat. No. APA007P.2) were then added to each well (1:2000, $60 \mu \mathrm{L} /$ well) and the plate was incubated for $\sim 1$ hour at room temperature. Unbound secondary antibodies were then discarded, the wells were washed four times with wash buffer and were subsequently incubated with $60 \mu \mathrm{L}$ of tetramethylbenzidine (BioShop, Burlington, ON, Canada, cat No. TMB333.100). After colour development, 60 $\mu \mathrm{L}$ of STOP solution (1M HCl, $60 \mu \mathrm{L} /$ well) was added to terminate the reaction and the absorbance was measured. To determine the efficiency of the probes, a test run using pooled samples was performed for all of the targets to compare the DNA binding activity of the well containing all the assay components to wells that are missing either the probe, protein or the primary antibody.

\subsubsection{Environmental TF-ELISA}

The same TF-ELISA protocol described above was performed with the following changes. To evaluate the effect of glucose on the DNA binding ability of NFATs, various concentrations of D-glucose $(0-400 \mathrm{mM})$ were added to the reaction mixture, at room temperature, containing the total native soluble protein homogenates from the 24 hour frozen groups. The DNA binding activity of all the wells were normalized to the DNA activity of the wells with $0 \mathrm{mM}$ of glucose. 
To create a comparable well environment to freezing conditions, the same environmental TF-ELISA with different $\mathrm{D}$-glucose concentrations was performed at $4^{\circ} \mathrm{C}$ using liver extracts from the 24 hour frozen group. The DNA binding activity of all the wells were normalized to the DNA activity of the wells with $0 \mathrm{mM}$ of glucose.

\subsection{Quantification and statistics}

Enhanced chemiluminescent and Coomassie blue stained immunoblots were visualized using the Chemi-Genius BioImaging system (Syngene, Fredrerich, MD, USA) and densitometic analysis was performed with the associated Gene Tools software (Syngene, Fredrerich, MD, USA). Immunoblot chemiluminescent band intensities were normalized against a group of Coomassie blue stained bands in the same lane that showed constant levels of protein expression between the control, 24 hour frozen, 8 hour thawed, 24 hour anoxia and 4 hour aerobic recovery groups (respectively for each stress/recovery condition) to correct for any minor variations in sample loading. The reported fold changes for the 24 hour frozen, 8 hour thawed, 24 hour anoxic and 4 hour recovered samples were relative to the control group by setting the control group to 1 . Data is obtained from $n=3-4$ independent biological replicates.

The absorbance for the TF-ELISA experiments was measured at $450 \mathrm{~nm}$ (with 655 $\mathrm{nm}$ as a reference) using the Multiskan spectrophotometer (Thermo Electron Corporation, Waltham, Massachusetts, USA). Data was analyzed using the SigmaPlot software (SYSTAT, San Jose, CA, USA) and the relative DNA binding activity for the 24 hour frozen, 8 hour thawed, 24 hour anoxic and 4 hour recovered groups were normalized to the control group which was set to 1 . 
The data obtained by western blotting and TF-ELISA were analyzed and graphed with One-way ANOVA with Holm-Sidak as a post-hoc test using the SigmaPlot software (SYSTAT, San Jose, CA, United States). Graphs show mean values \pm SEM of $n=3-4$ independent biological replicates; ${ }^{*} \mathrm{p}<0.05$. 
Chapter 3: Nuclear factor of activated T cell (NFAT) regulated glucose metabolism over the freeze/thaw cycle in wood frogs 


\subsection{Introduction}

Many organisms are faced with environmental conditions that could be challenging to their survival. Extreme cold temperature in winter is one such challenge that organisms must overcome to survive. While some organisms simply migrate to warmer climates to avoid winter, many others face winter in their natural habitat by adjusting their physiology, biochemistry and behavior to survive winter. Rana sylvatica, also known as wood frogs, are one of the few vertebrates known to date that are capable of surviving cold winter months by using a freeze-tolerant strategy (Schmid, 1982). Being able to survive freezing also requires the capability to withstand prolonged anoxic exposure, dehydration and hyperglycemia; stresses these wood frogs have mastered even in their unfrozen states. While the behavioral and physiological changes to prepare for freezing are important, this chapter will focus on the biochemical adaptations required to deal with freezing. As discussed earlier, during freezing wood frogs depress their metabolic rates and conserve the energy available by reprioritizing fuel consumption for processes crucial for survival. One way to regulate metabolic rate is through the regulation of gene expression, specifically by modulating the activity of key transcription factors. This study will examine the role of the nuclear factor of activated T cells (NFATs) over the wood frog freeze/thaw cycle.

As discussed in chapter 1, NFATc1-c4 are involved in coordinating several processes including the regulation of glucose metabolism (Nilsson et al., 2006; Yang et al., 2006). Previous studies have shown that glucose can increase intracellular calcium levels through the release of extracellular uridine 5' triphosphate (UTP) and ATP (Parodi et al., 2002; Lazaroski et al., 2003). The released UTP causes an influx of intracellular and 
extracellular calcium from inositol triphosphate receptors and L-type voltage-dependent calcium channels (VDCCs) respectively (Lawrence et al., 2002; Nilsson et al., 2006). These high levels of calcium will then activate calcineurin (a calcium-calmodulin phosphatase) and allow it to dephosphorylate and activate NFATs (Rao et al., 1997). Once activated, NFATs enter the nucleus to elicit the transcription of their target genes.

Emerging studies are elucidating the role of NFATs in mediating glucose metabolism. A study by Lawrence et al. (2002) has shown that glucose and glucagon-like peptide-1 both induce the expression of the rat insulin I gene via the NFAT signaling pathway in pancreatic $\beta$-cells. Moreover, NFATc $2^{-/-}$and $\mathrm{NFATc}^{-/-}$mice had a reduced expression of resistin and leptin, two adipokines that are involved in glucose metabolism (Yang et al., 2006). Other studies have shown that NFATc3 is responsible for inducing the expression of osteopontin under high glucose conditions (Nilsson-Berglund et al., 2010; Zetterqvist et al., 2015). Interestingly, the expression of osteopontin by NFATc3 was shown to be regulated by the release of extracellular nucleotides such as UTP, which as explained earlier causes the release of calcium (Renault et al., 2003; Nilsson-Berglund et al., 2010).

Once the transcription of the target genes is complete and NFAT-mediated transcription is no longer needed, several kinases including glycogen synthase kinase $3 \beta$ (GSK3 $\beta$ ) re-phosphorylate NFATs (particularly NFATc3) and mediate their nuclear export back to the cytoplasm (Velden et al., 2008). In addition to its role as a transcription factor regulator, GSK3 $\beta$ is also involved in negatively regulating the activity of glycogen synthase, an enzyme that mediates the biosynthesis of glycogen when glucose levels are high (Woodgett et al., 1984; Lawrence \& Roach, 1997). 
While GSK3 $\beta$ deactivates glycogen synthase via phosphorylation at serine $3 \mathrm{a}, \mathrm{b}$ and $\mathrm{c}$, studies have shown that insulin can activate glycogen synthase by facilitating dephosphorylation at these three sites (Zhang et al., 1993; Skurat \& Roach, 1996; Lawrence \& Roach, 1997). Insulin can also stimulate the AKT signaling pathway which has been shown to phosphorylate and deactivate GSK3 $\beta$ in various cell types (Cross et al., 1995; Cross et al., 1997). Interestingly, previous studies by our group have shown that plasma insulin levels increase from $17 \mu \mathrm{Units} / \mathrm{ml}$ during active control to approximately 35 $\mu$ Units/ml under freezing conditions (Hemmings \& Storey, 1996). This increase in insulin levels during freezing also correlates with the increase in AKT activation in liver but not in skeletal muscle (Zhang \& Storey, 2013). Based on the previously known regulatory relation between AKT and GSK3 $\beta$, an increase in AKT activity was expected to correlate with a decrease in GSK3 $\beta$ activity. The decrease in GSK3 $\beta$ activity would then allow glycogen synthase to remain active and carry on glycogenesis when glucose levels are high; however, this is not the case. AKT did not seem to inhibit GSK3 $\beta$ activity as p-GSK3 $\beta$ (Ser 9) levels were found to be significantly decrease in liver and skeletal muscle during freezing, implying that GSK3 $\beta$ was indeed active (Dieni et al., 2012). Moreover, Russell \& Storey (1995) have found that freezing significantly decreases the activity of glycogen synthase in liver but not skeletal muscle in $R$. sylvatica.

Maintaining a hyperglycemic state during freezing is important as the available glucose functions to cryopreserve the organs and prevent mechanical ice damage. A recent study has found that GSK3 $\beta$ can complex with AMP-activated protein kinase (AMPK) and inhibit its activity (Bultot et al., 2012; Suzuki et al., 2013). Interestingly, AMPK protein levels were found to significantly increase during freezing in both $R$. sylvatica liver and 
skeletal muscle (Rider et al., 2006). The contradictory results between an active GSK3 $\beta$ as measured by Dieni et al., (2012) and an active AMPK as measured by Rider et al., (2006) prompted this study to investigate the regulatory mechanism involved in GSK3 $\beta$ expression during freezing in $R$. sylvatica liver and skeletal muscle.

A thorough literature review revealed that NFATs may play a role in regulating GSK3 $\beta$ expression. Osteopontin as suggested earlier is a downstream target of NFATc3 capable of causing the activation of the signal transducer and activator of transcription 3 (STAT3) transcription factor in hepatocytes (Nilsson-Berglund et al., 2010; Wen et al., 2015; Zetterqvist et al., 2015). Interestingly, high levels of insulin have been shown to elicit the nuclear translocation of the activated STAT3, which when bound to the GSK3 $\beta$ regulatory element prevented its transcription (Moh et al., 2008). Moreover, while activated STAT3 prevents GSk3 $\beta$ transcription, it does not alter the activity of alreadyavailable GSK3 $\beta$ enzymes present in the cell. Based on these findings, two hypotheses were postulated:

1. NFATs will be differentially regulated during the freeze/thaw cycle with NFATc3 showing an increase in expression after exposure to freezing.

2. Activation of the NFATc3 signaling pathway will result in GSk3 $\beta$ transcriptional suppression during freezing. 


\subsection{Materials and Methods}

Animal treatment and tissue collection

Male wood frogs were collected, treated and sacrificed as previously described in chapter 2.

\section{Protein isolation and immunoblotting}

Total protein isolation for western blotting, TF-ELISA, and the cyto-nuclear protein extraction protocols are described in chapter 2. For western botting, the samples were run on SDS-PAGE at a constant voltage (180V) and transferred to PVDF membranes at a constant amperage $(160 \mathrm{~mA})$. For a summary of the antibodies and blotting conditions used, see Table 3.1.

\section{TF-ELISA DNA binding activity}

The DNA binding analysis was performed using the control, 24 hour frozen and 8 hour thawed samples as stated in Chapter 2. For a summary of antibody list and treatment conditions used, see Table 3.2. 
Table 3.1: Summary of experimental conditions and antibodies used for western blotting for the freeze/thaw experiment.

\begin{tabular}{|c|c|c|c|c|c|}
\hline $\begin{array}{l}\text { Primary } \\
\text { antibody }\end{array}$ & Tissue & $\begin{array}{c}\text { Blocking } \\
\text { condition (in } \\
\text { TBST) }\end{array}$ & $\begin{array}{c}\text { Probing } \\
\text { conditions } \\
\text { (dilution) }\end{array}$ & $\begin{array}{l}\text { Secondary } \\
\text { antibody } \\
\text { (dilution) }\end{array}$ & $\begin{array}{c}\text { Primary } \\
\text { antibody } \\
\text { source }\end{array}$ \\
\hline NFATc1 & Liver & $\begin{array}{l}5 \% \text { milk for } \\
60 \mathrm{~min}\end{array}$ & $\begin{array}{l}\text { 1:1000 } \\
\text { overnight }\end{array}$ & $\begin{array}{l}1: 5000 \text { for } 30 \\
\text { mins }\end{array}$ & Santa Cruz \\
\hline NFATc2 & Liver & $\begin{array}{l}1 \% \text { milk for } \\
30 \text { mins }\end{array}$ & $\begin{array}{l}1: 1000 \\
\text { overnight }\end{array}$ & $\begin{array}{l}1: 7000 \text { for } 30 \\
\text { mins }\end{array}$ & Santa Cruz \\
\hline NFATc3 & Liver & $\begin{array}{l}5 \% \text { milk for } \\
60 \text { mins }\end{array}$ & $\begin{array}{l}1: 500 \\
48 \text { hours }\end{array}$ & $\begin{array}{l}1: 5000 \text { for } 30 \\
\text { mins }\end{array}$ & Santa Cruz \\
\hline NFATc3 & $\begin{array}{l}\text { Liver } \\
\text { (cyto/nuc) }\end{array}$ & $\begin{array}{l}2 \% \text { milk for } \\
30 \text { mins }\end{array}$ & $\begin{array}{l}1: 500 \\
\text { overnight }\end{array}$ & $\begin{array}{l}1: 7000 \text { for } 30 \\
\text { mins }\end{array}$ & Santa Cruz \\
\hline NFATc4 & Liver & $\begin{array}{l}2.5 \% \text { milk for } \\
30 \text { mins }\end{array}$ & $\begin{array}{l}1: 1000 \\
\text { overnight }\end{array}$ & $\begin{array}{l}1: 6000 \text { for } 30 \\
\text { mins }\end{array}$ & Santa Cruz \\
\hline NFATc1 & Muscle & $\begin{array}{l}3 \% \text { milk for } \\
30 \text { mins }\end{array}$ & $\begin{array}{l}1: 500 \\
48 \text { hours }\end{array}$ & $\begin{array}{l}1: 5000 \text { for } 30 \\
\text { mins }\end{array}$ & Santa Cruz \\
\hline NFATc2 & Muscle & $\begin{array}{l}3 \% \text { milk for } \\
30 \text { mins }\end{array}$ & $\begin{array}{l}1: 500 \\
48 \text { hours }\end{array}$ & $\begin{array}{l}1: 5000 \text { for } 20 \\
\text { mins }\end{array}$ & Santa Cruz \\
\hline NFATc3 & Muscle & $\begin{array}{l}1 \% \text { milk for } \\
30 \text { mins }\end{array}$ & $\begin{array}{l}1: 1000 \\
\text { overnight }\end{array}$ & $\begin{array}{l}1: 7000 \text { for } 30 \\
\text { mins }\end{array}$ & Santa Cruz \\
\hline NFATc4 & Muscle & $\begin{array}{l}1 \% \text { for } 30 \\
\text { mins }\end{array}$ & $\begin{array}{l}1: 1000 \\
\text { overnight }\end{array}$ & $\begin{array}{l}1: 7000 \text { for } 30 \\
\text { mins }\end{array}$ & Santa Cruz \\
\hline Osteopontin & Liver & $\begin{array}{l}2 \mathrm{mg} / \mathrm{mL} \\
\mathrm{HMW} \text { PVA } \\
\text { for } 3 \mathrm{mins}\end{array}$ & $\begin{array}{l}1: 1000 \\
\text { overnight }\end{array}$ & $\begin{array}{l}1: 7000 \text { for } 30 \\
\text { mins }\end{array}$ & $\begin{array}{l}\text { DSHB } \\
\text { University } \\
\text { of Iowa }\end{array}$ \\
\hline Osteopontin & Muscle & $\begin{array}{l}2 \mathrm{mg} / \mathrm{mL} \\
\mathrm{HMW} \text { PVA } \\
\text { for } 3 \mathrm{mins}\end{array}$ & $\begin{array}{l}1: 1000 \\
\text { overnight }\end{array}$ & $\begin{array}{l}1: 7000 \text { for } 30 \\
\text { mins }\end{array}$ & $\begin{array}{l}\text { DSHB } \\
\text { University } \\
\text { of Iowa }\end{array}$ \\
\hline $\begin{array}{l}\text { Calcineurin } \\
\text { A }\end{array}$ & Liver & $\begin{array}{l}4 \% \text { milk for } \\
30 \text { mins }\end{array}$ & $\begin{array}{l}1: 1000 \\
\text { overnight }\end{array}$ & $\begin{array}{l}1: 7000 \text { for } 30 \\
\text { mins }\end{array}$ & GeneTex \\
\hline $\begin{array}{l}\text { Calcineurin } \\
\text { A }\end{array}$ & Muscle & $\begin{array}{l}4 \% \text { milk for } \\
30 \text { mins }\end{array}$ & $\begin{array}{l}1: 1000 \\
\text { overnight }\end{array}$ & $\begin{array}{l}1: 7000 \text { for } 30 \\
\text { mins }\end{array}$ & GeneTex \\
\hline GSK3 $\beta$ & Liver & $\begin{array}{l}5 \% \text { milk for } \\
30 \text { mins }\end{array}$ & $\begin{array}{l}1: 1000 \\
\text { overnight }\end{array}$ & $\begin{array}{l}1: 7000 \text { for } 30 \\
\text { mins }\end{array}$ & Santa Cruz \\
\hline GSK3 $\beta$ & Muscle & $\begin{array}{l}5 \% \text { milk for } \\
30 \text { mins }\end{array}$ & $\begin{array}{l}1: 1000 \\
\text { overnight }\end{array}$ & $\begin{array}{l}1: 7000 \text { for } 30 \\
\text { mins }\end{array}$ & Santa Cruz \\
\hline $\begin{array}{l}\text { p-STAT3 } \\
\text { Y705 }\end{array}$ & Liver & $\begin{array}{l}2 \% \text { milk for } \\
30 \text { mins }\end{array}$ & $\begin{array}{l}1: 1000 \\
\text { overnight }\end{array}$ & $\begin{array}{l}1: 7000 \text { for } 30 \\
\text { mins }\end{array}$ & $\begin{array}{l}\text { Cell } \\
\text { Signaling }\end{array}$ \\
\hline $\begin{array}{l}\text { p-STAT3 } \\
\text { Y705 }\end{array}$ & Muscle & $\begin{array}{l}2 \% \text { milk for } \\
30 \text { mins }\end{array}$ & $\begin{array}{l}1: 1000 \\
\text { overnight }\end{array}$ & $\begin{array}{l}1: 7000 \text { for } 30 \\
\text { mins }\end{array}$ & $\begin{array}{l}\text { Cell } \\
\text { Signaling }\end{array}$ \\
\hline $\begin{array}{l}\text { p-STAT3 } \\
\text { S727 }\end{array}$ & Liver & $\begin{array}{l}2 \% \text { milk for } \\
30 \text { mins }\end{array}$ & $\begin{array}{l}1: 1000 \\
\text { overnight }\end{array}$ & $\begin{array}{l}1: 7000 \text { for } 30 \\
\text { mins }\end{array}$ & $\begin{array}{l}\text { Cell } \\
\text { Signaling }\end{array}$ \\
\hline
\end{tabular}


Table 3.2: Summary of experimental conditions and antibodies used for TF-ELISAs for the freeze/thaw experiment.

\begin{tabular}{|l|l|l|l|l|}
\hline $\begin{array}{c}\text { Primary antibody } \\
\text { and probing } \\
\text { condition (dilution } \\
\text { in PBST) }\end{array}$ & Tissue & Treatment & $\begin{array}{c}\text { Secondary } \\
\text { antibody and } \\
\text { condition } \\
\text { (dilution in } \\
\text { PBST })\end{array}$ & $\begin{array}{c}\text { Protein amount } \\
(\boldsymbol{\mu g})\end{array}$ \\
\hline $\begin{array}{l}\text { NFATc1 } \\
\text { 1:1000 for } \sim 60 \text { mins }\end{array}$ & Liver & None & $1: 2000$ for 1 hour & 30 \\
\hline $\begin{array}{l}\text { NFATc2 1:1000 for } \\
\sim 80 \text { mins }\end{array}$ & Liver & None & $1: 2000$ for 1 hour & 40 \\
\hline $\begin{array}{l}\text { NFATc3 1:1000 for } \\
\sim 90 \text { mins }\end{array}$ & Liver & None & $1: 2000$ for 1 hour & 20 \\
\hline $\begin{array}{l}\text { NFATc4 1:1000 for } \\
\sim 60 \text { mins }\end{array}$ & Liver & None & $1: 2000$ for 1 hour & 40 \\
\hline $\begin{array}{l}\text { NFATc1 1:1000 for } \\
\sim 90 \text { mins }\end{array}$ & Muscle & None & $1: 2000$ for 1 hour & 40 \\
\hline $\begin{array}{l}\text { NFATc2 1:1000 for } \\
\sim 90 \text { mins }\end{array}$ & Muscle & None & $1: 2000$ for 1 hour & 30 \\
\hline $\begin{array}{l}\text { NFATc3 1:1000 for } \\
\sim 70-80 \text { mins }\end{array}$ & Muscle & None & $1: 2000$ for 1 hour & 40 \\
\hline $\begin{array}{l}\text { NFATc4 1:1000 for } \\
\sim 90 \text { mins }\end{array}$ & Muscle & None & $1: 2000$ for 1 hour & 30 \\
\hline $\begin{array}{l}\text { NFATc3 1:1000 for } \\
\sim 70 \text { mins }\end{array}$ & Liver & Glucose & $1: 2000$ for 1 hour & 20 \\
\hline $\begin{array}{l}\text { NFATc3 1:1000 for } \\
\sim 70 \text { mins }\end{array}$ & Liver & $\begin{array}{l}\text { Glucose }+ \\
4{ }^{\circ} \mathrm{C}\end{array}$ & $1: 2000$ for 1 hour & 20 \\
\hline $\begin{array}{l}\text { NFATc3 1:1000 for } \\
\sim 60 \text { mins }\end{array}$ & Muscle & Glucose & $1: 2000$ for 1 hour & 40 \\
\hline
\end{tabular}




\subsection{Results}

\section{Analysis of total NFAT protein level}

Total NFAT protein levels in both liver and skeletal muscle were measured using western immunoblotting to compare expression between the control at $5^{\circ} \mathrm{C}, 24$ hour frozen group at $-2.5^{\circ} \mathrm{C}$, and 8 hour thawed group at $5^{\circ} \mathrm{C}$. Mammalian polyclonal antibodies were used for western blotting and each cross-reacted with a band near the expected molecular weight.

Figure 3.1 shows the pattern of NFATc1-4 expression during the freeze/thaw cycle in wood frog liver. The antibodies used cross reacted with a single band for each NFAT at the following molecular weights: NFATc1: 140 Kda, NFATc2 $\sim 98 \mathrm{KDa}, \mathrm{NFATc} 3 \sim 98$ KDa, NFATc4 100 KDa). Exposure to 24 hours of freezing caused a significant decrease in NFATc1 $(0.74 \pm 0.08)$ and NFATc2 $(0.74 \pm 0.07)$ compared to their respective control groups $(1.00 \pm 0.08$ and $1.00 \pm 0.04$ respectively). After 8 hours of thawing, NFATc1 $(0.99$ $\pm 0.06)$, and NFATc2 $(1.05 \pm 0.02)$ expression levels were found to rebound back to control with NFATc2 showing a significant increase compared to the 24 hour frozen group. Exposure to 24 hour of freezing caused a significant increase in NFATc3 $(2.16 \pm 0.05)$ protein expression and levels remained significantly high during 8 hour of thawing $(1.79 \pm$ $0.19)$ compared to the control group $(1.00 \pm 0.15)$. Levels of NFATc4 protein expression increased significantly $(1.15 \pm 0.03)$ during 24 hour of freezing but levels rebound back to control $(1.00 \pm 0.01)$ after 8 hour of thawing $(1.05 \pm 0.04)$.

Figure 3.2 shows the pattern of NFATc1-c4 expression during the freeze/thaw cycle in wood frog skeletal muscle. Exposure to 24 hour of freezing had no effect on NFATc1 $(1.00 \pm 0.07)$ and NFATc3 $(1.00 \pm 0.05)$ protein expression during freezing compared to 
the control groups $(1.00 \pm 0.13$ and $1.00 \pm 0.19$ respectively). During 8 hour of thawing, a significant increase in protein expression levels was observed for NFATc1 $(1.74 \pm 0.09)$ and NFATc3 $(2.17 \pm 0.09)$, relative to control and frozen levels. Protein expression levels of NFATc2 $(0.61 \pm 0.08)$ decreased significantly after 24 hour of freezing and remained significantly low $(0.67 \pm 0.05)$ after 8 hour of thawing compared to the control group $(1.00$ $\pm 0.05)$. Protein expression levels of NFATc4 also significantly decreased after 24 hour of freezing $(0.70 \pm 0.03)$ compared to the control $(1.00 \pm 0.05)$. During 8 hour of thawing, NFATc4 protein expression $(0.92 \pm 0.05)$ returned back to control levels and showed a significant increase compared to the 24 hour frozen group.

\section{DNA binding activity of NFATs}

Figure 3.3 shows the relative DNA binding activity of NFATs to their consensus sequence measured using TF-ELISAs in liver. The DNA binding activity of NFATc1 significantly decreased $(0.56 \pm 0.1)$ after 24 hour of freezing but levels returned to control values $(1.00 \pm 0.06)$ after 8 hour of thawing $(1.16 \pm 0.06)$. The DNA binding activity of NFATc2 did not show a significant change after 24 hours of freezing $(0.88 \pm 0.04)$ or after 8 hours of thawing $(1.13 \pm 0.07)$ compared to the control group $(1.00 \pm 0.09)$. Exposure to 24 hours of freezing caused a significant increase in NFATc3 DNA binding activity (1.33 $\pm 0.04)$ compared to the control group $(1.00 \pm 0.08)$. The DNA binding activity of NFATc3 returned to control levels after 8 hours of thawing $(0.97 \pm 0.08)$ but also showed a significant decrease compared to the 24 hour frozen group. The DNA binding activity of NFATc4 showed a significant decrease after 24 hours of freezing $(0.29 \pm 0.16)$ and levels remained low after 8 hour of thawing $(0.31 \pm 0.11)$ compared to the control group $(1.00 \pm$ $0.05)$. 
Figure 3.4 shows the relative DNA binding activity of NFATs to their consensus sequence in skeletal muscle. The DNA binding activity of NFATc1 showed a significant decrease $(0.37 \pm 0.09)$ after 24 hours of freezing and levels remained significantly low $(0.29 \pm 0.12)$ compared to the control group $(1.00 \pm 0.03)$. Exposure to 24 hours of freezing caused a significant decrease $(0.69 \pm 0.05)$ in NFATc2 DNA binding activity compared to the control $(1.00 \pm 0.03)$ and 8 hour thawed group. The DNA binding activity returned to control levels after 8 hour of thawing $(0.94 \pm 0.063)$. There was no significant change in DNA binding activity of NFATc3 after 24 hours of freezing $(0.87 \pm 0.11)$ or after 8 hours of thawing $(0.84 \pm 0.11)$ compared to the control group $(1.00 \pm 0.09)$. Exposure to 24 hour of freezing caused a significant decrease in NFATc4 DNA binding activity $(0.67 \pm 0.10)$ compared to the control group $(1.00 \pm 0.02)$ and levels remained low after 8 hour of thawing $(0.74 \pm 0.07)$.

Figures 3.5 and 3.6 shows the relative DNA binding activity of NFATc3 to its consensus sequence in the presence of a glucose gradient during freezing in liver and skeletal muscle at room temperature. Varying the concentrations of glucose did not affect the DNA binding activity of NFATc3 in either of the tissues.

Figure 3.7 shows the change in DNA binding activity of NFATc3 in the 24 hour frozen group in presence of a glucose gradient at $4^{\circ} \mathrm{C}$. The combination of glucose gradient and cold temperature also did not show any effect on the DNA binding activity of NFATc3.

\section{Nuclear localization levels of NFATc3}

Protein levels of NFATc3 in the nuclear fractions of the control and the 24 hour frozen group was measured using western blotting. Figure 3.8 shows that exposure to 24 
hours of freezing $(2.05 \pm 0.33)$ caused a significant increase in nuclear levels of NFATc3 as compared to the control nuclear fraction $(1.00 \pm 0.23)$.

\section{Analysis of total calcineurin A, GSK3ß, osteopontin, p-STAT3 (Tyr 705), p-Stat3 (Ser} 727)

Figure 3.9 shows the protein expression levels of calcineurin A in liver and skeletal muscle. The anti- calcineurin A antibody used detected a single band at approximately 57.5 $\mathrm{KDa}$ in both liver and skeletal muscle of wood frogs. Levels of calcineurin A remained constant during freezing $(0.86 \pm 0.04)$ but were found to be significantly elevated $(1.36 \pm$ $0.13)$ after 8 hour of thawing, compared to the control $(1.00 \pm 0.07)$ and 24 hour frozen groups in liver. Exposure to 24 hours of freezing caused a significant decrease $(0.51 \pm$ $0.003)$ in calcineurin A protein expression compared to the control group $(1.00 \pm 0.02)$. After 8 hours of thawing $(0.78 \pm 0.02)$ protein levels increased significantly compared to the 24 hour frozen group but remained significantly low compared to the control group.

Figure 3.10 shows the protein expression levels of GSK3 $\beta$ in liver and skeletal muscle. The anti-GSK3 $\beta$ antibody used detected a single band at $\sim 47 \mathrm{KDa}$. Exposure to 24 hours of freezing caused a significant decrease $(0.58 \pm 0.07)$ in GSK3 $\beta$ protein expression compared to the control in liver $(1.00 \pm 0.13)$. GSK3 $\beta$ expression returned to control levels $(1.04 \pm 0.04)$ after 8 hour of thawing but showed a significant increase in comparison to the 24 hour frozen group in liver. Expression levels of GSK3 $\beta$ did not change after 24 hour of freezing $(0.95 \pm 0.07)$ or 8 hour of thawing $(0.77 \pm 0.3)$ in skeletal muscle compared to the control group $(1.00 \pm 0.07)$. 
Figure 3.11 shows the protein expression levels of osteopontin in liver and skeletal muscle. The anti-osteopontin antibody used detected a single band at $35 \mathrm{KDa}$ in both liver and skeletal muscle of wood frogs. Protein levels of osteopontin increased significantly after 24 hour of freezing $(2.1 \pm 0.12)$ in liver relative to the control group $(1.00 \pm 0.10)$. After 8 hour of thawing, osteopontin levels $(1.6 \pm 0.14)$ remained significantly higher than the control group but showed a significant decrease compared to the 24 hour frozen group. Osteopontin protein levels did not change after 24 hours of freezing $(0.85 \pm 0.13)$ or after 8 hours of thawing $(1.09 \pm 0.14)$ compared to the control group $(1.00 \pm 0.02)$ in skeletal muscle.

Figure 3.12a shows the levels of p-STAT (Tyr 705) in liver and skeletal muscle. The antibody used detected a single band at approximately $88 \mathrm{KDa}$. Levels of p-STAT (Tyr $705)$ did not show a significant change after 24 hours of freezing $(1.43 \pm 0.09)$ but showed a significant increase after 8 hours of thawing $(8.36 \pm 1.3)$ compared to the control $(1.00 \pm$ 0.07 ) and the 24 hour frozen group in liver. Exposure to 24 hours of freezing did not show a significant change $(1.45 \pm 0.23)$ in p-STAT (Tyr 705) protein expression and levels remained unchanged after 8 hour of thawing $(1.88 \pm 0.66)$ compared to the control group $(1.00 \pm 0.13)$ in skeletal muscle.

Figure 3.12b shows the levels of p-STAT (Ser 727) in liver. Exposure to 24 hours of freezing caused a significant increase $(6.2 \pm 1.28)$ in protein expression compared to the control group $(1.00 \pm 0.09)$. Protein levels decreased significantly compared to the 24 hour frozen group aftern8 hours of thawing $(2.4 \pm 0.35)$ but remained significantly high compared to the control group. The same antibody used did not detect any bands in skeletal muscle. 


\subsection{Discussion}

Studying freeze tolerance in natural models can provide insightful information about the molecular mechanisms necessary for mediating survival. Thorough understanding of these mechanisms can aid in developing appropriate cryopreservation techniques that could prolong organ preservation time and organ viability prior to transplantation. Freeze tolerant frogs also provide an excellent natural model for studying diabetes, as they go through prolonged periods of hyperglycemia with glucose levels (300 $\mathrm{mM}$ ) well exceeding those of patients with severe diabetic ketoacidosis (40 mM) (Kearney \& Dang, 2007). Although faced with a finite amount of energy and a global suppression of gene expression, these frogs can selectively and strategically up regulate necessary pathways that mediate survival, even during periods of extreme hypometabolism. For example, during freezing blood delivery to organs is interrupted. This interruption causes the production of reactive oxygen species (ROS) which is challenging to the cell. To protect against ROS, $R$. sylvatica up regulate several antioxidants metabolites and antioxidant enzymes to help combat oxidative damage. On the contrary, some signaling pathways are not essential to the cell during freezing. For example, the extracellular signal-regulated kinase (ERK) is responsible for cellular growth and proliferation (Cowan \& Storey, 2001). Indeed, ERK activity in liver, kidney, heart and brain showed no significant increase in this condition, suggesting that cellular growth is not favoured during freezing (Joanisse \& Storey, 1996; Greenway \& Storey, 2001; Cowan \& Storey, 2001). Freezing is a complex process that requires the tissue-specific regulation of cellular functions. For example, the mitogen-activated protein kinase (MAPK) signaling pathway is activated in a tissue specific manner in frozen wood frogs, where c-Fos protein levels increased in the brain and kidney but remained unaltered in liver and heart during freezing (Greenway \& Storey, 
2000). Similarly, Zhang \& Storey (2013) found that AKT signaling was found to be regulated in a tissue-specific manner, AKT was inhibited in skeletal muscle, kidney and heart while remaining active in liver after freezing exposure. The current study aimed to investigate the NFAT signaling pathway in liver and skeletal muscle over the freeze/thaw cycle in R. sylvatica.

The liver is the main site for glycogen storage in the body. This organ was of particular interest to this study as it plays a pivotal role in modulating survival by producing large quantities of glucose to cryopreserve all organs during freezing and by clearing the excess glucose upon thawing (Costanzo, 1993; Storey, 2003; Zhang \& Storey, 2013). In contrast, the small glycogen stores in skeletal muscle are preserved during freezing and confined to the muscle itself to mediate function within the tissue (Hemming \& Storey, 2001). Due to the contrasting role of liver and skeletal muscle glycogen storage and usage, it was of interest to compare NFAT signaling in these two tissues.

R. sylvatica can produce large quantities of glucose to protect itself against freezing. Several studies have shown that high levels of glucose cause an increase in intracellular calcium in several cell types including pancreatic islets, cardiac myocytes and vascular smooth muscle cells (Fadda \& Massry, 1991; Barbagallo et al., 1995; Smogorzewski et al., 1998). The increase in calcium levels is attributed to the fact that glucose causes an increase in extracellular UTP levels, which in turn causes the release of calcium both from intracellular and extracellular storage by acting on the inositol triphosphate receptors and VDCCs, respectively (Lawrence et al., 2002; Parodi et al., 2002; Lazaroswki et al., 2003; Nilsson et al., 2006). Since freezing in wood frogs is considered a hyperglycemic event, 
and NFATs are activated by calcium, this prompted the investigation of NFAT signaling in liver and skeletal muscle during the freeze/thaw cycle in wood frogs.

Total protein levels of NFATc1-c4 were measured by western blotting in both tissues. In general, as seen in Figure 3.1 and Figure 3.3, only NFATc3 showed a significant increase in protein expression by $1.90 \pm 0.10$ folds as well as DNA binding activity by 1.33 \pm 0.04 folds after 24 hours of freezing in liver. In contrast, none of the four NFATs showed a significant increase in protein expression or DNA binding activity after 24 hours of freezing in skeletal muscle (Figure 3.2, 3.4). While the increase in NFATc3 activity was expected in both tissues due to high levels of glucose, the discrepancy in skeletal muscle may be attributed to various factors that may prevent the release of calcium in this tissue even when glucose levels are high as explained earlier. Perhaps the discrepancy between protein levels and DNA binding activity of the other NFATs in both tissues can be explained by post-translational modifications. As seen in Figure 3.1, protein levels of NFATc4 are significantly up regulated during freezing, however there is a significant downregulation in DNA binding activity as seen in Figure 3.3 in the corresponding conditions in liver. Because the antibody used in this experiment was able to detect total NFATc4 (including both p-NFATc4 and normal NFATc4), it is possible that the increase seen in this experiment was a result of p-NFATc4 elevation. This hypothesis would explain the significant decrease in DNA binding levels while NFAT protein levels remain high; however, this would need to be further validated with the use of a phospho-specific pNFATc4 (Ser 168, 170) antibody.

When NFATs are not needed, they are heavily phosphorylated by "maintenance kinases" and are sequestered in the cytoplasm (Rao et al., 1997). A member of the mitogen- 
activated protein kinase (MAPKs), c-Jun N-terminal kinase (JNK), was shown to phosphorylate NFATc1 near the calcineurin binding domain and prevent its nuclear accumulation (Chow et al., 2000). Studies from our lab have shown that JNK activity remained unchanged during freezing in liver; however, JNK activity increased significantly 90 minutes after thawing in liver before returning to baseline levels after 4 hours of thawing in R. sylvatica (Greenway \& Storey, 2000). Perhaps it is the inhibitory effect of JNK together with the decrease in NFATc1 protein levels that prevents nuclear accumulation leading to a significant decrease in NFATc1 DNA binding as shown in Figure 3.3 in the liver during freezing. Moreover, while JNK was not measured at 8 hours post thawing, it is possible that the decrease in its phosphorylating activity is responsible for the increase in DNA binding activity of NFATc1 in liver (Figure 3.3). Similarly, although the enzymatic activity of JNK were not directly measured in skeletal muscle, it is possible that perhaps the decrease in DNA binding activity of NFATc1 after 24 hours of freezing and 8 hours of thawing is attributed to the increase in JNK activity in those conditions (Figure 3.4). Further experiments are needed to fully understand the role of JNK activity in regulating NFATc1 phosphorylation in both liver and skeletal muscle.

A member of the MAPK family, p38, is also responsible for phosphorylating NFATc2 and NFATc4, resulting in their localization in the cytoplasm (Arco et al., 2000; Yang et al., 2002). While p38 activity was not measured after 24 hours of freezing and 8 hours of thawing in wood frog liver and skeletal muscle, it is possible that perhaps an increase in p38 activity is responsible for causing the significant decrease in NFATc4 DNA binding levels in liver after 24 hours of freezing and 8 hours of thawing and in skeletal muscle after 24 hours of freezing (Figure 3.3, 3.4). It is noteworthy to mention that since 
the anti-NFATc 4 antibody used detected both NFATc4 and p-NFATc 4 , it is highly possible that the significant increase seen after 24 hours in liver is actually an increase in the deactivated form, p-NFATc4. This would explain the significant decrease in NFATc4 DNA binding activity as seen in Figure 3.3 compared to protein levels as seen in Figure 3.1. This however can only be proven by measuring the level of p-NFATc4 modification in liver after 24 hours of freezing. The discrepancy between NFATc2 protein levels and DNA binding activity can also be clarified and measured using a phospho-specific antiNFATc2 antibody by western blotting (Figure 3.1, 3.3). With respect to the results obtained, it is evident that freezing causes a differential regulation in NFAT protein expression and DNA binding activity in a tissue specific manner. These results suggest that under a hypometabolic state where energy reserves are limited, only signaling pathways necessary for survival are activated.

Frozen wood frogs are subjected to high levels of glucose, and since NFATc3 showed a significant increase in protein expression as well as DNA binding levels during freezing, it was of interest to asses the effect of glucose on the DNA binding ability of this transcription factor. As seen in Figure 3.5 in liver and Figure 3.6 in skeletal muscle, adding varying concentrations of glucose, even at biologically relevant levels during freezing $(\sim 300 \mathrm{mM})$ did not cause a significant change in NFATc3 DNA binding. Likewise, the same DNA binding assay was performed at $4^{\circ} \mathrm{C}$, in efforts to mimic the freezing conditions in wood frogs, but it also failed to show a significant change in the DNA binding of NFATc3 (Figure 3.7). Although there are studies that show that glucose can enter the nucleus, it is possible that there is no physical interaction between glucose and NFATc3 that could enhance its DNA binding activity (Kaminski et al., 2013). As mentioned earlier, 
glucose causes the release of extracellular UTP which through a series of steps causes an increase in intracellular calcium levels (Nilsson et al., 2006). The increase in calcium in turn instigates a cascade of events that activate calcineurin, a phosphatase known to dephosphorylate NFATs and lead to their activation (Hogan et al., 2003; Rusnak \& Mertz, 2000). Interestingly, the study by Nilsson et al. (2006) concluded that high glucose activates NFATc3 specifically. This prompted a deeper examination of NFATc3 activation in both tissues over the freeze/thaw cycle.

To further confirm the activity of NFATc3, we measured the amount of NFATc3 localized in the nuclear fractions of the control and the 24 hour frozen wood frog liver. As seen in Figure 3.8, after 24 hours of freezing, NFATc3 nuclear localization increased by $\sim 2.05 \pm 0.33$ folds compared to the nuclear localization in the control group. The increased nuclear translocation of NFATc3 further confirms the results obtained from the DNA binding experiment and concludes that NFATc3 is likely involved in gene transcription during freezing in the liver.

In order for NFATc3 to enter the nucleus, it needs to be dephosphorylated by the $\mathrm{Ca}^{2+} /$ calmodulin-dependent serine phosphatase calcineurin (Hogan et al., 2003). Exposure to 24 hours freezing did not have an effect on protein expression levels of calcineurin A in liver but was found to significantly decrease the protein expression of this target in skeletal muscle (Figure 3.9). After 8 hours of thawing, calcineurin A showed a significant increase compared to the control and the 24 hour frozen group in liver while showing a significant decrease and increase compared to the control and the 24 hour frozen group in skeletal muscle. While the significant decrease of calcineurin A protein levels may be responsible for the decrease in NFATc1, $\mathrm{c} 2$ and $\mathrm{c} 4$ DNA binding activity observed during freezing 
(Figure 3.4) in skeletal muscle, the unchanged protein levels during 24 hours freezing may be sufficient to dephosphorylate NFATc3 and facilitate its nuclear shuttling, DNA binding and specific activation of gene transcription in liver (Figure 3.3, 3.8).

Once NFATc3 is no longer needed in the nucleus, GSK3 $\beta$ will re-phosphorylate it and cause its nuclear exit (Veldon et al., 2008). GSK3 $\beta$ also regulates the activity of several other proteins including enzymes involved in metabolism (e.g. glycogen synthase), structural proteins (e.g. Tau), signaling proteins (IRS-1) and transcription factors (e.g. Nrf2) (Woodgett et al., 1984; Hanger et al., 1992; Liberman \& Eldar-Finkelman, 2005; Velden et al., 2008, Rojo et al., 2008). Moreover, GSK3 $\beta$ was shown to inhibit the activity of AMP-activated protein kinase (AMPK) by forming a complex with its $\beta$ subunit (Suzuki et al., 2013). Previously, Dieni et al., (2012) determined that total GSK (both $\alpha$ and $\beta$ ) protein levels do not change during the course of freezing in liver or skeletal muscle. The present study shows that GSK3$\beta$ protein levels are significantly downregulated in liver after 24 hours of freezing and rebound to control levels after 8 hours of thawing, where skeletal muscle showed no significant change in GSK3 $\beta$ protein expression over the freeze/thaw cycle (Figure 3.10). Interestingly, the same study by Dieni et al., (2012) measured protein levels of the inactive form of GSK3 $\beta$, p-GSK3 $\beta$ (Ser 9), and found that phosphorylated levels decreased significantly during freezing in liver and skeletal muscle suggesting that this protein is likely active during freezing. With respect to NFATc3 nuclear localization, it is possible that although GSK3 $\beta$ is active in the liver, it may not impose an inhibitory effect on NFATc3 nuclear accumulation, as nuclear levels of NFATc3 after 24 hours of freezing significantly increased relative to control levels (Figure 3.8). This is perhaps due to the fact that GSK3 $\beta$ often requires the target protein to be "primed". In 
this case, other kinases are required to phosphorylate the target protein. This priming facilitates the inhibitory phosphorylation of that target by GSK3 $\beta$ (Lee \& Kim, 2007). The absence of prime phosphorylation on NFATc3 and AMPK is perhaps responsible for the ineffectiveness of GSK3 $\beta$ in phosphorylating and deactivating these two targets.

The relationship between AMPK and GSK3 $\beta$ is important for wood frog survival during freezing. There are several pathways that are regulated by AMPK including the inhibitory phosphorylation of glycogen synthase which prevents glycogen synthesis under high glucose conditions (Bultot et al., 2012; Suzuki et al., 2013). Rider et al. (2006) have reported that during freezing, there is a 2-fold increase in AMPK protein levels in liver where levels returns to control state after 4 hours of thawing (Rider et al., 2006). Likewise, skeletal muscle also showed a significant 4.5-fold increase in AMPK protein levels during freezing but levels remained 3-fold higher compared to the control after 6 hours of thawing (Rider et al., 2006). In correlation to this study, a decrease in GSK3 $\beta$ protein levels during freezing is beneficial as it would decrease the number of complexes made with AMPK, complexes that lead to the inhibition of AMPK activity. Again, the increase in GSK3 $\beta$ activity as well as AMPK protein levels in frozen wood frog liver and skeletal muscle are extremely important as they both inhibit the activity of glycogen synthase, an enzyme that mediates glycogen synthesis. This inhibition is crucial, as high glucose levels during freezing would activate glycogen synthase and force the conversion of glucose back to glycogen. Rider et al (2006) have suggested that while AMPK facilitates glucose secretion in the liver, AMPK activity in skeletal muscle is likely important for the uptake of glucose during freezing which is necessary for cryopreservation. It was shown that GSK3$\beta$ protein levels were not affected during the freeze/thaw cycle in skeletal muscle (Figure 3.10), 
suggesting that it might be playing a role in other inhibitory functions necessary for freeze survival such as the inhibition of protein synthesis and energy preservation. While freezing did not inhibit GSk3 $\beta$ activity, thawing may do so as high levels of glucose in a normal metabolic state leads to the activation of glycogen synthase and glycogen synthesis (Dieni et al., 2012). Although the time required to fully restore GSK3 $\beta$ protein levels to control levels may vary between tissues as seen in Figure 3.10, the increase in GSk3 $\beta$ protein levels in the liver after 8 hours of thawing may be responsible for deactivating AMPK and facilitating the conversion of cryprotective glucose back into glycogen to be stored for future freeze/thaw cycles (Storey \& Storey, 2004b).

The mechanisms by which GSK3 $\beta$ expression is repressed in freezing conditions is not yet known in wood frogs. It was shown that NFATc3 plays a role in inducing osteopontin expression in several cell types under hyperglycemic conditions (NilssonBerglund et al., 2010; Zetterqvist et al., 2015). Osteopontin is a cytokine that is known to play a role in a variety of cellular functions including the induction of chronic inflammation (Nilsson-Berglund et al., 2010). A study by Wen et al. (2015) showed that osteopontin null mice exhibited a decrease in interleukin 6 (IL-6) secretion and STAT3 activation in hepatocytes after liver injury. Indeed, IL-6 null livers showed minimal STAT3 activation after liver injury but showed a restored STAT3 activation after a dose of IL-6 (Cressman et al., 1996). The role of STAT3 is critical for liver regeneration, as it is involved in orchestrating a variety of signaling pathways including the induction of immediate-early genes, mitogenesis and anti-apoptosis (Taub, 2003). A study by Moh et al. (2008) has shown that insulin dependent nuclear accumulation of p-STAT3 (Ser 727) and not pSTAT3 (Tyr 705) is shown to supress GSK3 $\beta$ gene expression by binding to GSK3 $\beta$ 's 
regulatory element at the promoter and preventing gene transcription. Interestingly, the same study found that the phosphorylation level of GSK3 $\beta$ was not affected by the inhibitory effect of p-STAT3 (S 727). These findings sparked a deeper investigation into whether the same correlation is observed between osteopontin and the two forms of $\mathrm{p}$ STAT3 in relation to GSK3 $\beta$ expression levels in wood frogs.

Current data shows a positive correlation with an increase in NFATc3 protein levels as seen in Figure 3.1 and DNA binding activity as seen in Figure 3.3 after 24 hours of freezing in liver. This trend also correlates with the increase in osteopontin protein levels after 24 hours freezing in liver (Figure 3.11). Although the increase in NFATc3 and osteopontin correlate after 8 hours of thawing (Figures 3.1,3.11), the DNA binding levels of NFATc3 after 8 hours of thawing does not reflect the same trend (Figure 3.3). Perhaps, the increase in osteopontin after 8 hours of thawing in the liver (Figure 3.11) is a remnant of its increase after exposure to 24 hours freezing and its inability to be degraded. Likewise, the stable levels of NFATc3 proteins (Figure 3.2) as well as DNA binding ability (Figure 3.4) after exposure to 24 hours freezing correlated with the stable expression of osteopontin (Figure 3.11) for the same conditions in skeletal muscle. While the protein levels of NFATc3 increased significantly after 8 hours of thawing (Figure 3.2), the DNA binding levels remained unchanged (Figure 3.4), which correlates with the unchanged expression of osteopontin (Figure 3.11) in skeletal muscle.

Moreover, the correlation between osteopontin and STAT3 levels was investigated. Figure 3.12a shows that there was no significant change in p-STAT3 (Tyr 705) levels after freezing exposure in either tissues. The increase in osteopontin levels during the freeze/thaw cycle in liver correlated with a significant increase in p-STAT3 (Ser 727) levels 
during freezing (Figure 3.12b). Interestingly, the same antibody used to detect p-STAT3 (Ser 727) in liver did not cross-react with any band in skeletal muscle. Perhaps it is the insufficient amount of osteopontin protein levels that prevented the activation/detection of p-STAT3 (Ser 727) in skeletal muscle.

Moreover, there are conflicting studies on the role of osteopontin in skeletal muscle. While some have shown that osteopontin released from myoblasts enhances muscle regeneration (Uaessontrachoon et al., 2008), others have concluded that high levels of osteopontin are associated with muscle dystrophy and ablation of this cytokine facilitates muscle repair (Capote et al., 2016). It is possible that an increase in osteopontin levels in wood frog skeletal muscle would favour the second case and cause muscular dystrophy during freezing. As such, the unaffected protein expression of osteopontin during freezing may actually provide protection to skeletal muscle cells by preventing muscle dystrophy (Figure 3.11). While plausible, further analysis is required to conclude the role of osteopontin during freezing in skeletal muscle.

Osteopontin signaling is involved in other pathways that mediate glucose metabolism. The expression of osteopontin plays a role in regulating glucose transport. Osteopontin has been shown to increase glucose transporters 1 and 3 (GLUT) in osteosarcoma cells via $\alpha \mathrm{v} \beta 3$ integrin by involving the AKT, JNK and p38 pathways (Hsieh et al., 2014). These two glucose transporters are hypoxia-responsive and have a high affinity for glucose (Hsieh et al., 2014). A study comparing the amount and activity of total GLUTs between freeze-tolerant $R$. sylvatica and non-freeze-tolerant Rana papiens showed that $R$. sylvatica has five times more GLUTs in liver (King et al., 1993). The same study also suggested that different tissues express different GLUTs. For example, while GLUT4 
transcripts were up regulated by 2.5 folds in the heart and 1.7 folds in skeletal muscle, kidney did not show any change in GLUT4 transcript levels in R. sylvatica (Aguilar \& Storey, unpublished data; Storey \& Storey 2004a). In correlation with our data, it is possible that the increase in osteopontin protein levels, JNK, P38 and AKT activity during 24 hours freezing in liver is responsible for the observed increase in GLUT 1 and GLUT3 in this tissue. The liver is responsible for distributing glucose to the whole body for cryoprotection; therefore, it is expected to see an increase in the levels of GLUTs to facilitate glucose transport. Whether GLUT1 and GLUT3 isoforms are present in liver and skeletal muscle is the subject of future studies.

In conclusion, this study outlined the role of NFATs in regulating glucose metabolism during freezing in R. sylvatica liver and skeletal muscle. The present data showed that freezing resulted in an increase in NFATc3 protein expression and DNA binding activity in liver, while no such up regulation of NFAT proteins or DNA binding activity was observed in skeletal muscle. Osteopontin-mediated activation of p-STAT3 (Ser 727) likely lead to the repression of the GSK3 $\beta$ gene transcription which in turn facilitated glycogenolysis in liver, but not in skeletal muscle. Altogether, our data correlates with previous studies that emphasize the involvement of liver, and to a lesser degree skeletal muscle in regulating cryoprotectant glucose during wood frog freezing. 
Figure 3.1: Western blot analysis on total protein extracts showing the effects of the freeze/thaw cycle on NFAT proteins in wood frog liver.

Changes in protein expression levels of total NFATc1-c4 in control, after 24 hours of freezing and 8 hours of thawing in wood frog liver. Representative ECL-detected bands are shown for each condition. All data are \pm means of $n=3-4$ independent biological replicates. Significance $(\mathrm{p}<0.05)$ from control and 24 hour frozen group is denoted by a and $b$ respectively. Statistical analysis was done using One-way Anova with Holm-Sidak post-hoc test.

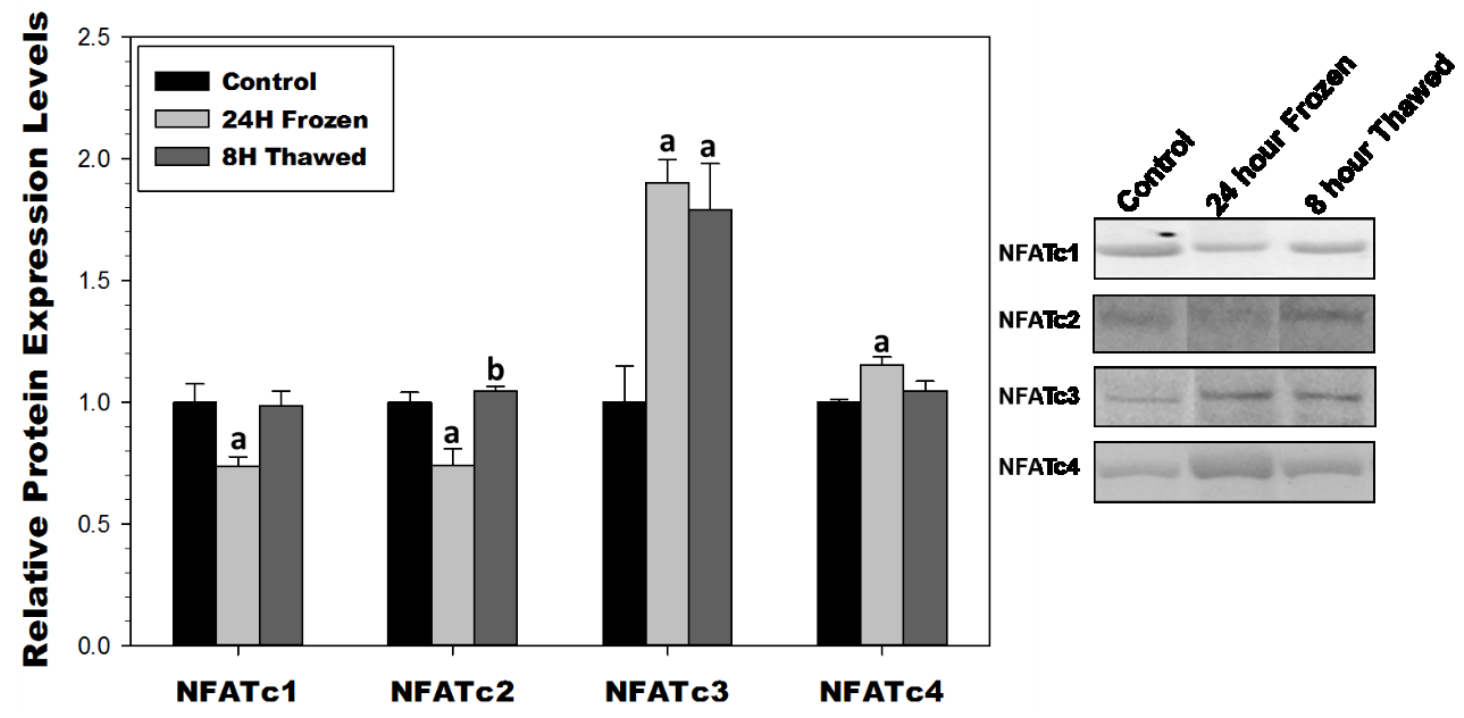


Figure 3.2: Western blot analysis on total protein extracts showing the effects of the freeze/thaw cycle on NFAT proteins in wood frog skeletal muscle.

Changes in protein levels of NFATc1-c4 in control, after 24 hours of freezing and 8 hours of thawing in wood frog skeletal muscle. Representative ECL-detected bands are shown for each condition. All data are \pm means of $n=3-4$ independent biological replicates. Significance $(p<0.05)$ from control and 24 hour frozen group is denoted by a and b respectively. Statistical analysis was done using One-way Anova with Holm-Sidak post-hoc test.

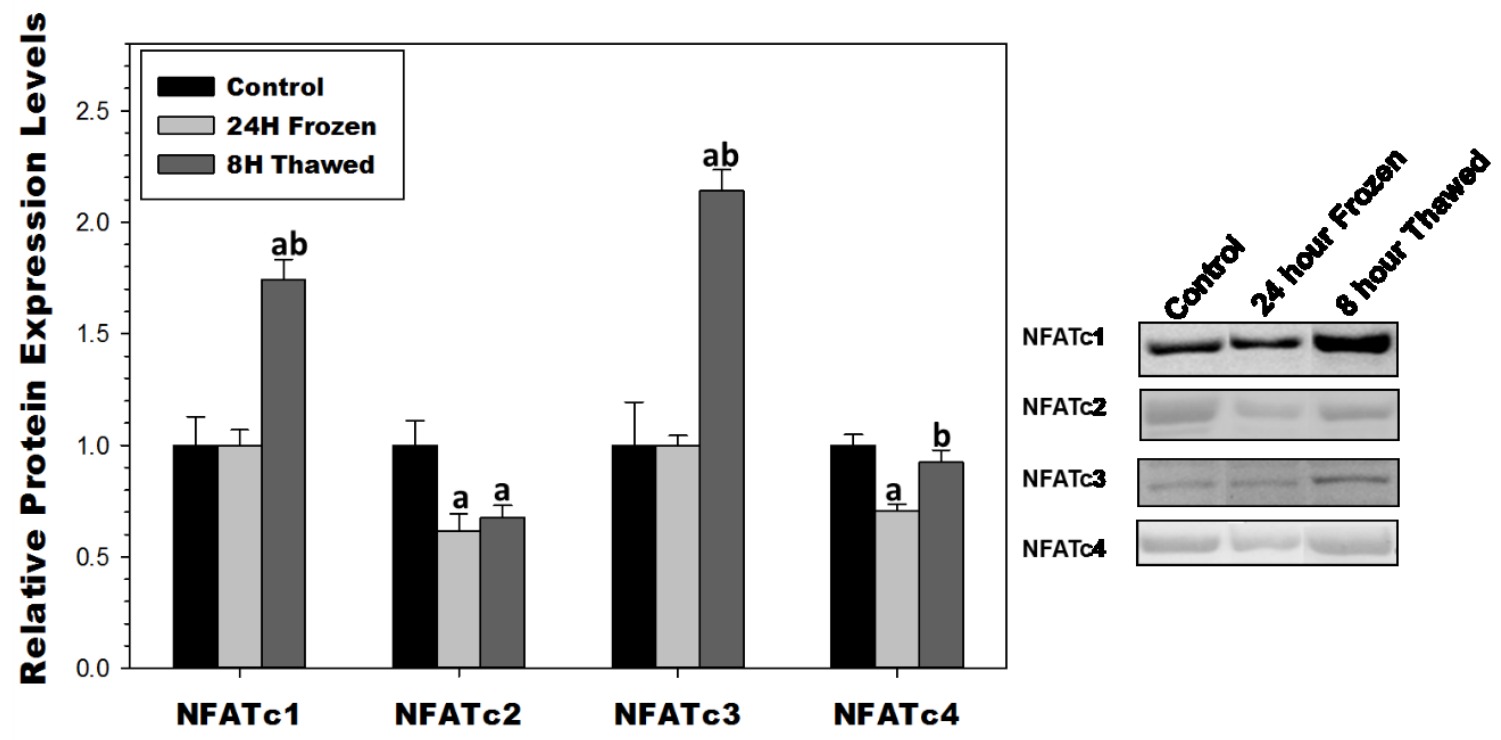


Figure 3.3: TF-ELISA analysis on total protein extracts showing the effects of the freeze/thaw cycle on the DNA binding ability of NFATs in wood frog liver.

Changes in DNA binding activity of NFATc1-c4 in control, after 24 hours of freezing and 8 hours of thaw in wood frog liver. All data are \pm means of $n=3-4$ independent biological replicates. Significance $(\mathrm{p}<0.05)$ from control and 24 hour frozen group is denoted by a and $\mathrm{b}$ respectively. Statistical analysis was done using One-way Anova with Holm-Sidak post-hoc test.

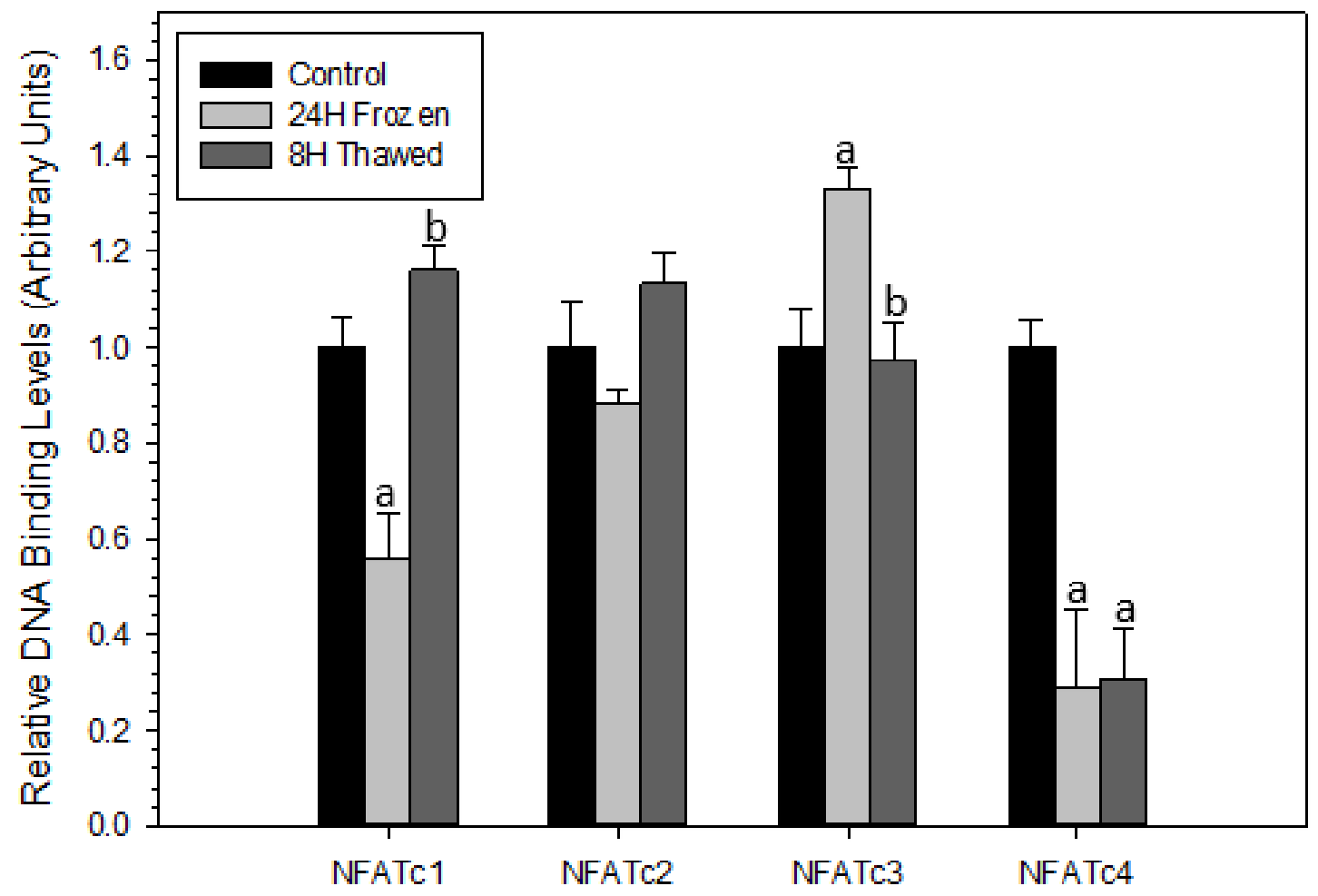


Figure 3.4: TF-ELISA analysis on total protein extracts showing the effects of the freeze/thaw cycle on the DNA binding ability of NFATs in wood frog skeletal muscle.

Changes in DNA binding activity of NFATs in control, after 24 hours of freezing and 8 hours of thawing in wood frog skeletal muscle. All data are \pm means of $n=3-4$ independent biological replicates. Significance $(\mathrm{p}<0.05)$ from control and 24 hour frozen group is denoted by and $b$ respectively. Statistical analysis was done using One-way Anova with Holm-Sidak post-hoc test.

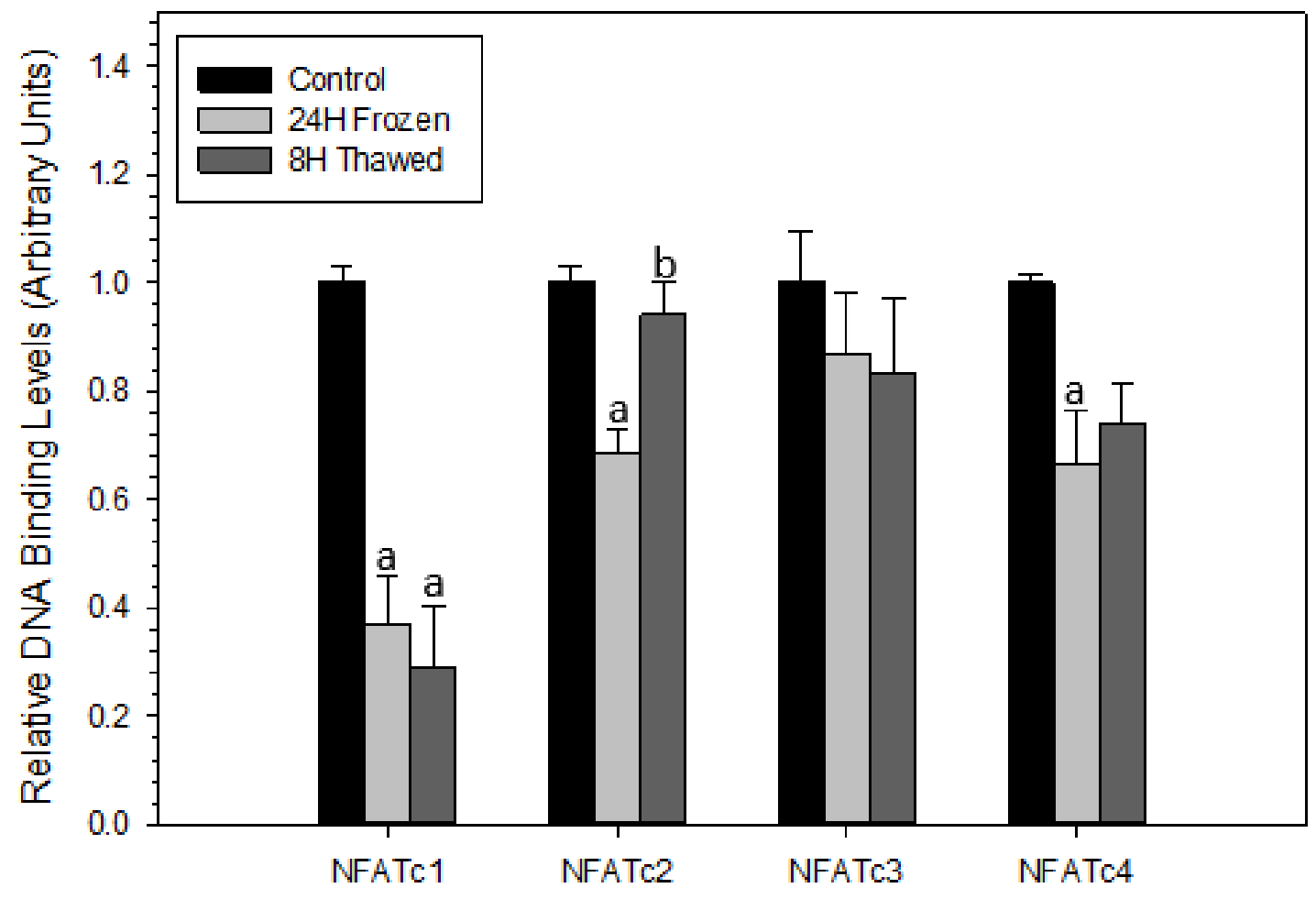


Figure 3.5: Environmental TF-ELISA analysis on total protein extracts showing the effect of glucose on NFATc3 DNA binding in wood frog liver.

Changes in DNA binding activity of NFATc3 from frozen wood frog liver in the presence of different concentrations of glucose at room temperature. All data are \pm means of $n=4$ independent biological replicates. One-way Anova analysis showed no statistical significance.

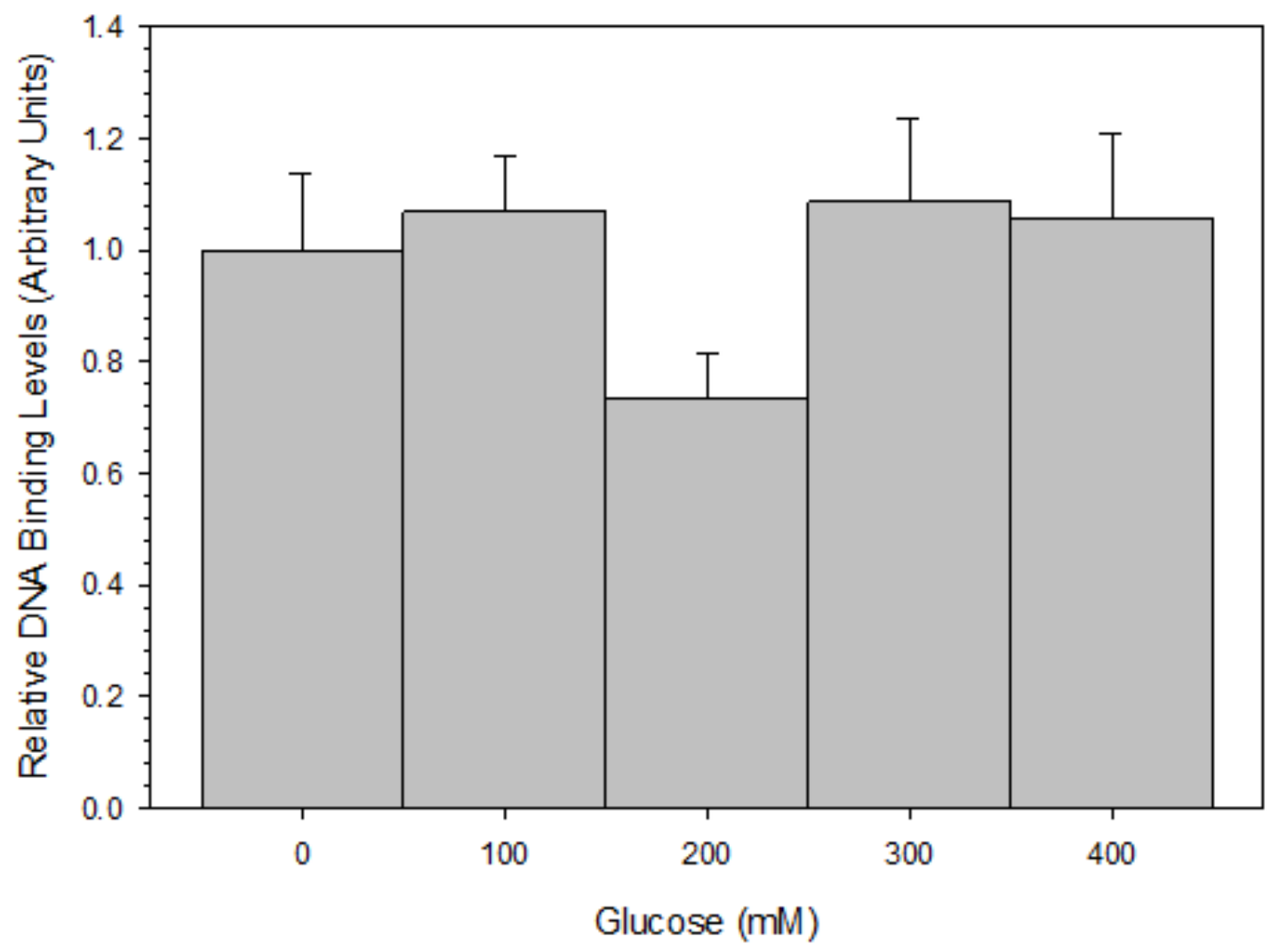


Figure 3.6: Environmental TF-ELISA analysis on total protein extracts showing the effect of glucose on NFATc3 DNA binding in wood frog skeletal muscle.

Changes in DNA binding activity of NFATc3 using protein extracts from 24 hour frozen wood frog skeletal muscle in the presence of different concentrations of glucose at room temperature. All data are \pm means of $n=3-4$ independent biological replicates. One-way Anova analysis showed no statistical significance.

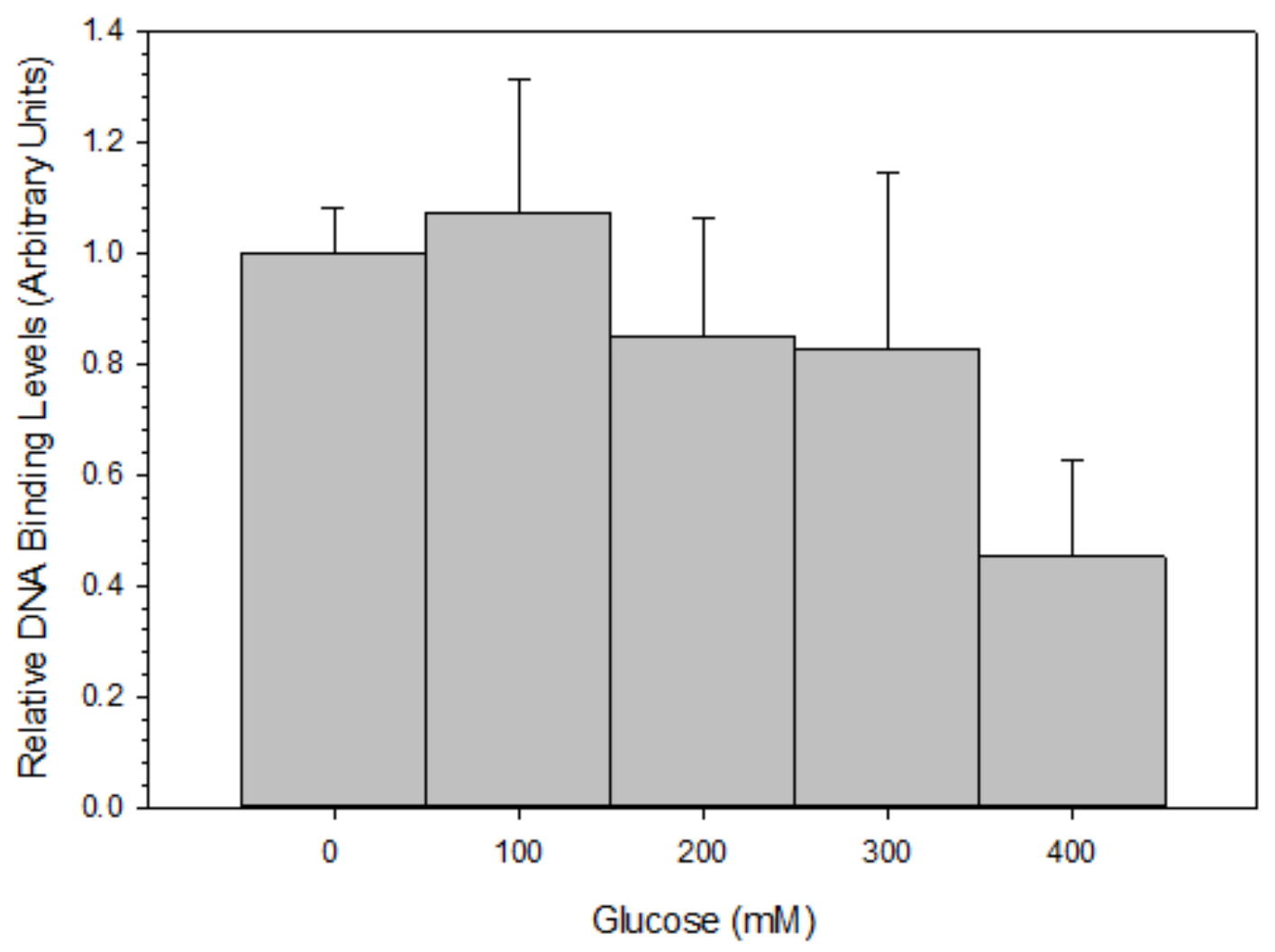


Figure 3.7: Environmental TF-ELISA analysis on total protein extracts showing the effect of glucose and temperature on NFATc3 DNA binding in wood frog liver.

Changes in DNA binding activity of NFATc3 using protein extracts from 24 hour frozen liver in the presence of different concentrations of glucose at $4^{\circ} \mathrm{C}$. All data are \pm means of $n=4$ independent biological replicates. One-way Anova analysis showed no statistical significance.

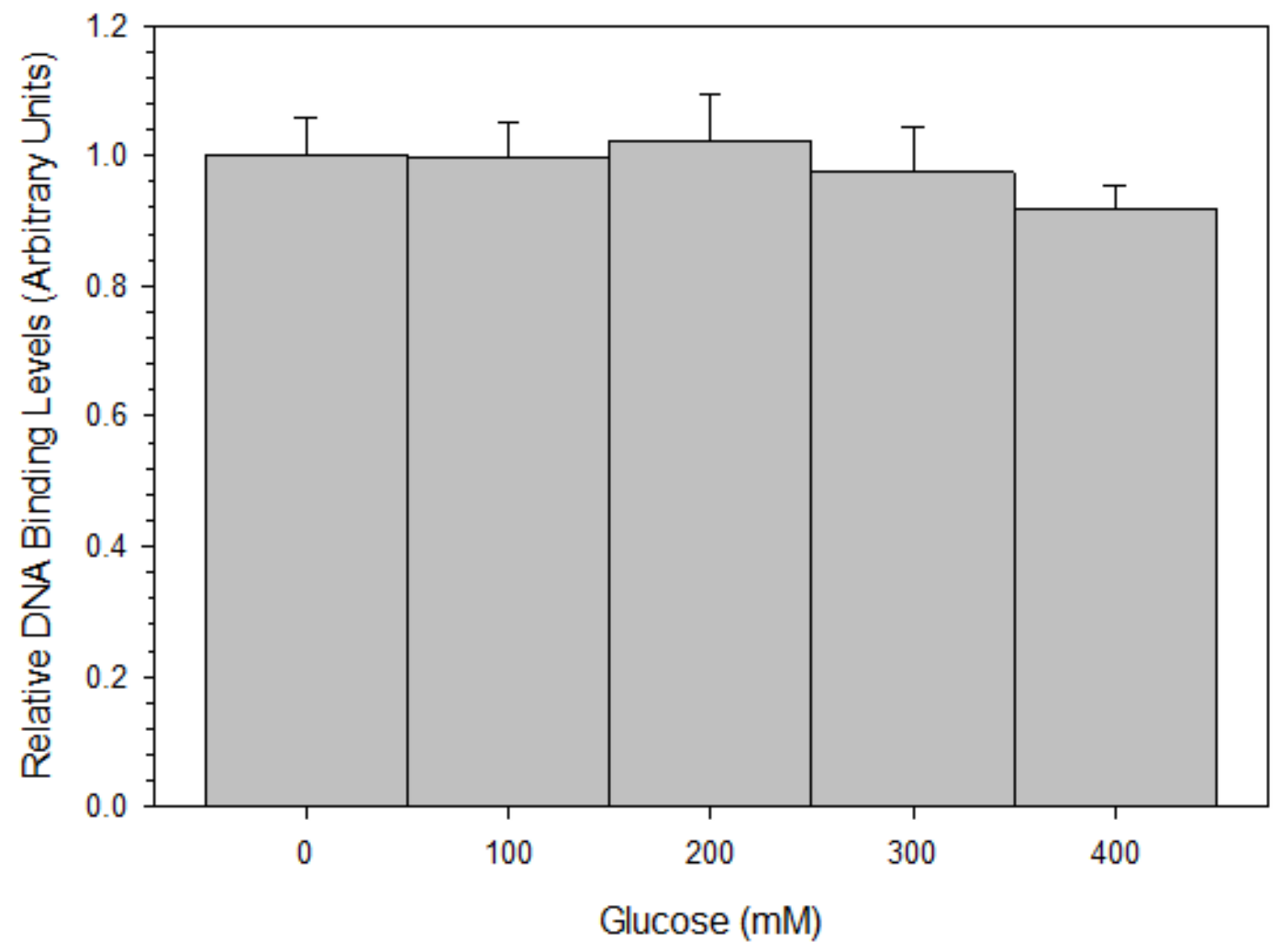


Figure 3.8: Western blot analysis showing the effect of freezing on nuclear distribution of NFATc3 in wood frog liver.

Nuclear distribution of NFATc3 of control and $24 \mathrm{H}$ frozen Rana sylvatica liver. All data are \pm means of $n=4$ independent biological replicates. Representative ECL-detected bands are shown for each condition. Significance $(\mathrm{p}<0.05)$ from control and 24 hour frozen nuclear samples is denoted by a. Statistical analysis was done using One-way Anova with Holm-Sidak post-hoc test.

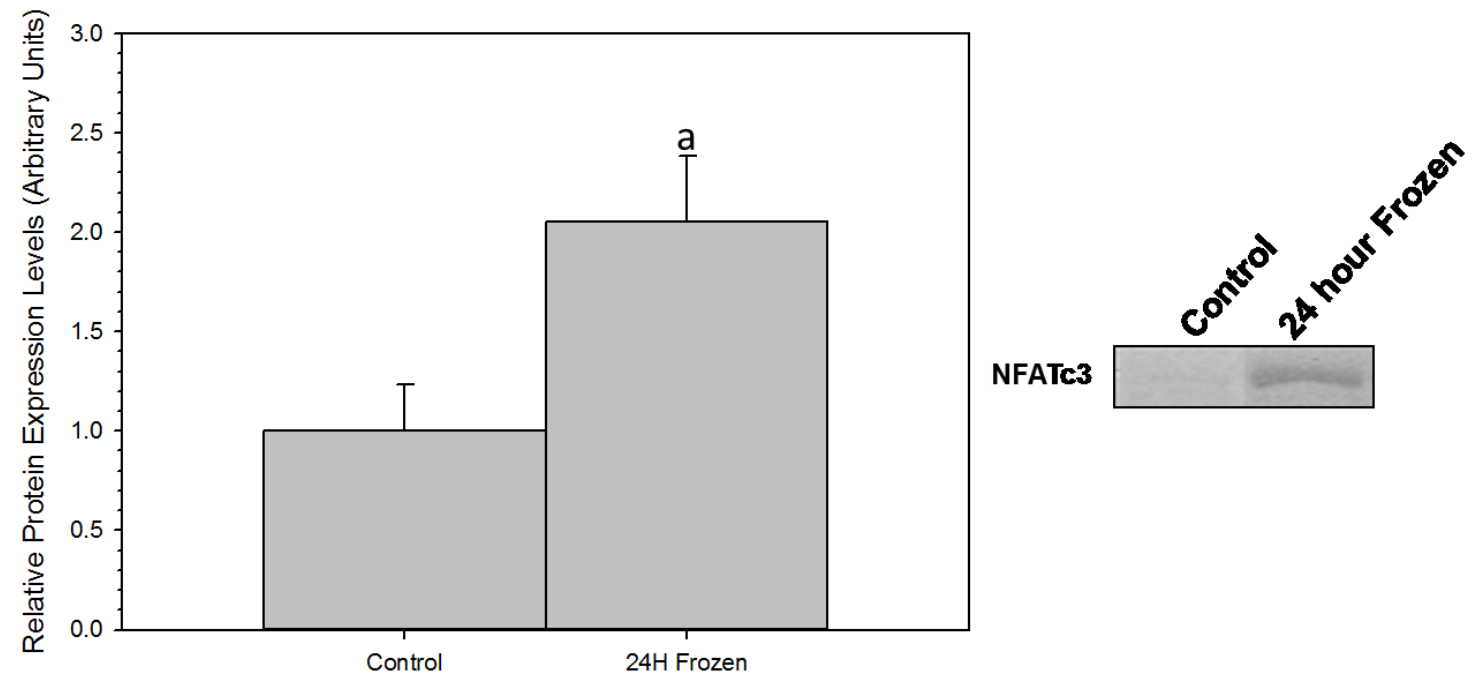


Figure 3.9: Western blot analysis on total protein extracts showing the effect of the freeze/thaw cycle on calcineurin A protein levels in wood frog liver.

Changes in protein levels of calcineurin A after 24 hours of freezing and 8 hours of thawing in Rana sylvatica liver and skeletal muscle. Representative ECL-detected bands are shown for each condition. All data are \pm means of $n=3-4$ biological replicates. Significance $(p<0.05)$ from control and 24 hour frozen group is denoted by a and b respectively. Statistical analysis was done using One-way Anova with Holm-Sidak post-hoc test.

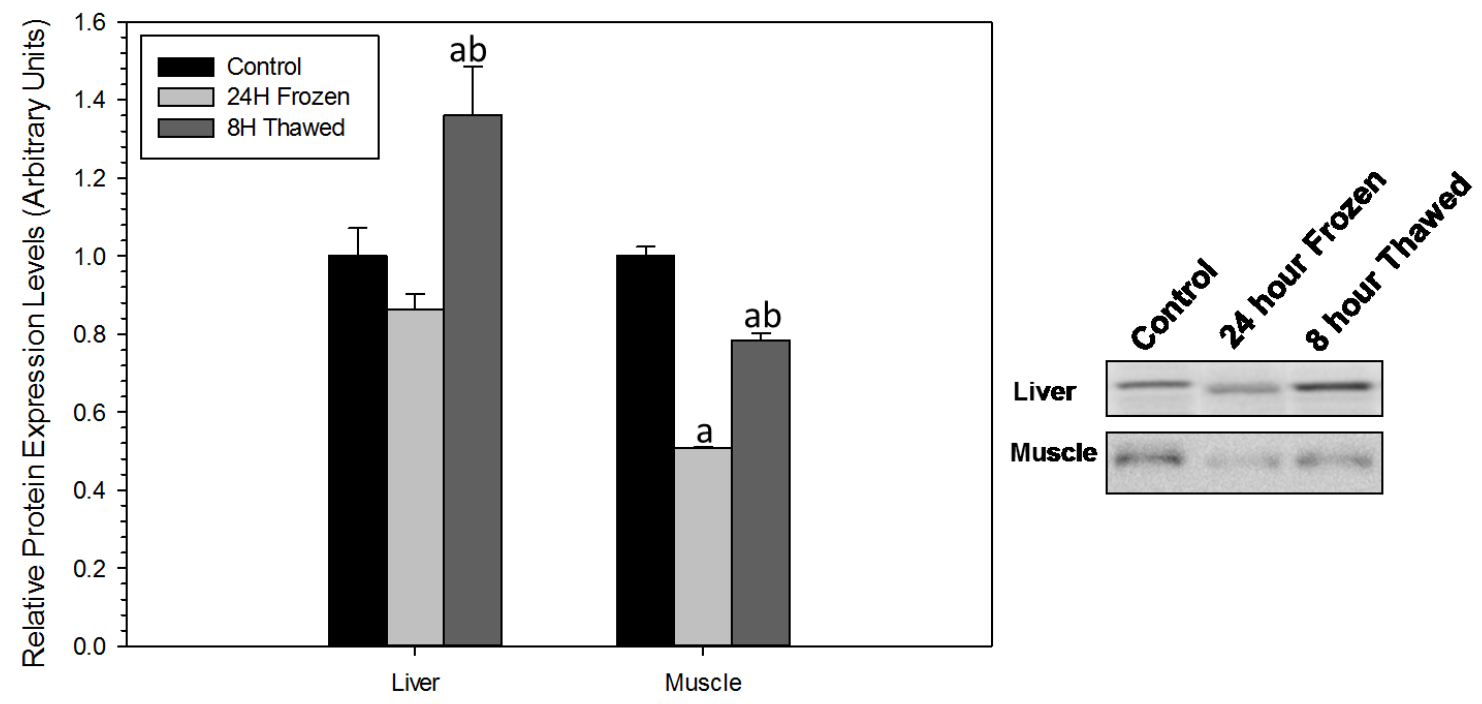


Figure 3.10: Western blot analysis on total protein extracts showing the effect of the freeze/thaw cycle on GSK3 $\beta$ protein levels in wood frog liver and skeletal muscle.

Changes in protein levels of GSK3 $\beta$ after 24 hours of freezing and 8 hours of thawing in Rana sylvatica liver and skeletal muscle. Representative ECL-detected bands are shown for each condition. All data are \pm means of $n=3-4$ biological replicates. Significance $(p<0.05)$ from control and 24 hour frozen group is denoted by a and b respectively. Statistical analysis was done using One-way Anova with Holm-Sidak post-hoc test.

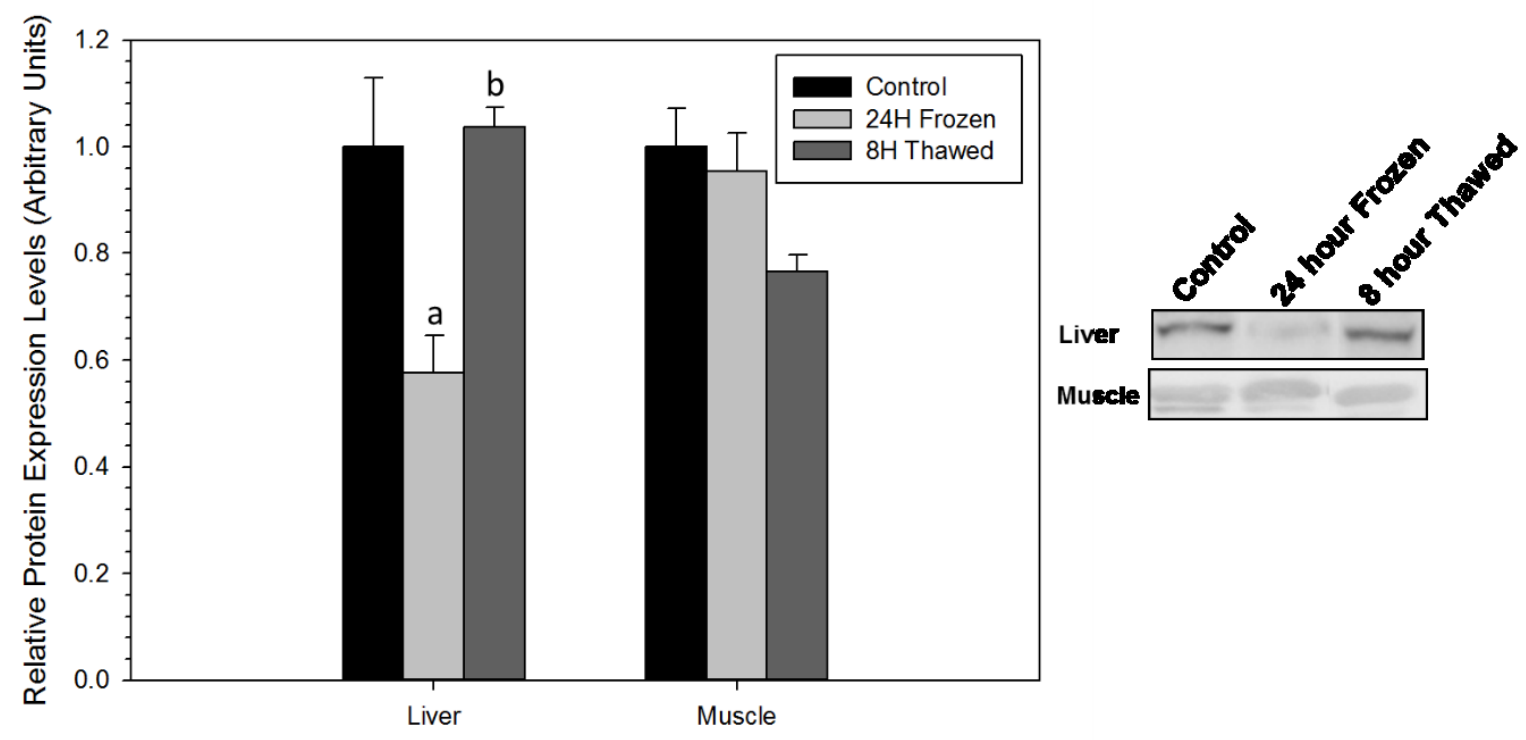


Figure 3.11: Western blot analysis on total protein extracts showing the effect of the freeze/thaw cycle on osteopontin protein levels in wood frog liver and skeletal muscle.

Changes in protein levels of osteopontin after 24 hours of freezing and 8 hours of thawing in Rana sylvatica liver and skeletal muscle. Representative ECL-detected bands are shown for each condition. All data are \pm means of $n=4$ independent biological replicates. Significance $(p<0.05)$ from control and 24 hour frozen group is denoted by a and b respectively. Statistical analysis was done using One-way Anova with Holm-Sidak post-hoc test.

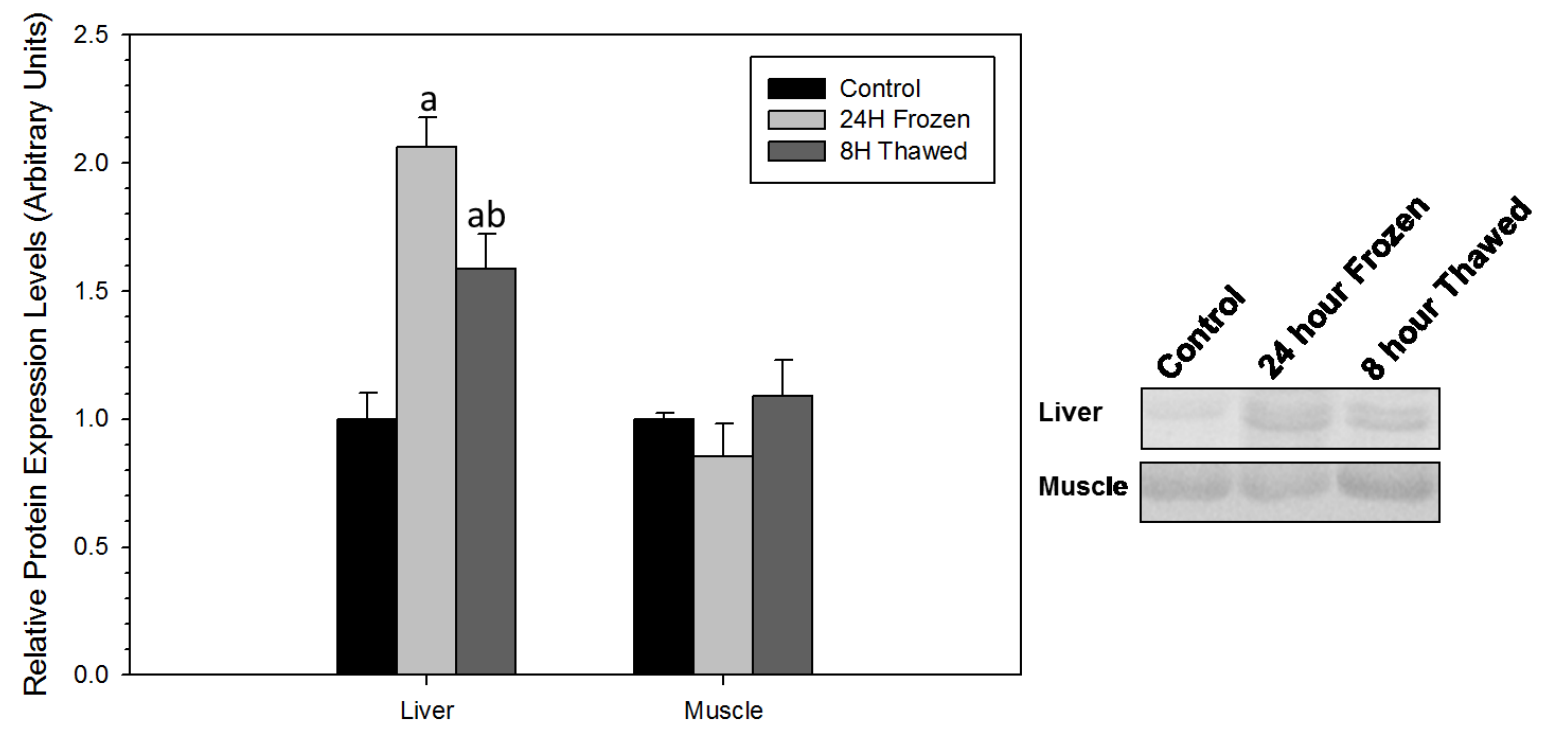


Figure 3.12a: Western blot analysis on total protein extracts showing the effect of the freeze/thaw cycle on p-STAT3 (Tyr 705) protein levels in wood frog liver and skeletal muscle.

Changes in protein levels of p-STAT3 (Tyr 705) after 24 hours of freezing and 8 hours of thawing in Rana sylvatica liver and skeletal muscle. Representative ECL-detected bands are shown for each condition. All data are \pm means of $n=3-4$ independent biological replicates. Significance ( $p$ $<0.05$ ) from control and 24 hour frozen group is denoted by a and b respectively. Statistical analysis was done using One-way Anova with Holm-Sidak post-hoc test.

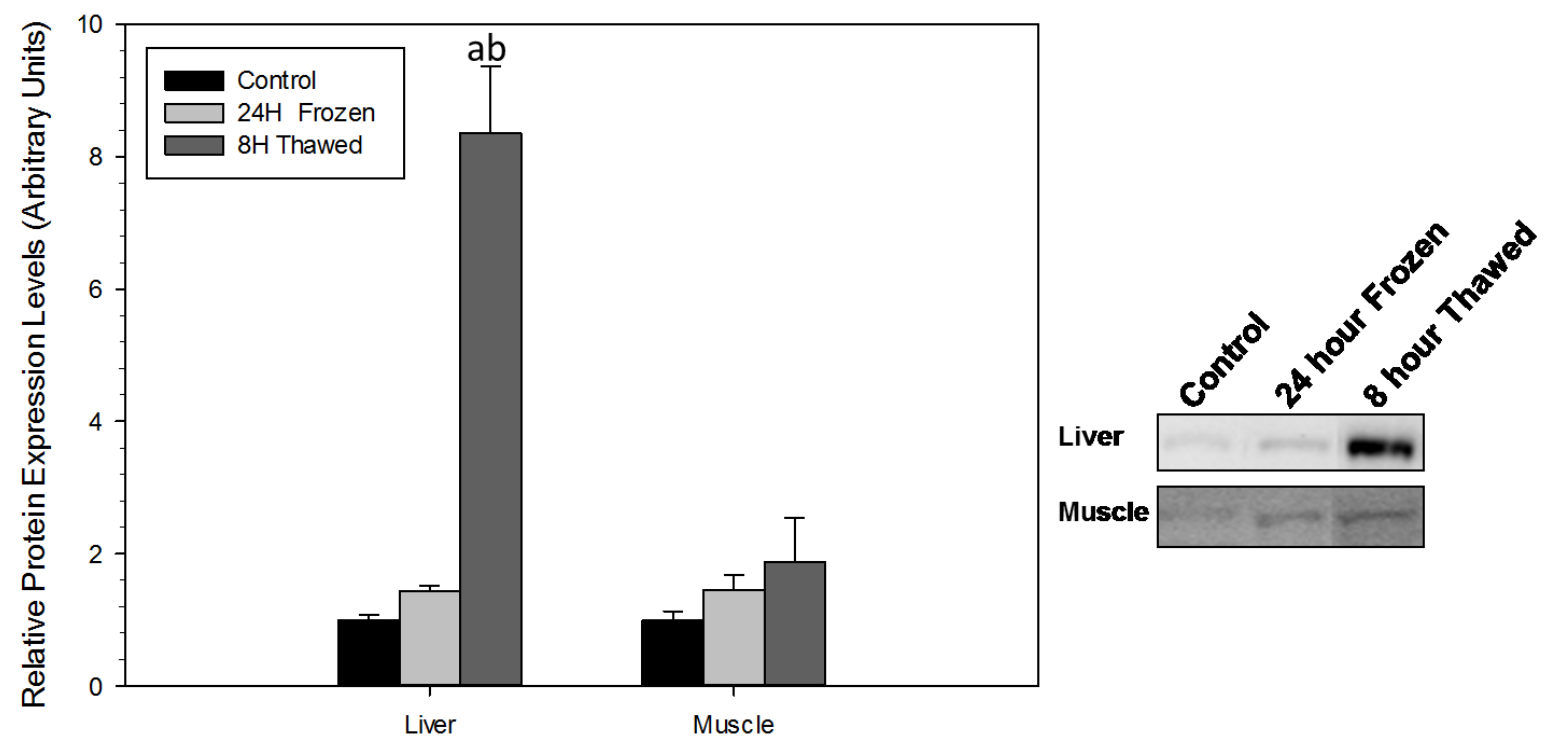


Figure 3.13b: Western blot analysis on total protein extracts showing the effect of the freeze/thaw cycle on p-STAT3 (S727) protein levels in wood frog liver.

Changes in protein levels of p-STAT3 (S727) after 24 hours of freezing and 8 hours of thawing in Rana sylvatica liver. Representative ECL-detected bands are shown for each condition. All data are \pm means of $n=3-4$ independent biological replicates. Significance $(p<0.05)$ from control and 24 hour frozen group is denoted by a and b respectively. Statistical analysis was done using One-way Anova with Holm-Sidak post-hoc test.

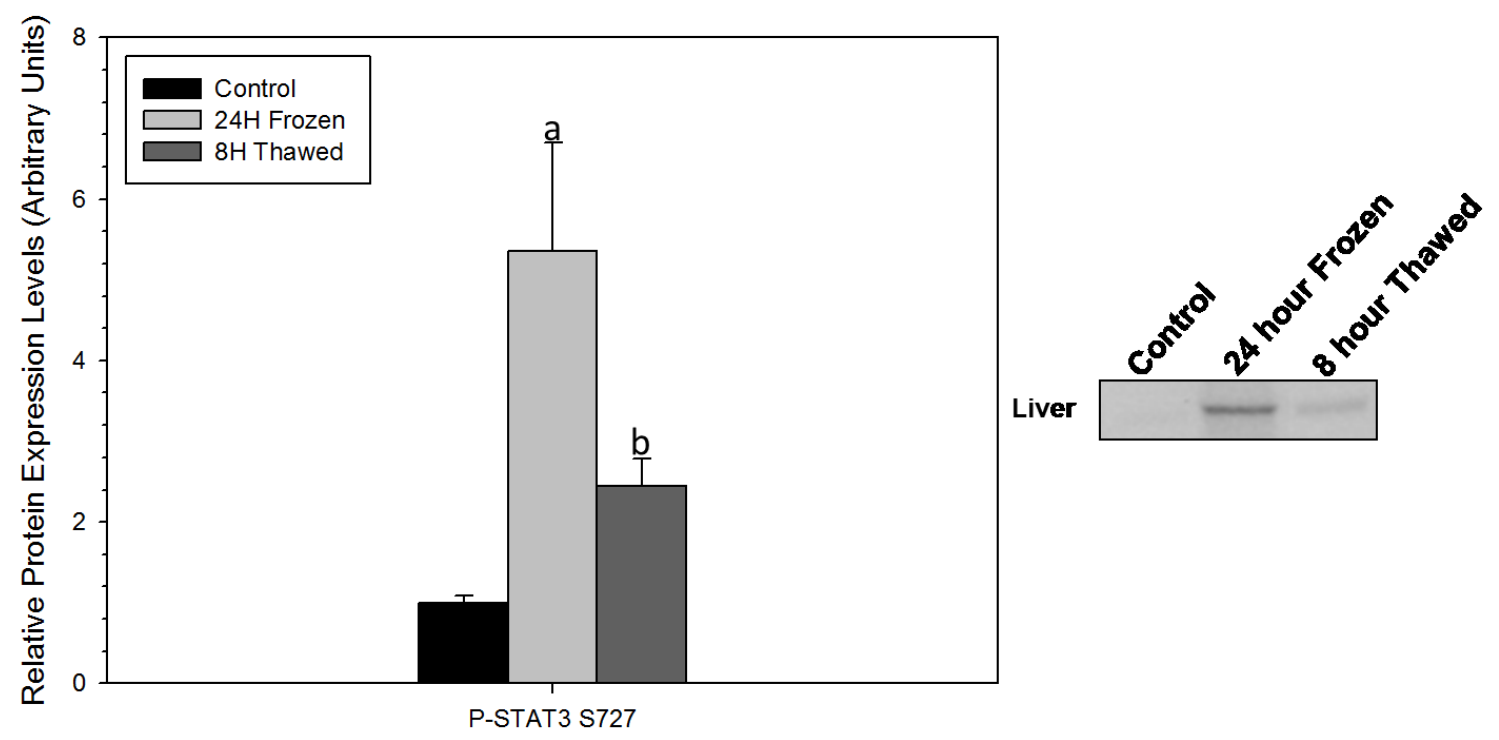




\section{Chapter 4: Nuclear factor of activated T cell (NFAT) regulation over the anoxia/re-oxygenation cycle in wood frogs}




\subsection{Introduction}

Most multicellular organisms require oxygen for survival. The dependency on oxygen is so high that it's depletion for as short as five minutes could impose challenges or even cause death in some organisms. While most living organisms are obligate aerobes, there are a few organisms (i.e. Trachemys scripta elegans, Carassius carassius, Hemiscyllium ocellatum and Rana sylvatica, to name a few) that can tolerate prolonged periods of anoxia (absence of oxygen) based on their environmental conditions (Storey \& Storey, 2004a; Nilsson \& Renshaw, 2004; Jackson \& Ultsch, 2010). Adaptation to anoxia requires a fuel source that could be used for energy. The fluctuating environmental conditions (i.e. lack of oxygen, freezing temperatures and extreme dehydration) prevents some vertebrates from emerging outside of their hibernacula; leaving them to rely on their internal fuel storage (mainly glycogen and or lipids) to generate energy (Storey \& Storey 2004c; Ruf \& Geiser, 2014). This feeding behavior aided some of the ectotherms exposed to cold temperatures to adapt and accumulate large quantities of glycogen in their liver which would later be catabolized to generate glucose. The glucose generated in this manner would provide the fuel needed for anaerobic metabolism and serve as a cryoprotectant when needed. The ability to generate energy in an anaerobic manner when oxygen levels fall has also prompted the frogs to develop a well orchestrated anoxia/re-oxygenation tolerance response, which is also necessary for their ability to freeze.

Rana sylvatica is freeze-tolerant and as a consequence of freezing, these organisms are also capable of tolerating anoxia because the freezing of the blood plasma interruptions oxygen delivery to organs. Interestingly, these amphibians can also tolerate complete anoxia even without being frozen (Holden \& Storey, 1997). This is important as freezing 
causes ischemia, an event characterized by inadequate blood circulation leading to insufficient oxygen delivery to organs. On the other hand, anoxia does not interrupt blood circulation, the blood circulating is simply deprived of oxygen. The importance of oxygen is related to the energy reservoir of the cell. Under aerobic conditions, catabolism of one glucose molecule to $\mathrm{CO}_{2}$ and $\mathrm{H}_{2} \mathrm{O}$ yields 36 ATP molecules which provides energy to support different cellular processes. Oxygen is the final electron acceptor in the electron transport chain and when oxygen levels fall or become depleted, the electron transport chain gets reduced; therefore, being unable to produce ATP (Krivoruchko \& Storey, 2010). Under these conditions, the amount of ATP required for cellular processes will exceed the amount of ATP available, therefore forcing the cells to generate more ATP in an oxygenindependent manner (Storey \& Storey, 2004c). Anoxia causes the synthesis of ATP via the glycolytic pathway where anaerobic catabolism of fermentable fuels is favoured. Once glycogen is broken down to glucose, the catabolism of one glucose molecules to two lactate molecules and $\mathrm{H}^{+}$can yield two ATPs (Storey \& Storey, 2004c). In the same process, lactate dehydrogenase converts pyruvate to lactate in a nicotinamide adenine dinucleotide (NADH)-dependent manner, resulting in the generation of NAD, a co-substrate required for glycolysis to continue (Storey \& Storey, 2004c) The amount of ATP synthesized under anoxic conditions ( $\sim 18$ fold less compared to aerobic respiration) most often does not meet the cell's energy demand. This creates a cellular environment with severe ATP imbalance. In addition, excessive production of lactate and $\mathrm{H}^{+}$ions would require the cells to release buffers such as $\mathrm{Ca}^{2+}$ and $\mathrm{HCO}_{3}{ }^{-}$to maintain a safe acid-base homeostasis in the cell and store large quantities of lactate (Storey, 2007; Jackson \& Ultsch, 2010). While anoxic tolerant animals are adapted to deal with the above complications of anoxia, the amount of 
energy generated by anaerobic metabolism of glucose is well below the amount of energy needed to sustain normal metabolic processes; therefore, to survive anoxia these organisms require to adjust their metabolic rates to meet the amount of energy available.

Anoxia tolerant vertebrates depress their metabolic rate by $\sim 90 \%$ when faced with low to no levels of oxygen (Storey, 2007; Jackson \& Ultsch, 2010). Metabolic rate depression helps anoxia tolerant organisms reduce ATP usage and directs the available energy in the cell toward processes that are crucial for survival. For example, the antioxidant defend response is activated during anoxia in liver and skeletal muscle of wood frogs. Previous studies done by our lab has shown that superoxide dismutase, catalase, glutathione S-transferase, glutathione reductase, and total Se-dependent glutathione peroxidase are significantly up regulated during anoxia in majority of the tissue (Joanisse \& Storey, 1996; Storey \& Storey, 2004b). In addition, non-enzymatic antioxidants such as glutathione also showed a significant upregulation during the freeze/thaw cycle (which is considered an anoxia/re-oxygenation event) (Storey \& Storey, 2004b). Metabolic rate depression is also beneficial as it would supress the signaling pathways that compromise the viability of the cell while up regulating signaling pathways that enable cell survival. Gerber et al. (2016) has shown that anoxic wood frogs selectively down regulate proapoptotic proteins while significantly up regulating proteins that are associated with cell survival in liver and skeletal muscle during anoxia. A cDNA library screen of anoxiatolerant turtle (Trachemys scripta elegans) revealed that anoxia caused the up regulation of several mitochondria encoded genes including Coxl, and Nad5 in the heart (Storey \& Storey, 2004c). Another cDNA library screen of anoxic brain showed the anoxic responsiveness of several targets including: adenosine A1 receptor, HSP70-1A, and $\alpha \mathrm{B}-$ 
Crystallin to name a few (Storey, 2007). In addition, several heat shock proteins (HSPs) showed tissue specific up regulation in this organism after anoxic exposure with the following results: Hsp25, Hsp40, Hsp90, Hsp70 and Hsc70 in white skeletal muscle, Hsp40, Hsc70, Hsp90 in kidney and Hsp40, Hsp60, Hsp70 and Hsc70 in liver (Krivoruchko \& Storey, 2010). Moreover, anoxia tolerant marine snails (L. littorina) have shown an anoxia-dependent regulation of several genes including the ribosomal protein L26 increased by three to five folds in snail tissues over 48 to 96 hours of anoxic exposure before going back to control levels after 1 hour of aerobic recovery (Storey \& Storey, 2004c). Marine snails also showed a significant up regulation of ferritin (by two folds) and metallothionein (three-five fold) within 12 hours of anoxic exposure which are two targets involved in the antioxidant defense response (Storey \& Storey, 2004c). All together these data show that even during periods of extreme hypometabolism and limited oxygen levels, these organisms can selectively and strategically up regulate specific genes and signaling pathways that mediate survival. The strict regulation of metabolic activity during periods of hypometabolism is achieved through several regulations, one of which is transcriptional control mediated by specific transcription factors. This thesis will examine the role of nuclear factor of activated $\mathrm{T}$ cells (NFATs) during the anoxia/re-oxygenation cycle in wood frog liver and skeletal muscle

NFATs are known to be regulated by calcium levels in the cell, therefore, it is important to understand how calcium levels are influenced by anoxia. It is known that exposure to hypoxia or anoxia initiates the production of ROS. When cells are exposed to hypoxic conditions, the mitochondrial electron transport chain is able to detect oxygen levels and mediate the release of ROS to act as second messengers (Waypa et al., 2002). A 
study by Mungai et al. (2011) has shown that even low levels of ROS as a result of hypoxic exposure is capable of triggering the release of calcium from the endoplasmic reticulum. This release mediates the translocation of the calcium released-activated channels (CRACs) to the plasma membrane where extracellular calcium will enter the intracellular space and lead to the activation of calcium sensing targets (Mungai et al., 2011). Indeed, many studies have outlined the importance of calcium in regulating different kinases and phosphatases under conditions where oxygen levels are low (Sheng et al., 1990). For example, Mottet et al. (2003) showed that hypoxia-mediated induction and activation of hypoxia inducible factor-1 (HIF-1) is calcium dependent as inhibiting calmodulin (a calcium sensor protein) or chelating calcium prevented this induction in HepG2 cells. Other groups showed that HIF-2 $\alpha$ accumulation and activity in PC12 cells is dependent on calcium (Millhorn et al., 2000). As explained in Chapter 1, NFATs are activated in response to an increase in intracellular calcium levels via dephosphorylation by calcineurin (Rao et al., 1997; Viola et al., 2005). Since the increase in calcium levels has shown to induce NFAT activation in freezing, we were interested in exploring whether NFATs play a role in anoxia tolerance in wood frogs.

Several studies outline the role of NFATs during hypoxia. One study showed that exposure to chronic hypoxia induced pulmonary arterial hypertension (PAH) as a result of NFATc3 mediated $\alpha$-actin expression (Frutos et al., 2007). Walczak-Drzewiecka et al. (2008) showed that NFATc4 is able to induce the expression of HIF-1 transcription factor in mast cells which is known to regulate processes involving the transportation of glucose, ischemic neovascularization, energy metabolism, apoptosis, and cancer (Forsythe et al., 1996; Carmeliet et al., 1998; Iyer et al., 1998; Ryan \& Johnson, 1998; Semenza, 2000; 
Seagroves et al., 2001). NFATc4 was also shown to induce the expression of atrial natriuretic peptide (ANP) (Carini et al.,2003). Indeed, several studies have focused on the role of NFATs in providing protection against ischemic injury. For example, Shaw et al. (1987) have shown that ANP ameliorates damage associated with kidneys exposed to cold and warm hypoxia through restoring glomerular filtration. Furthermore, ANP activity was shown to protect hepatocytes after reperfusion injury by attenuating inflammation and initiating a heat shock response (Kiemer et al., 2000; Kiemer et al., 2002). The involvement of ANP in preventing ischemic-mediated injury in multiple tissues, prompted the current study to understand signaling pathways involved in inducing this hormone. This decision was based on the fact that hypoxia causes an increase in intracellular calcium levels and NFATs are activated by calcium; therefore, I hypothesized that:

1. NFATs will be differentially regulated during the anoxia/re-oxygenation cycle with NFATc4 showing an increase in activity after anoxic exposure.

2. Activation of the NFATc4 signaling pathway will result in ANP expression over the anoxia/re-oxygenation cycle. 


\subsection{Materials \& methods}

\section{Animal treatment and tissue collection}

Male wood frogs were collected, treated, and sacrificed according to the description in chapter 2 for anoxic exposure.

\section{Protein isolation and immunoblotting}

The total protein isolations for western blotting and TF-ELISA were followed as explained in chapter 2. For western botting, the samples were run on SDS-PAGE at constant voltage $(180 \mathrm{~V})$ and transferred to PVDF membranes at constant amperage $(160 \mathrm{~mA})$.

\section{TF-ELISA DNA binding activity}

TF-ELISAs performed using the control, 24 hour anoxic and 4 hour aerobically recovered samples as stated in chapter 2 . 
Table 4.1: Summary of experimental conditions and antibodies used for western blotting used in the anoxia/re-oxygenation experiment.

\begin{tabular}{|c|c|c|c|c|c|}
\hline $\begin{array}{l}\text { Primary } \\
\text { antibody }\end{array}$ & Tissue & $\begin{array}{c}\text { Blocking } \\
\text { condition (in } \\
\text { TBST) }\end{array}$ & $\begin{array}{c}\text { Probing } \\
\text { conditions } \\
\text { (dilution in } \\
\text { TBST) }\end{array}$ & $\begin{array}{l}\text { Secondary } \\
\text { antibody } \\
\text { (dilution in } \\
\text { TBST) }\end{array}$ & $\begin{array}{c}\text { Primary } \\
\text { antibody } \\
\text { source }\end{array}$ \\
\hline NFATc1 & Liver & $\begin{array}{l}2 \% \text { milk for } \\
30 \text { mins }\end{array}$ & $\begin{array}{l}\text { 1:500 for } 48 \\
\text { hours }\end{array}$ & $\begin{array}{l}1: 5000 \text { for } 30 \\
\text { mins }\end{array}$ & Santa Cruz \\
\hline NFATc2 & Liver & $\begin{array}{l}5 \% \text { for } 40 \\
\text { mins }\end{array}$ & $\begin{array}{l}\text { 1:1000 } \\
\text { overnight }\end{array}$ & $\begin{array}{l}1: 5000 \text { for } 30 \\
\text { mins }\end{array}$ & Santa Cruz \\
\hline NFATc3 & Liver & $\begin{array}{l}1 \% \text { milk for } \\
30 \text { mins }\end{array}$ & $\begin{array}{l}1: 1000 \\
\text { overnight }\end{array}$ & $\begin{array}{l}1: 7000 \text { for } 30 \\
\text { mins }\end{array}$ & Santa Cruz \\
\hline NFATc4 & Liver & $\begin{array}{l}1 \% \text { milk for } \\
30 \text { mins }\end{array}$ & $\begin{array}{l}1: 1000 \\
\text { overnight }\end{array}$ & $\begin{array}{l}1: 6000 \text { for } 30 \\
\text { mins }\end{array}$ & Santa Cruz \\
\hline NFATc1 & Muscle & $\begin{array}{l}5 \% \text { milk for } \\
60 \text { mins }\end{array}$ & $\begin{array}{l}1: 1000 \\
\text { overnight }\end{array}$ & $\begin{array}{l}1: 5000 \text { for } 30 \\
\text { mins }\end{array}$ & Santa Cruz \\
\hline NFATc2 & Muscle & $\begin{array}{l}2 \% \text { milk for } \\
30 \text { mins }\end{array}$ & $\begin{array}{l}1: 500 \\
\text { overnight }\end{array}$ & $\begin{array}{l}1: 5000 \text { for } 20 \\
\text { mins }\end{array}$ & Santa Cruz \\
\hline NFATc3 & Muscle & $\begin{array}{l}2 \% \text { milk for } \\
30 \text { mins }\end{array}$ & $\begin{array}{l}1: 1000 \\
\text { overnight }\end{array}$ & $\begin{array}{l}1: 7000 \text { for } 30 \\
\text { mins }\end{array}$ & Santa Cruz \\
\hline NFATc4 & Muscle & $\begin{array}{l}1 \% \text { for } 30 \\
\text { mins }\end{array}$ & $\begin{array}{l}1: 500 \\
\text { overnight }\end{array}$ & $\begin{array}{l}1: 5000 \text { for } 20 \\
\text { mins }\end{array}$ & Santa Cruz \\
\hline GSK3 $\beta$ & Liver & $\begin{array}{l}3 \% \text { milk for } \\
30 \text { mins }\end{array}$ & $\begin{array}{l}1: 1000 \\
\text { overnight }\end{array}$ & $\begin{array}{l}1: 7000 \text { for } 30 \\
\text { mins }\end{array}$ & Santa Cruz \\
\hline GSK3 $\beta$ & Muscle & $\begin{array}{l}5 \% \text { milk for } \\
30 \text { mins }\end{array}$ & $\begin{array}{l}1: 1000 \\
\text { overnight }\end{array}$ & $\begin{array}{l}1: 7000 \text { for } 30 \\
\text { mins }\end{array}$ & Santa Cruz \\
\hline $\begin{array}{l}\text { Calcineurin } \\
\text { A }\end{array}$ & Liver & $\begin{array}{l}4 \% \text { milk for } \\
30 \text { mins }\end{array}$ & $\begin{array}{l}\text { 1:1000 } \\
\text { overnight }\end{array}$ & $\begin{array}{l}1: 7000 \text { for } 30 \\
\text { mins }\end{array}$ & GeneTex \\
\hline $\begin{array}{l}\text { Calcineurin } \\
\text { A }\end{array}$ & Muscle & $\begin{array}{l}4 \% \text { milk for } \\
30 \text { mins }\end{array}$ & $\begin{array}{l}1: 1000 \\
\text { overnight }\end{array}$ & $\begin{array}{l}1: 7000 \text { for } 30 \\
\text { mins }\end{array}$ & GeneTex \\
\hline ANP & Liver & $\begin{array}{l}2.5 \% \text { for } 30 \\
\text { mins }\end{array}$ & $\begin{array}{l}\text { 1:1000 } \\
\text { overnight }\end{array}$ & $\begin{array}{l}1: 6000 \text { for } 30 \\
\text { mins }\end{array}$ & GeneTex \\
\hline Osteopontin & Muscle & $\begin{array}{l}2 \mathrm{mg} / \mathrm{mL} \\
\text { HMW PVA } 3 \\
\text { mins }\end{array}$ & $\begin{array}{l}1: 1000 \\
\text { overnight }\end{array}$ & $\begin{array}{l}1: 5000 \text { for } 30 \\
\text { mins }\end{array}$ & $\begin{array}{l}\text { DSHB } \\
\text { University } \\
\text { of Iowa }\end{array}$ \\
\hline
\end{tabular}


Table 4.2: Summary of experimental conditions and antibodies used for TF-ELISAs used in the anoxia/re-oxygenation experiment.

\begin{tabular}{|l|l|l|l|l|}
\hline $\begin{array}{l}\text { Primary antibody } \\
\text { and probing } \\
\text { condition (dilution } \\
\text { in PBST) }\end{array}$ & Tissue & Treatment & $\begin{array}{c}\text { Secondary } \\
\text { antibody and } \\
\text { condition } \\
\text { (dilution in } \\
\text { PBST) }\end{array}$ & $\begin{array}{c}\text { Protein amount } \\
(\boldsymbol{\mu g})\end{array}$ \\
\hline $\begin{array}{l}\text { NFATc1 1:1000 for } \sim \\
\text { 60 mins }\end{array}$ & Liver & None & $\begin{array}{l}1: 2000 \text { for } 60 \\
\text { mins }\end{array}$ & 40 \\
\hline $\begin{array}{l}\text { NFATc2 1:1000 for } \\
\sim 60 \text { mins }\end{array}$ & Liver & None & $\begin{array}{l}1: 2000 \text { for } 60 \\
\text { mins }\end{array}$ & 40 \\
\hline $\begin{array}{l}\text { NFATc3 1:1000 for } \\
\sim 60 \text { mins }\end{array}$ & Liver & None & $\begin{array}{l}1: 2000 \text { for } 60 \\
\text { mins }\end{array}$ & 30 \\
\hline $\begin{array}{l}\text { NFATc4 1:1000 for } \\
\sim 60 \text { mins }\end{array}$ & Liver & None & $\begin{array}{l}1: 2000 \text { for } 60 \\
\text { mins }\end{array}$ & 20 \\
\hline $\begin{array}{l}\text { NFATc1 1:1000 for } \\
\sim 60 \text { mins }\end{array}$ & Muscle & None & $\begin{array}{l}1: 2000 \text { for } 60 \\
\text { mins }\end{array}$ & 30 \\
\hline $\begin{array}{l}\text { NFATc2 1:1000 for } \\
\sim 60 \text { mins }\end{array}$ & Muscle & None & $\begin{array}{l}1: 2000 \text { for } 60 \\
\text { mins }\end{array}$ & 30 \\
\hline $\begin{array}{l}\text { NFATc3 1:1000 for } \\
\sim 60 \text { mins }\end{array}$ & Muscle & None & $\begin{array}{l}1: 2000 \text { for } 60 \\
\text { mins }\end{array}$ & 30 \\
\hline $\begin{array}{l}\text { NFATc4 1:1000 for } \\
\sim 60 \text { mins }\end{array}$ & Muscle & None & $\begin{array}{l}1: 2000 \text { for } 60 \\
\text { mins }\end{array}$ & 30 \\
\hline
\end{tabular}




\subsection{Results}

\section{Analysis of total NFAT protein level}

Total NFAT protein levels in liver and skeletal muscle were measured using western blotting to compare the relative expression levels between the control at $5^{\circ} \mathrm{C}, 24$ hours anoxic at $5{ }^{\circ} \mathrm{C}$, and 4 hours aerobic recovered at $5{ }^{\circ} \mathrm{C}$. The mammalian polyclonal antibodies were used for western blotting and each reacted to a single band at the corresponding molecular weights.

Figure 4.1 shows the total protein expression levels of NFATc1-c4 in liver over the anoxia/re-oxygenation measured by western immunoblotting. NFATc1 (MW 138KDa) protein levels increased significantly compared to the control $(1.00 \pm 0.04)$ after 24 hours of anoxic exposure $(1.41 \pm 0.11)$ and after 4 hours of aerobic recovery $(1.54 \pm 0.06)$. NFATc2 (MW $~ 98 \mathrm{KDa}$ ) protein levels did not change after exposure to 24 hours of anoxia $(0.54 \pm 0.05)$ or after 4 hours of aerobic recovery $(1.12 \pm 0.42)$ compared to the control group $(1.00 \pm 0.13)$. NFATc3 $(\mathrm{MW} \sim 90 \mathrm{KDa})$ protein levels also did not show a significant change after 24 hours of anoxia $(0.63 \pm 0.07)$ or after 4 hours of aerobic recovery $(0.80 \pm$ $0.08)$ compared to the control $(1.00 \pm 0.12)$. NFATc4 $(\mathrm{MW} \sim 125 \mathrm{KDa})$ protein levels showed a significant increase after 24 hours of anoxic exposure $(3.04 \pm 0.28)$ compared to the control $(1.00 \pm 0.10)$ and 4 hours of aerobic recovery $(1.77 \pm 0.34)$ treatments.

Figure 4.2 shows the total protein expression levels of NFATc1-c4 in skeletal muscle over the anoxia/re-oxygenation cycle measured by western immunoblotting. NFATc1 $(\mathrm{MW} \sim 98 \mathrm{KDa})$ protein levels decreased significantly compared to the control $(1.00 \pm$ $0.09)$ after 24 hours of anoxic exposure $(0.41 \pm 0.08)$ and remained significantly low after 4 hours of aerobic recovery $(0.58 \pm 0.11)$ compared to the control group. NFATc2 protein 
levels remained unchanged after 24 hours of anoxic exposure $(0.80 \pm 0.12)$ and 4 hours of aerobic recovery $(0.81 \pm 0.10)$ compared to the control group $(1.00 \pm 0.026)$. NFATc3 protein levels increased significantly after 24 hours of anoxic exposure $(1.44 \pm 0.07)$ compared to the control $(1.00 \pm 0.10)$ and returned to baseline after 4 hours of aerobic recovery $(1.11 \pm 0.1)$. NFATc4 protein levels showed a significant decrease after 24 hours of anoxia $(0.63 \pm 0.08)$ compared to the control group $(1.00 \pm 0.04)$ and returned to baseline after 4 hours of aerobic recovery $(0.81 \pm 0.06)$.

\section{DNA binding levels of NFATs}

The DNA binding ability of NFATs to their consensus sequence was measured in liver and skeletal muscle. The antibodies used in this analysis were the same antibodies used for western blotting. Figure 4.3 shows the DNA binding levels of NFATc1-c4 in liver during the 24 hour anoxic/4 hour aerobic recovery cycle. The DNA binding levels of NFATc1 did not show a significant change after 24 hours of anoxic exposure $(0.62 \pm 0.15)$ or after 4 hours of aerobic recovery $(1.10 \pm 0.25)$ compared to the control group $(1.00 \pm$ 0.18). However, NFATc2 showed a significant decrease in DNA binding levels after 24 hours of anoxic exposure $(0.15 \pm 0.05)$ compared to the control group $(1.00 \pm 0.13)$ and the 4 hour aerobic recovery group $(0.82 \pm 0.07)$ where DNA binding levels returned to baseline. NFATc3 DNA binding levels did not show a significant change after 24 hours of anoxic exposure $(0.60 \pm 0.08)$ or after 4 hours of aerobic recovery $(0.65 \pm 0.04)$ compared to the control group $(1.00 \pm 0.19)$. The DNA binding levels of NFATc4 increased significantly after 24 hours of anoxic exposure $(1.38 \pm 0.11)$ and after 4 hours of aerobic recovery $(1.58 \pm 0.11)$ compared to the control group $(1.00 \pm 0.06)$. 
Figure 4.4 shows the DNA binding levels of NFATc1-c4 over the 24 hour anoxic/4 hour aerobic recovery cycle in skeletal muscle. NFATc1 showed a significant decrease in DNA binding levels after 24 hours of anoxic exposure $(0.33 \pm 0.10)$ compared to the control group $(1.00 \pm 0.12)$ and levels rebound to baseline after 4 hours of aerobic recovery $(0.67 \pm 0.12)$. NFATc2 showed no significant change in DNA binding levels after 24 hours of anoxic exposure $(1.72 \pm 0.38)$ compare to the control group $(1.00 \pm 0.32)$. NFATc2 DNA binding levels increased significantly after 4 hours of aerobic recovery $(3.67 \pm 0.67)$ compared to the control group. NATc3 binding levels did not show a significant change after 24 hours of anoxic exposure $(0.85 \pm 0.18)$ or after 4 hours of aerobic recovery $(0.58$ $\pm 0.17)$ compared to the control group $(1.00 \pm 0.07)$. Likewise, NFATc4 binding levels also did not show a significant change after 24 hours of anoxic exposure $(0.93 \pm 0.09)$ or after 4 hours of aerobic recovery $(1.21 \pm 0.26)$ compared to the control group $(1.00 \pm 0.03)$.

\section{Analysis of GSK3 $\beta$ and calcineurin A protein expression levels}

Protein expression level of the downstream de-activator of NFATc3, GSk3 $\beta$ was measured by western immunoblotting in liver and skeletal muscle of $R$. sylvatica (Figure 4.5). The antibody used cross reacted with a single band at approximately $47 \mathrm{KDa}$ in both liver and skeletal muscle. GSk3 $\beta$ protein expression did not change after 24 hours of anoxic exposure $(1.29 \pm 0.17)$ or after 4 hours of aerobic recovery $(1.45 \pm 0.21)$ compared to the control group $(1.00 \pm 0.14)$ in liver. Likewise, in skeletal muscle, 24 hours of anoxic exposure $(1.12 \pm 0.13)$ or 4 hours of aerobic recovery $(1.29 \pm 0.1)$ did not cause a significant change in GSK3 $\beta$ protein expression levels compared to the control $(1.00 \pm 0.04)$.

The protein expression levels of the upstream activator of NFATs, calcineurin A was

measured by western immunoblotting in liver and skeletal muscle (Figure 4.6). The 
antibody used cross reacted with a single band at $57.5 \mathrm{KDa}$ in both tissues. Calcineurin $\mathrm{A}$ protein levels increased significantly after 24 hours of anoxic exposure $(1.78 \pm 0.07)$ and levels remained significantly high after 4 hours of aerobic recovery $(2.14 \pm 0.16)$ compared to the control $(1.00 \pm 0.17)$ in liver. Protein levels of calcineurin A in skeletal muscle showed no significant change after 24 hours of anoxic exposure $(0.15 \pm 0.09)$ compared to the control group $(1.00 \pm 0.18)$ but levels increased significantly after 4 hours of aerobic recovery $(2.11 \pm 0.23)$ compared to both the control and the anoxic group.

\section{Analysis of atrial natriuretic peptide and osteopontin}

Figure 4.7 shows the protein expression levels of ANP, one of the down stream targets of NFATc4. The antibody used cross reacted with a single band at approximately $17 \mathrm{KDa}$ in liver. Exposure to 24 hours of anoxia resulted in a significant increase in ANP protein levels $(3.8 \pm 0.34)$ compared to the control $(1.00 \pm 0.31)$ and levels remained significantly high $(3.64 \pm 0.25)$ after 4 hours of aerobic recovery compared to the control group in liver.

Figure 4.8 shows the expression of a downstream target of NFATc3, osteopontin, in skeletal muscle. The anti-osteopontin antibody used cross-reacted to a single band at 35 $\mathrm{KDa}$ in skeletal muscle. As seen in Figure 5, osteopontin protein levels showed no significant change after 24 hours of anoxic exposure $(0.72 \pm 0.07)$ or 4 hours of aerobic recovery $(0.81 \pm 0.09)$ compared to the control group $(1.00 \pm 0.07)$.

\subsection{Discussion}

Understanding the molecular mechanisms involved in adaptation to anoxia/reoxygenation in a naturally tolerant model may provide insightful information on solving current medical problems that are associated with stroke, ischemia/reperfusion, and enhancing the viability of transplantable organs. Many ranid frogs are shown to be able to 
tolerate hypoxia (Tattersall and Ultsch, 2008; Jackson and Ultsch, 2010). This adaptation is as a result of having large glycogen stores that can be catabolized to generate ATP in an anaerobic manner when oxygen levels fall (Storey \& Storey 2004c; Ruf \& Geiser, 2015). When environmental temperatures fall below the freezing point $\left(-0.5^{\circ} \mathrm{C}\right)$, wood frogs start a controlled ice nucleation processes that result in whole body freezing (Storey \& Storey, 2013). As a result, blood plasma also freezes which interrupts oxygen delivery to organs, leaving them in an ischemic state. Interestingly, our laboratory has shown that Rana sylvatica can survive anoxic conditions for at least 48 hours in chambers filled with nitrogen gas at $5^{\circ} \mathrm{C}$ even when unfrozen, which further highlights their evolutionary adaptations leading to being freeze-tolerant (Holden \& Storey, 1997).

While adapting to anoxic environments is important for survival in most amphibians, it comes at a cost. Due to the fact that the amount of ATP generated under anaerobic conditions $(<10 \%$ of aerobic amount) is far less than the amount of ATP generated under aerobic respiration, these animals are forced to allocate and reprioritize the available energy to processes that enable survival (Storey, 2007; Overgaard et al., 2007; Jackson \& Ultsch, 2010). For this reason, many organisms that are anoxia tolerant must also be capable of depressing their metabolic rates to match the amount of energy generated under anaerobic conditions (Storey \& Storey, 2004c; Storey, 2007; Overgaard et al., 2007; Jackson \& Ultsch, 2010). For example, while some turtle species can reduce their metabolic rates under anoxia to $10-20 \%$ compared to their aerobic state, molluscs can reduce their rates even further to $2-10 \%$ compared to their aerobic rates (Herbert \& Jackson, 1985; Storey \& Storey, 2004c). In fact, it is the reduced metabolic rates that enable turtles to survive up to 3 months in anoxic and up to 5 months in aerated ice-locked ponds 
in winter; long enough for the duration of winter (Ultsch \& Jackson, 1982; Ultsch, 1985; Ultsch et al., 1999). Furthermore, reducing the metabolic rates also helps with reducing the amount of end products made as a result of anaerobic respiration (such as lactate $\& \mathrm{H}^{+}$ ions) (Storey \& Storey, 2004c). The reduction in metabolic rates can be controlled at several levels as discussed in Chapter 1.

Metabolic rate depression is greatly aided by several control mechanisms, one of which is transcriptional regulation mediated by specific transcription factors. Previous studies have shown that exposure to hypoxia and generation of ROS can cause an increase in intracellular calcium levels (Waypa et al., 2002; Mungai et al., 2011). In fact, it is the elevation of calcium under hypoxia that seems to play a role in helping cells adapt to this condition. For example, the increase in intracellular calcium promoted phenotypic remodeling in smooth muscle cells and induced the activation of the cAMP response element binding protein (CREBP) and c-fos in hypertensive rats (Wellman et al., 2001). Interestingly, in anoxic wood frogs, protein levels of activated CREBP (Ser 133) also increased significantly in the brain (Wu \& Storey, Unpublished data). Moreover, calcium and ROS were shown to activate NFאB (nuclear factor $\kappa \mathrm{B}$ ), a pro-inflammatory transcription factor that is responsible for mediating the transcription of several targets (Dolmetsch et al., 1998; Tabory et al., 2006). In correlation with anoxia-tolerant animals, the subunits of $\mathrm{NF \kappa B}, \mathrm{p} 50$ and $\mathrm{p} 65$, showed elevated transcript levels in anoxic turtle liver (Krivoruchko \& Storey, 2010). The same study also found that the DNA binding and nuclear levels of NFkB were also significantly increased during anoxia. Similar trends were seen in frozen wood frog (also an anoxic event) liver and skeletal muscle where p50 and p65 protein levels were significantly elevated (Brooks \& Storey, unpublished data). 
Likewise, calcium levels have also shown to regulate the activity of NFAT transcription factors (Rao et al., 1997). The involvement of NFATs in regulating several cellular pathways including the cell cycle, apoptosis, skeletal/cardiac and adipocyte differentiation, glucose homeostasis, and muscle hypertrophy, prompted the investigation of this family of transcription factors in wood frogs (Ho et al., 1998; Molkentin et al., 1998; Backsh et al, 2000; Delling et al., 2000; Backsh et al., 2002; Viola et al., 2005; Yang et al., 2006; Wang et al., 2010). Since ROS as a result of anoxic/hypoxic exposure increase intracellular calcium levels and NFATs are activated by calcium, it was of interest to see how this family of transcription factors is regulated in wood frogs during the anoxia/re-oxygenation cycle. This chapter examines the role of NFAT transcription under the anoxic/re-oxygenation cycle in liver and skeletal muscle of $R$. sylvatica.

Liver and skeletal muscle were a good candidate for this study as they both have reservoirs of glycogen. Liver contains the largest glycogen reservoir in wood frogs and through glycogenolysis, this organ provides the glucose needed for energy and cryopreservative purposes for the remaining organs in the body during freezing (Costanzo, 1993; Storey, 2003; Zhang \& Storey, 2013). The same studies have also suggested that the liver is responsible for clearing and re-storing the excess glucose upon thawing. On the other hand, the glycogen storage in skeletal muscle is used within the tissue it self (Hemming \& Storey, 2001). During anoxic conditions where glucose is used for energy, it is the glycogen storage from the liver and not the skeletal muscle that provides the glucose needed for anaerobic metabolism. It is the contrasting role of liver and skeletal muscle in glycogen storage and glucose secretion that prompted the investigation of NFAT signaling in these two tissues. 
In order to see the effect of anoxia/re-oxygenation cycle on NFAT expression, protein levels of NFATc1-NFATc4 were measured by western blotting. With the exception of NFATc1 protein levels, both the protein expression and the DNA binding levels of NFATc1-NFATc3 either decrease or remained unchanged over the anoxia/re-oxygenation cycle in liver (Figure 4.1, 4.3). Similarly, in skeletal muscle, only NFATc3 showed a significant increase in protein expression levels while both the protein levels of NFATc1c3 and the DNA binding levels of all four NFATs either decreased or remained unaltered (Figure 4.2 and 4.4). Overall, only NFATc4 showed a significant increase in both protein expression and DNA binding levels after 24 hours of anoxia in liver (Figures 4.1 and 4.3); suggesting that NFATc4 activity could be necessary for surviving in this tissue. The discrepancy between the expressed protein levels (NFATc1 in liver and NFATc3 in skeletal muscle as seen in Figure 4.1 and 4.2) and the DNA binding activity (Figure 4.3 and 4.4) can be explained by the effect of post-translational modifications on protein activity. Previous studies have outline the role of phosphorylation in inhibiting NFAT activity (Rao et al., 1997; Hogan et al., 2003). When NFAT transcriptional activity is not needed, these transcription factors are heavily phosphorylated by different kinases and reside in the cytoplasm (Rao et al., 1997; Hogan et al., 2003; Viola et al., 2005). It is note worthy to mention that the antibodies used for NFATc1-c4 detect the total level of those NFATs (both the phospho and the dephospho forms); therefore, the increase in protein expression levels may in fact be an increase in the p-NFATc1 and p-NFATc3 levels in liver and skeletal muscle respectively (Figure 4.1, 4.2). This can be supported by the DNA binding levels of those NFATs in the respective tissues. For example, while the protein levels of NFATc1 in liver (Figure 4.1) (which also showed a slightly higher molecular 
weight than expected) and NFATc3 (Figure 4.2) in skeletal muscle were significantly upregulated during anoxia, there was no significant increase in the DNA binding activity as seen in Figure 4.3 and 4.4 respectively. This problem could be eliminated by detecting the inactive levels of NFATs using phospho-specific antibodies.

The decrease in baseline activity of NFATc1-c3 in liver and all four NFATs in skeletal muscle is expected, as transcription is an energy-expensive process and cells undergoing hypometabolism need to conserve energy for pro-survival pathways while supressing processes that are problematic to the cell. For example, NFATc1 was shown to be overexpressed in hepatocellular carcinoma cells and was responsible for inducing cellular proliferation (Wang et al., 2010). Since cancer cells are hypoxic, it is possible to correlate the expression of NFATc1 in these cells to cellular proliferation during hypoxia. Based on this argument, it is possible that NFATc1 could cause cellular proliferation under anoxic conditions in wood frog. Since anoxic wood frogs are in a hypometabolic state and need to conserve energy, it is understandable that there would a downregulation in signaling pathways that promote cellular proliferation. The decrease in NFATc1 DNA binding levels in skeletal muscle (Figure 4.4) and the unchanged DNA binding levels in liver (Figure 4.3) during anoxia is perhaps a response to attenuate cellular proliferation in these two tissues. Moreover, NFATc2 was shown to cause muscle growth as a result of causing an increase in myotube size and nuclear numbers by mediating the fusion of mature muscle cells with multinucleated ones (Horsley et al., 2001). As mentioned earlier, to conserve energy, cellular growth is interrupted during stress and is resumed during or soon after the recovery phase. NFATc2 DNA binding levels decreased significantly in liver but remained unaltered in skeletal muscle after exposure to anoxia (Figure 4.3, 4.4), suggesting 
that NFATc2 activity is attenuated under anoxic conditions. Indeed, NFATc2 DNA binding levels increased significantly compared to the control after 4 hours of aerobic recovery in skeletal muscle (Figure 4.4) indicating that perhaps it is facilitating skeletal muscle repair. Likewise, because NFATc2 activity is not needed in the liver, it is suppressed under anoxic conditions to conserve energy and is rebound after 4 hours of aerobic recovery; yet showing another tissue specific-response. NFATc3 was shown to increase in expression in response to chronic hypoxia (Bierer et al., 2011). This increase resulted in vasculature remodeling in primary pulmonary artery smooth muscle cells in both adult and neonatal mice leading to pulmonary hypertension (Frutos et al., 2007; Bierer et al., 2011). Perhaps the unchanged DNA binding activity of NFATc3 in both liver and skeletal muscle (Figure 4.3, 4.4) is a protective response against anoxia to protect both tissues from vasculature remodeling. All together, it is evident that unnecessary or harmful NFATs are strictly regulated under anoxic conditions in a tissue-specific manner in order to avoid and limit tissue damage during this stress.

Several kinases are involved in phosphorylating NFATs to facilitate their nuclear export back to the cytoplasm. For example, studies have shown that nuclear localization of NFATc1 is inhibited by c-Jun N-terminal kinase (JNK). JNK phosphorylates NFATc1 near calcineurin binding site (Chow et al., 2000). Studies by Greenway \& Storey (1999; 2000) have shown that JNK activity increased significantly after 5 hours of anoxic exposure but started to decrease for longer periods in anoxia-tolerant adult and hatchling turtles. Although JNK activity was not measured in anoxic $R$. sylvatica liver and skeletal muscle, based on previous research done in other animals, it is possible that anoxic exposure would perhaps increase the activity of JNK, leading to the phosphorylation of NFATc1 and 
subsequently its cytoplasmic retention. As seen in Figures 4.3 and 4.4, while total NFATc1 protein expression levels significantly increased in liver, the activity remained unaltered in contrast to skeletal muscle where both protein levels and DNA binding activity were significantly down regulated after 24 hours of anoxic exposure. Perhaps, the JNK activity trend seen in adult and hatchling turtles is similar to what is happening in anoxic wood frogs where JNK activity increases early after anoxic exposure but start to decline for longer periods (Greenway \& Storey 1999, 2000). This would explain the DNA binding activity trend seen in both liver and skeletal muscle. While this hypothesis is plausible, further experiments are required to asses the relationship between JNK and NFATc1 phosphorylation. Moreover, as explained in chapter 3, phosphorylation of NFATc2 and NFATc4 by p38 causes the nuclear exit of these transcription factors (Arco et al., 1999; Yang et al., 2002). While p38 activity was not measured in $R$. sylvatica in response to anoxic conditions, the active form of $\mathrm{p} 38$ ( $\mathrm{p}-\mathrm{p} 38)$ remained unchanged after exposure to 20 hours of anoxia in turtle organs (Greenway \& Storey, 2000). Perhaps, the unchanged kinase activity of p38 is responsible for allowing NFATc4 nuclear accumulation in the liver and subsequent increase in DNA binding levels during the anoxia/re-oxygenation cycle (Figure 4.3). Another study showed that casein kinase (CK1) can also phosphorylate NFATc2 and cause its nuclear export (Okamura et al., 2004). Perhaps it is the combinatory effect of CKI, p38 and the decrease in NFATc2 protein levels that mediate the decrease in DNA binding levels of this transcription after 24 hours of anoxic exposure in liver (Figure 4.1, 4.3). With caution, it is perhaps safe to speculate that activity of NFATc2 and NFATc4 are regulated by $\mathrm{CK} 1$ and $\mathrm{p} 38$; however, further analysis of the relationship between $\mathrm{CK} 1$ and $\mathrm{p} 38$, on the DNA binding activity of NFATc1 and NFATc4 is required in R. sylvatica 
under such conditions. With respect to NFATc3, studies have shown that when this transcription factor is no longer needed in the nucleus, GSK3 $\beta$ will phosphorylate it and cause its nuclear export (Velden et al., 2008). Western blot analysis of total GSK3 $\beta$ (Figure 4.5) showed that the anoxia/re-oxygenation cycle had no effect on its protein expression in liver or skeletal muscle, which correlates with the unchanged DNA binding activity of NFATc3 in both liver and skeletal muscle (Figure 4.3, 4.4).

Inactive NFATs are heavily phosphorylated and are sequestered in the cytoplasm (Rao et al., 1997). It is only upon stimulation with calcium and subsequent calcineurin activation that these transcription factors can enter the nucleus and start the transcription of target genes (Rao et al., 1997). Levels of calcineurin A were measured by western blotting and the results are shown in Figure 4.6. While calcineurin A protein levels showed a significant up regulation during the anoxia/re-oxygenation cycle in liver, levels remained unchanged after 24 hours of anoxia but increased significantly compared to both the control and the anoxic group in skeletal muscle. This pattern corresponds to the expression and activity data in liver and muscle. The significant up-regulation of NFATc4 proteins (Figure 4.1) as well as DNA binding activity (Figure 4.3) is agreeable with calcineurin A protein up regulation (Figure 4.6) in liver. The expression pattern of calcineurin A after 24 hours of anoxic exposure also correlated with the expression and activity of NFATs in skeletal muscle as seen in Figure 4.2 and Figure 4.4. These findings indicate that NFATc4 signaling pathway is active in liver but not in skeletal muscle during anoxia, perhaps due to tissue specific protection it may offer.

To see the effect of NFATc4 activation under anoxic condition in liver, ANP, one of the downstream targets of this transcription facto was analyzed (Carini et al., 2003). This 
peptide hormone is shown to play a role in a variety of cellular processes including protecting against ischemic/reperfusion injury in different tissues (Shaw et al., 1987; Kiemer et al., 2000; Kiemer et al., 2002). Yamada et al. (2013) have shown that continuous administration of ANP through the ischemia/reperfusion state prevents liver damage by decreasing transaminase levels and apoptosis potentially through maintaining the integrity of the microvascular blood flow. Another group has shown that preconditioning hepatocytes with ANP decreases cell death due to apoptosis as well as necrosis in liver (Gerwig et al., 2003). Furthermore, ANP induction was shown to be associated with an increase in the heat shock response as outlined by Kiemer et al. (2002). Indeed, ANP caused the up regulation of heat shock protein 70 (HSP70) via cyclic guanosine monophosphate (cGMP). HSP70 was then complexed with the inhibitory factor $\kappa \beta$ (Iк $\beta)$, resulting in the decrease of the pro-inflammatory activity of NFא $\beta$ upon reperfusion (Kiemer et al., 2002; Kiemer et al., 2000). All together, these and several other studies have thoroughly outlined the protective effects of ANP in different conditions, which prompted the investigation of ANP levels during the anoxia/re-oxygenation cycle in $R$. sylvatica.

Western blot analysis of ANP protein levels in liver revealed that exposure to 24 hours of anoxia caused a 3.8 fold up regulation and remained at 3.6 folds compared to the control after 4 hours of aerobic recovery (Figure 4.7). The increase in ANP expression levels strongly correlated with the increase in NFATc4 protein expression and DNA binding levels during the anoxia/re-oxygenation cycle in liver (Figure 4.1, 4.3). This response is expected as several groups have shown the protective effects of ANP upon ischemia/reperfusion event in different organs. Carini et al. (1999) have shown that under anoxic conditions, intracellular sodium ion concentrations increase resulting in cell 
swelling and potentially necrosis. A follow up study by the same group has concluded that ANP prevents sodium ion concentration overload by directly regulating $\mathrm{Na}^{+} / \mathrm{H}^{+}$exchanger activity; thereby preventing the accumulation of this ion in the cell and preventing cell swelling (Carini et al., 2003). Furthermore, Gerwig et al. (2003) have demonstrated that an increase in ANP protein level prevents apoptosis under hypoxic conditions. A previous study by our group has shown that apoptotic response is inhibited in the liver of $R$. sylvatica exposed to the anoxic/re-oxygenation cycle (Gerber et al., 2016). Perhaps the inhibition of apoptosis seen in anoxic liver of wood frogs is a response to the ANP protein expression as demonstrated in this study.

Since there was no significant increase in DNA binding levels in any of the four NFATs (Figure 4.4) in skeletal muscle and only NFATc3 showed a significant up regulation in protein levels, one downstream target of NFATc3 (osteopontin) was used for analysis (Figure 4.2). As explained in chapter 1, osteopontin is one of the downstream targets of NFATc3 (Nilsson-Berglund et al., 2010; Zetterqvist et al., 2015). In addition to regulating hyperglycemia, osteopontin has also been shown to play a role in muscle regeneration. Hirata et al. (2003) have shown that osteopontin levels are highly expressed in regenerating muscle. Another group showed that osteopontin null mice had a delay in muscle regeneration as a result of slower neutrophil and macrophage infiltration response (Uaesoontrachoon et al., 2013). Moreover, a study has shown that mice lacking osteopontin were prone to matrix disorganization, lack of collagen production and wound healing (Liaw et al., 1998). Indeed, the prominent role of osteopontin in muscle regeneration has been highlighted in a study by Kuraoka et al. (2016) where they concluded that osteopontin can be used as a biomarker for detecting muscle regeneration. Due to its importance in muscle 
regeneration, it was of interest to measure osteopontin levels in skeletal muscle undergone the anoxia/re-oxygenation cycle. As seen in Figure 4.8, there is no significant change in the protein expression levels of osteopontin in skeletal muscle over the anoxia/reoxygenation cycle. Despite the importance of this cytokine in mediating muscle regeneration, the trend seen in osteopontin protein levels was expected as the DNA binding levels of its transcription factor, NFATc3, remained constant over the anoxia/reoxygenation cycle in skeletal muscle (Figure 4.4). As explained earlier, the increase in NFATc3 protein levels is probably as a result of an increase in the phosphorylated form of NFATc3. Moreover, protein levels of GSk3 $\beta$, which is responsible for re-phosphorylating and causing the nuclear exit of NFATc3 also remains unchanged over the anoxia/reoxygenation cycle in skeletal muscle. Overall, while osteopontin may be important in mediating skeletal muscle remodeling and regeneration, its function is perhaps unnecessary as wood frogs show no sign of muscle impairment during the anoxia/re-oxygenation cycle (laboratory observations). While muscle reflexes were not measured in anoxic/recovered wood frogs, previously frozen wood frogs showed no muscle impairment after thawing (Layne et al., 1991). This is physiologically relevant as freezing is considered an ischemic event due to the interruption of blood flow to organs and thawing is considered a reperfusion event where oxygen delivery to organs is restored. The same study by Layne et al. (1991) has shown that the freeze/thaw cycle did not damage muscle contraction. In fact, there were no significant differences with regards to contraction strength between muscles that were thawed for 1, 2 or 24 hours compared to the control groups (Layne et al., 1991). With regards to these findings, it is understandable that wood frogs would downregulate skeletal muscle regeneration mechanisms, especially during periods where 
energy reservoirs are limited. Perhaps, $R$. sylvatica prevents damage to skeletal muscle by up-regulating targets that would stabilize the structural integrity of the muscle cells; therefore, eliminating the need for muscle regeneration upon thawing. While this hypothesis is plausible, further experiments are required to make this conclusion.

As mentioned earlier, the role of liver and skeletal muscle is different with respect to glucose secretion and cryoprotection. While the liver has the largest glycogen storage and provides the glucose needed for anaerobic metabolism in other tissues, the skeletal muscle confines its glycogen storage strictly for itself. Since the liver plays a significant role in allowing $R$. sylvatica to survive under anoxic conditions, it is understandable that even during periods of extreme hypometabolism, pro-survival signaling pathways would be activated to protect this tissue. On the other hand, since the skeletal muscle is not involved in glucose secretion to other tissues and is not vital to wood frog survival under anoxic conditions, it is understandable that it would not be active; as seen by absence of an increase in transcriptional activity in this chapter and chapter 3.

In conclusion, to our knowledge this is the first study to explore the role of NFATs in liver and skeletal muscle of $R$. sylvatica in response to anoxia/re-oxygenation. In liver, up regulation of NFATc4 protein expression levels as well as the DNA binding activity correlated with the increase in ANP protein levels during the anoxia/re-oxygenation cycle. With respect to data from literature, it is safe to conclude that ANP offers cytoprotection to liver undergoing periods of limited oxygen availability and subsequent oxygen reperfusion. As for skeletal muscle, there were no significant DNA binding activity in any of the four NFATs. Osteopontin, a downstream target of NFATc3, also showed no significant change over the anoxia/re-oxygenation cycle in skeletal muscle, suggesting that 
this tissue doesn't require regeneration during anoxia. All together, this data suggests that once again liver is active under stress while skeletal muscle, as seen in Chapter 3, is not. 
Figure 4.1: Western blot analysis on total protein extracts showing the effects of the anoxia/re-oxygenation cycle on NFAT proteins in wood frog liver.

Changes in protein expression level of total NFATc1-c4 after 24 hours of anoxia and 4 hours of aerobic recovery in wood frog liver. Representative ECL-detected bands are shown for each condition. All data are \pm means of $n=3-4$ independent biological replicates. Significant $(\mathrm{P}<0.05)$ from control and 24 hour anoxia is denoted by a and $\mathrm{b}$ respectively. Statistical analysis was done using One-way Anova with Holm-Sidak post-hoc test.

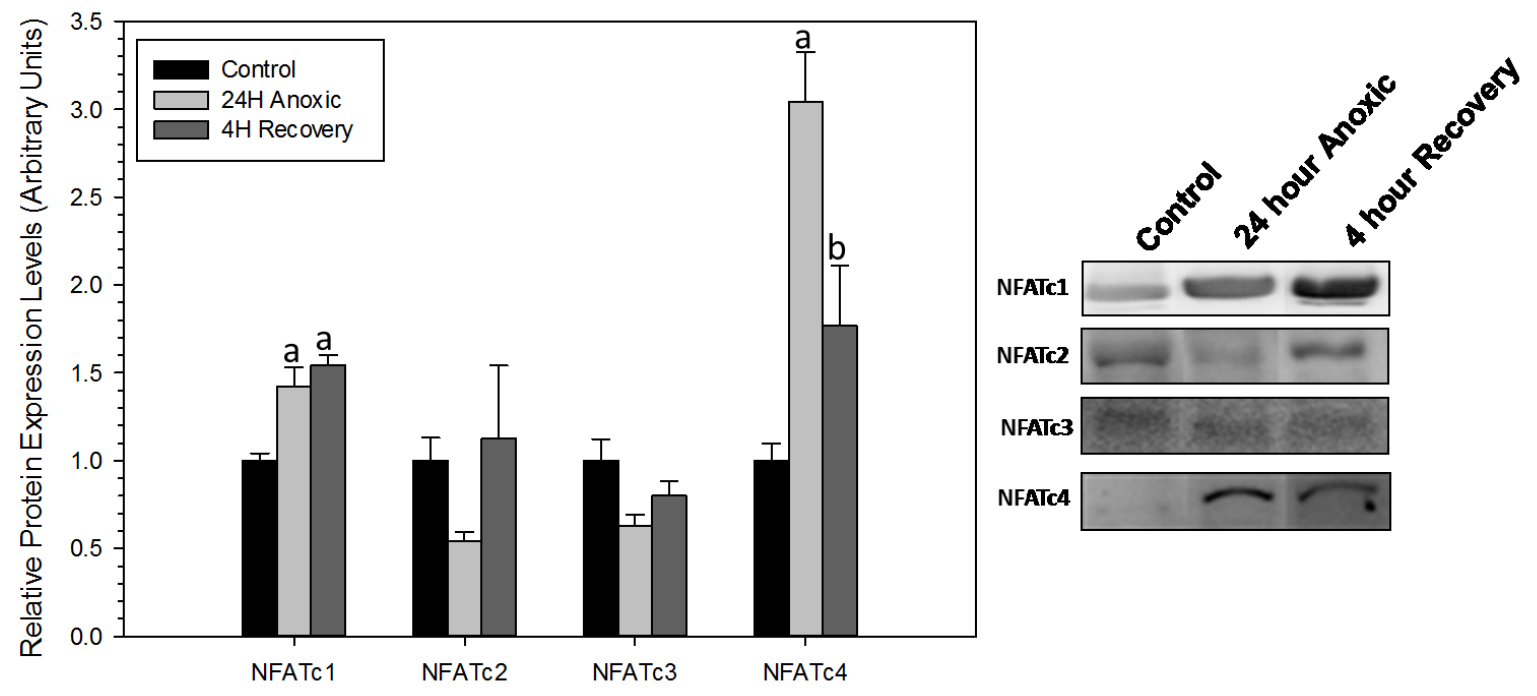


Figure 4.2: Western blot analysis on total protein extracts showing the effects of the anoxia/re-oxygenation cycle on NFAT proteins in wood frog skeletal muscle.

Changes in protein expression levels of total NFATc1-c4 after 24 hours of anoxia and 4 hours of aerobic recovery in wood frog skeletal muscle. Representative ECL-detected bands are shown for each condition. All data are \pm means of $n=3-4$ independent biological replicates. Significant $(\mathrm{P}<0.05)$ from control and 24 hour anoxia is denoted by a and $\mathrm{b}$ respectively. Statistical analysis was done using One-way Anova with Holm-Sidak posthoc test.
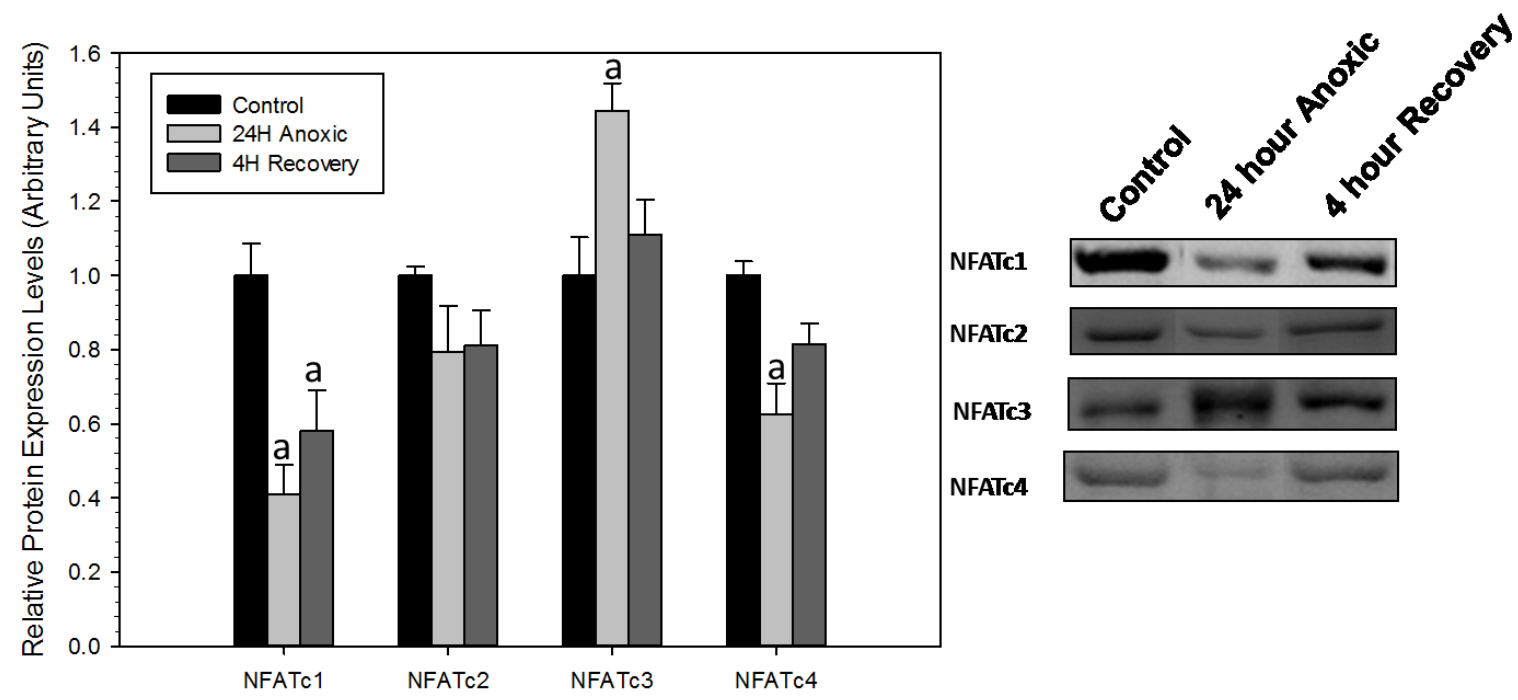
Figure 4.3: TF-ELISA analysis on total protein extracts showing the effects of the anoxia/re-oxygenation cycle on the DNA binding ability of NFATs in wood frog liver.

Changes in DNA binding levels of NFATc1-4 to the NFAT consensus sequence after 24 hours of anoxia and 4 hours of aerobic recovery in wood frog liver. All data are \pm means of $n=3-4$ independent biological replicates. Significant $(\mathrm{P}<0.05)$ from control and 24 hour anoxia is denoted by a and $b$ respectively. Statistical analysis was done using One-way Anova with Holm-Sidak post-hoc test.

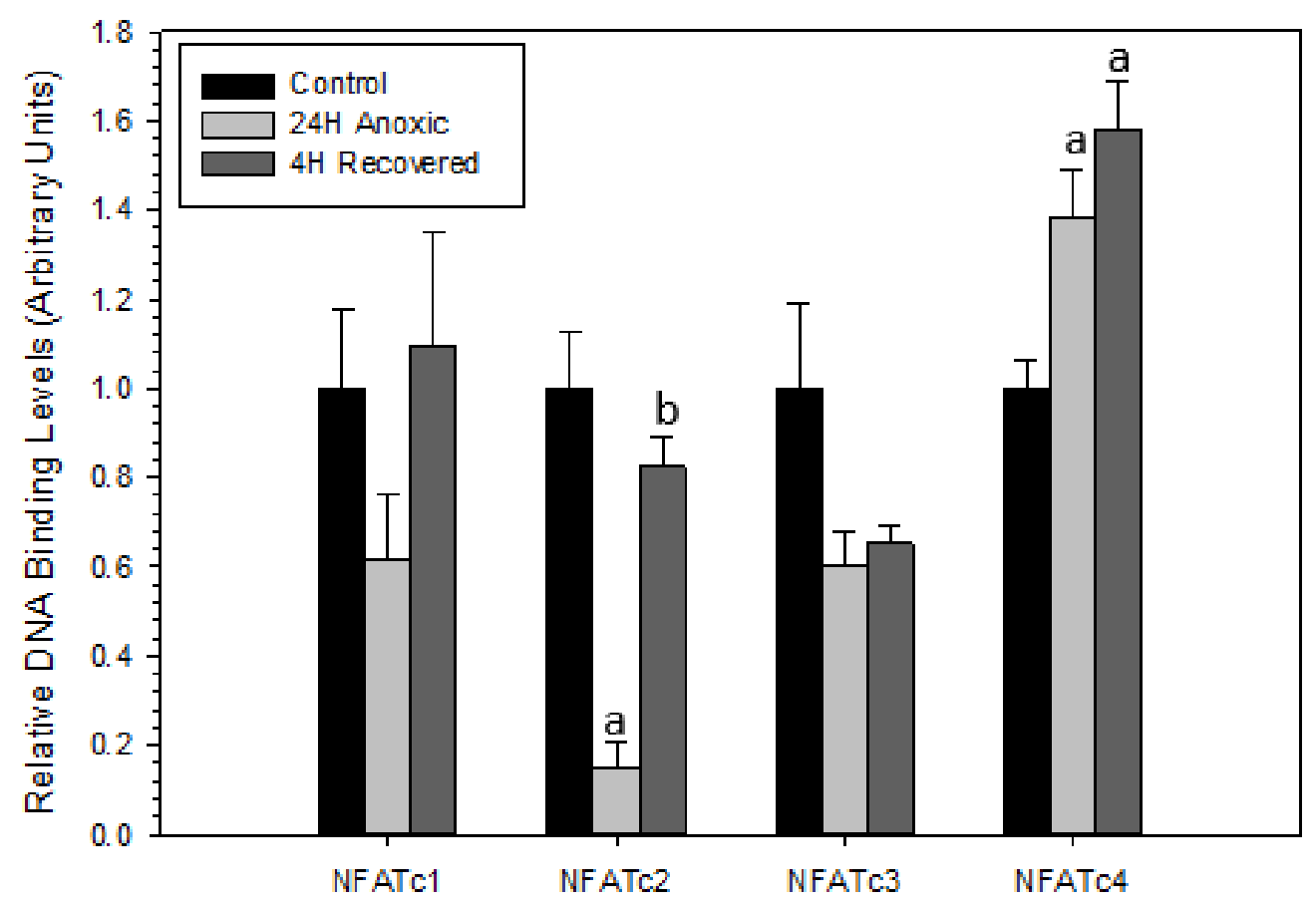


Figure 4.4: TF-ELISA analysis on total protein extracts showing the effects of the anoxia/re-oxygenation cycle on the DNA binding ability of NFATs in wood frog skeletal muscle.

Changes in DNA binding levels of NFATc1-4 to their consensus sequence after 24 hours of anoxia and 4 hours of aerobic recovery in wood frog skeletal muscle. All data are \pm means of $n=3-4$ independent biological replicates. Significant $(\mathrm{P}<0.05)$ from control and 24 hour anoxia is denoted by a and b respectively. Statistical analysis was done using Oneway Anova with Holm-Sidak post-hoc test.

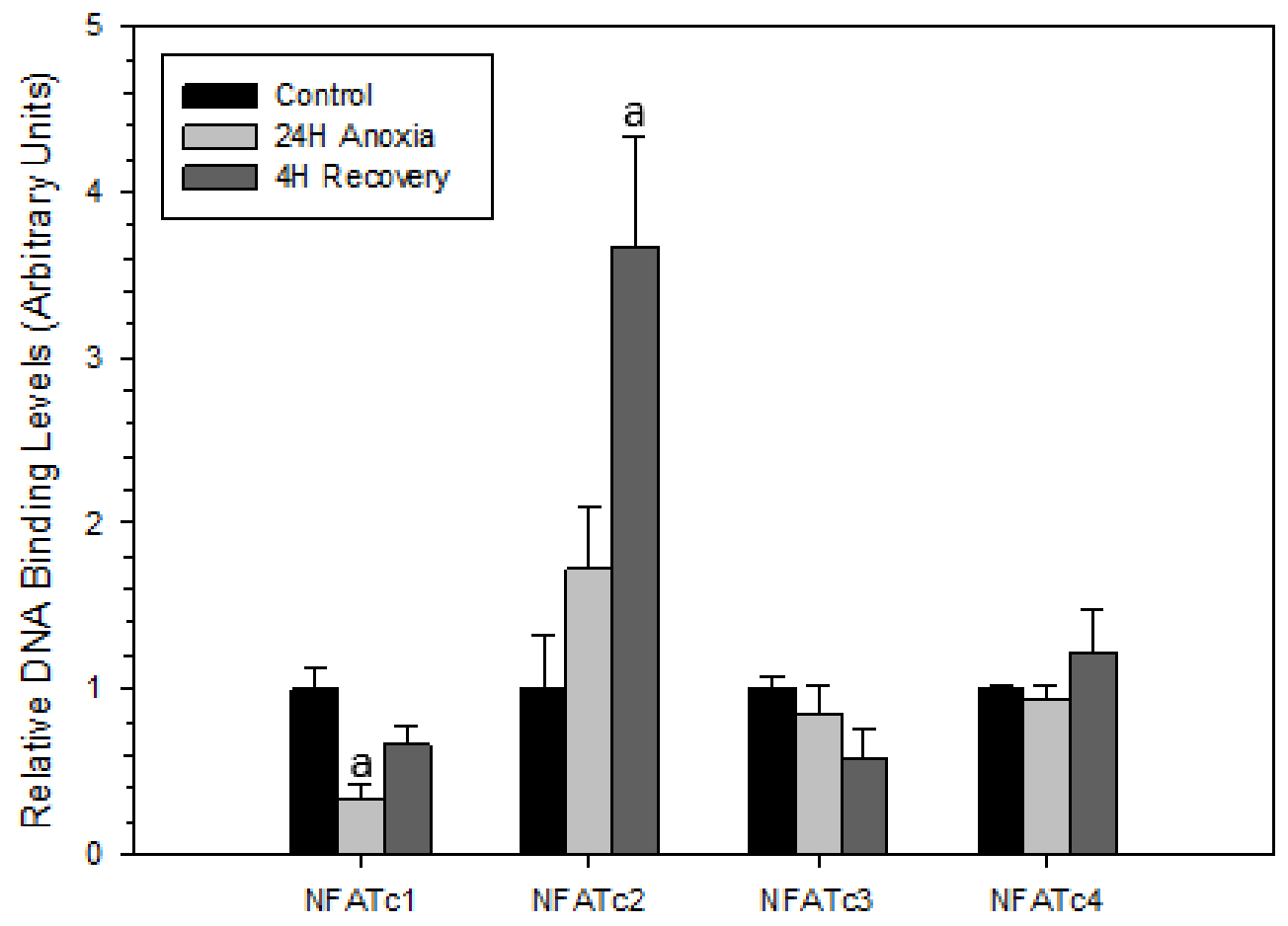


Figure 4.5: Western blot analysis on total protein extracts showing the effect of the anoxia/re-oxygenation cycle on protein levels of GSK3 $\beta$ in wood frog liver and skeletal muscle.

Changes in protein expression levels of GSK3 $\beta$ after 24 hours of anoxia and 4 hours of aerobic recovery in wood frog liver and skeletal muscle. Representative ECL-detected bands are shown for each condition. All data are \pm means of $n=4$ independent biological replicates. One-way Anova analysis showed no statistical significance.

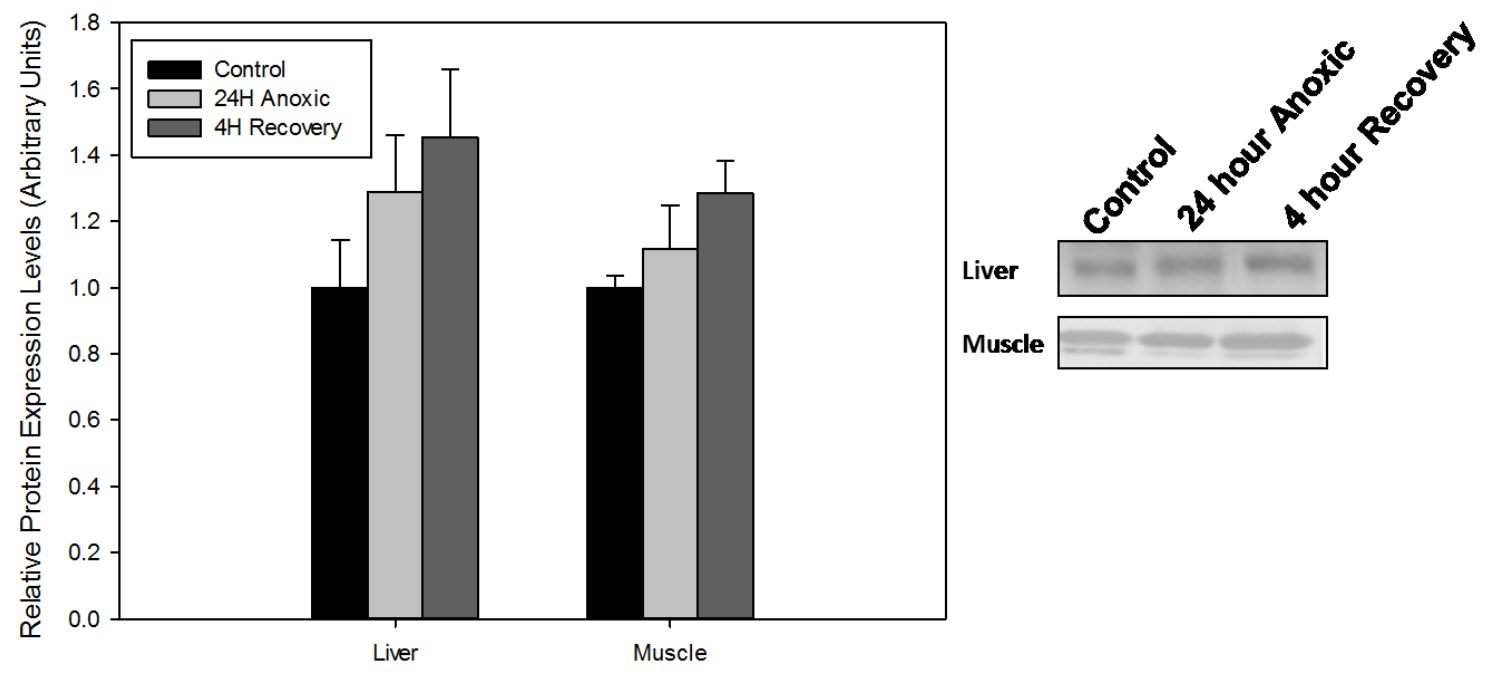


Figure 4.6: Western blot analysis on total protein extracts showing the effect of the anoxia/re-oxygenation cycle on protein levels of calcineurin A in wood frog liver and skeletal muscle.

Changes in protein expression levels of calcineurin A after 24 hours of anoxia and 4 hours of aerobic recovery in wood frog liver and skeletal muscle. Representative ECL-detected bands are shown for each condition. All data are \pm means of $n=4$ independent biological replicates. Significant $(\mathrm{P}<0.05)$ from control and 24 hour anoxia is denoted by a and $b$ respectively. Statistical analysis was done using One-way Anova with Holm-Sidak posthoc test.

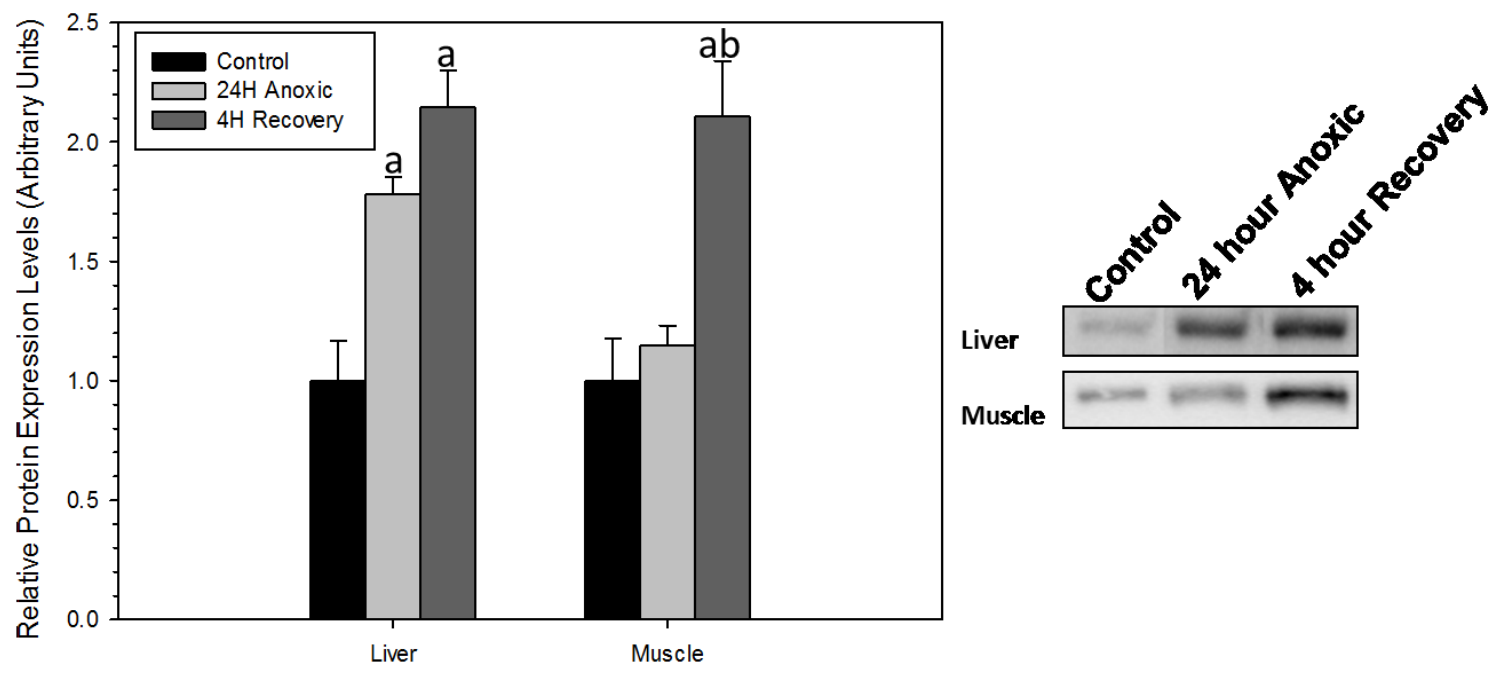


Figure 4.7: Western blot analysis on total protein extracts showing the effect of the anoxia/re-oxygenation cycle on protein levels of ANP in wood frog liver.

Changes in protein expression levels of ANP after 24 hours of anoxia and 4 hours of aerobic recovery in wood frog liver. Representative ECL-detected bands are shown for each condition. All data are \pm means of $n=4$ independent biological replicates. Significant $(\mathrm{P}<0.05)$ from control and 24 hour anoxia is denoted by a and $\mathrm{b}$ respectively. Statistical analysis was done using One-way Anova with Holm-Sidak post-hoc test.

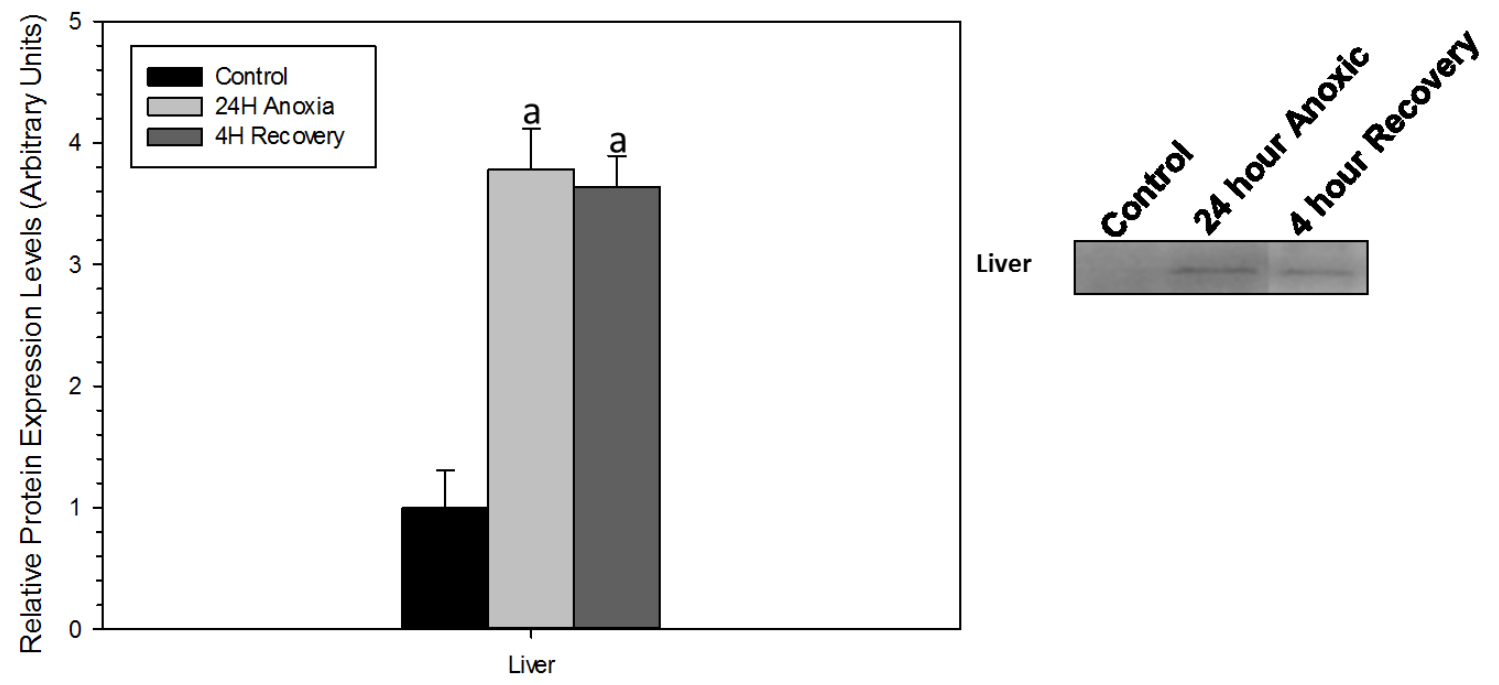


Figure 4.8: Western blot analysis on total protein extracts showing the effect of the anoxia/re-oxygenation cycle on protein levels of osteopontin in wood frog skeletal muscle.

Changes in protein expression levels of osteopontin after 24 hours of anoxia and 4 hours of aerobic recovery in wood frog skeletal muscle. Representative ECL-detected bands are shown for each condition. All data are \pm means of $n=4$ independent biological replicates. One-way Anova analysis showed no statistical significance.

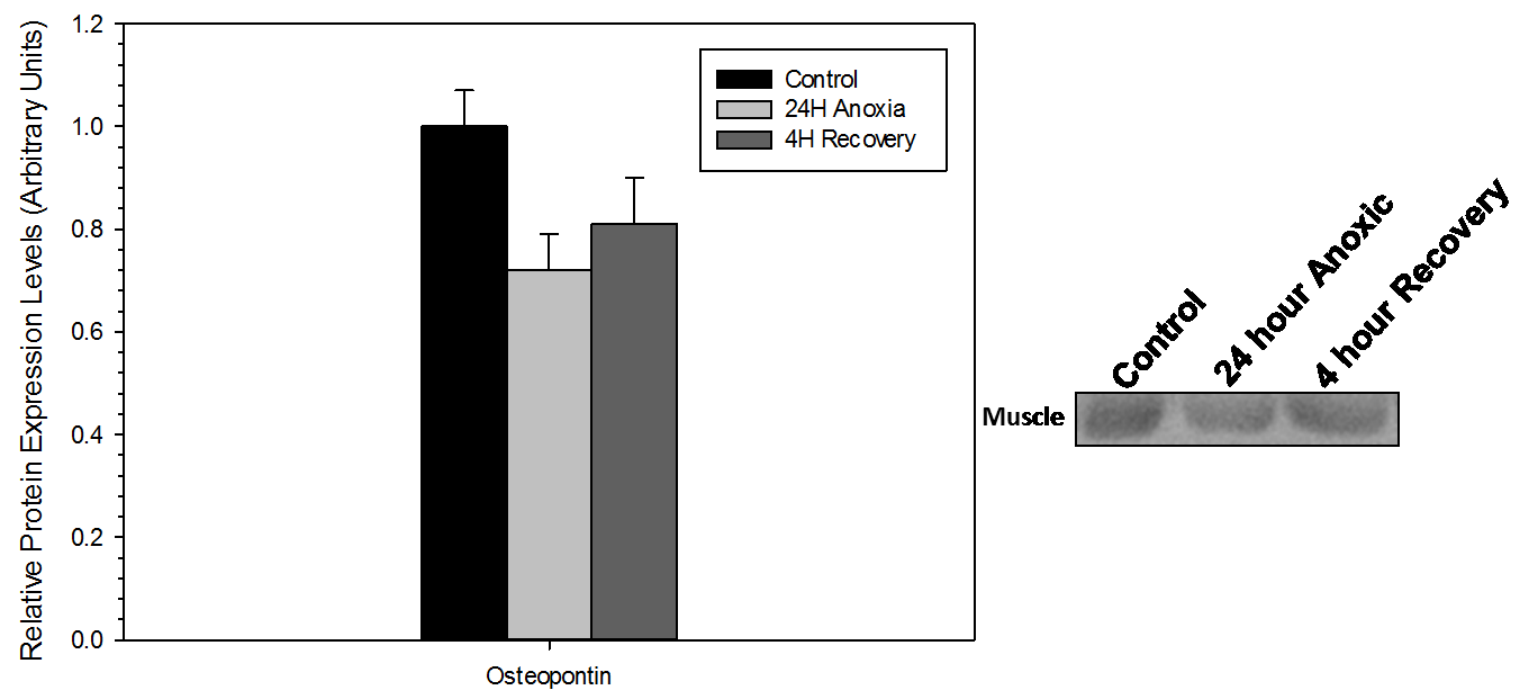




\section{Chapter 5: General discussion}




\subsection{General Discussion}

Most organisms in the wild are exposed to environmental fluctuations and seasonal changes that impose a variety of challenges on everyday life. While some organisms avoid these challenges by migrating to more suitable environments, others adapt by reorganizing their physiological and biochemical responses in order to tolerate harsh environmental conditions. One such organism is Rana sylvatica (the wood frog), which combats cold winters by adopting a freeze-tolerant strategy. During freezing, approximately $65-70 \%$ of total body water is withdrawn from cells into the extracellular matrix to form ice crystals, leaving the wood frog in a state of extreme dehydration. As a result of freezing, blood delivery to different tissues is disrupted, which forces wood frog organs to overwinter in a state of complete anoxia. To protect its organs during freezing, $R$. sylvatica raises its glucose levels from 1-5 mM under normal conditions to approximately $300 \mathrm{mM}$ when frozen, leaving the frog in an extremely hypoglycemic state (Storey \& Storey, 1984). Thus, freeze-tolerance in wood frogs is associated with tolerance to four different stresses: freezing itself, dehydration, anoxia, and hyperglycemia. Interestingly, while wood frogs are naturally exposed to these stresses when frozen, they are also able to tolerate hyperglycemia, dehydration and anoxia even when unfrozen; making $R$. sylvatica an excellent natural model for studying stress-tolerance. Thoroughly analyzing and understanding the molecular mechanisms involved in regulating how $R$. sylvatica adapted to tolerate freezing, dehydration, anoxia and hyperglycemia can provide novel insights and aid in the development of therapeutics for medical problems associated with prolonging organ preservation time, diabetes and ischemic stroke/reperfusion in humans. 
Each of the aforementioned conditions have their own complications that wood frogs must overcome. For example, ice growth as a result of freezing can physically disrupt the architecture of cells, damage capillaries and lead to cell death (Storey \& Storey, 2007). Dehydration as a result of water loss can shrink cells and cause an increase in the intracellular ionic strength as well as osmolality and anoxia can cause a burst in ROS which can cause damage to macromolecules in the cell (Storey \& Storey, 2004c). Moreover, when glucose levels are high and iron and copper metals are present, glucose undergoes autooxidation to generate hydrogen peroxide and protein-reactive dicarboyl compounds which results in cellular damage (Storey \& Storey, 2004c). In addition to the stressed state, the recovery phase (thawing, rehydration, re-oxygenation and glucose homeostasis recovery) associated with each stress can also impose challenges to these frogs. For example, the liver of wood frogs up-regulates fibrinogen during freezing, dehydration and hyperglycemia (glucose-loaded frogs) in order to repair tissue damage upon thawing, rehydration and glucose homeostasis as these conditions might disrupt tissue architecture and cause internal bleeding (Cai \& Storey, 1997b; Storey \& Storey, 2004c). Alternatively, anoxic wood frogs up regulate a myriad of anti oxidant enzymes and metabolites in order to protect the cells from the ROS generated during periods of oxygen deprivation and upon re-perfusion (Joanisse \& Storey, 1996). Therefore, it becomes imperative for these frogs to develop a well organized defense mechanism not only during stress but also during the recovery phase. While wood frogs have developed a set of defense mechanisms for each of these stresses, without metabolic reorganization, supplying enough energy to cellular processes under these conditions becomes impossible. For this reason, wood frogs and other organisms (such as thirteen-lined ground squirrels, mollusks, and red ear slider turtles 
to name a few) exposed to challenging environmental conditions go through periods of metabolic rate depression where they depress most of their metabolic processes to converse energy (Storey \& Storey, 2004c). Metabolic rate depression is beneficial as it allocates the finite amount of energy available to processes necessary for survival while supressing undesirable processes that may be challenging to the viability of the cell.

\subsection{Transcription under metabolic rate depression}

Metabolic rate depression is mediated by several control mechanisms (as discussed in chapter 1), one of which is transcriptional regulation. A cDNA microarray screen of frozen wood frog heart revealed more than 200 genes that were up regulated, some of which include: HIF-1, antioxidant enzymes, adenosine A1 and ANP receptors and several other targets (Storey \& Storey, 2004b). In addition, a cDNA library screen of control and 24 hour frozen wood frog liver has revealed another set of targets that were significantly up regulated including: the $\alpha$ and $\Upsilon$ subunits of fibrinogen, ADP/ATP translocase, and FR10 (Cai \& Storey, 1997a; 1997b, 1997c). All together, these up regulated targets confirm that even during periods of extreme hypometabolism, the transcription of pro-survival targets remains active. Transcription is carried out by specific transcription factors that work in a tissue/stress dependent manner. To date, several studies performed on R. sylvatica under frozen, dehydrated, anoxic and hyperglycemic conditions have revealed the differential regulation of the same transcription factors under different conditions and tissues. The current study outlined one such transcription factor family, NFATs, and characterized their role over the freeze/thaw and anoxic/re-oxygenation cycle in liver and skeletal muscle of R. sylvatica. 
NFATs are a family of transcription factors that regulate the expression of genes associated with the immune system, cell cycle, apoptosis, cell differentiation, glucose homeostasis, and cardiac hypertrophy (Ho et al., 1998; Molkentin et al., 1998; Backsh et al., 2000; Delling et al., 2000; Wang et al., 2001; Backsh et al., 2002; Viola et al., 2005; Yang et al., 2006). While some studies have outline the role of NFATs under hyperglycemic and hypoxic conditions in other organisms; no study to date has analyzed NFAT regulation under freezing and anoxic conditions in wood frogs. For this reason, it was of interest to investigate how NFATs regulate gene expression in $R$. sylvatica under the hypometabolic states of freezing and anoxia in liver and skeletal muscle.

\subsection{NFAT signaling during the freeze/thaw cycle}

Chapter 3 examined NFAT regulation over the freeze/thaw cycle in liver and skeletal muscle. Total protein expression and DNA binding analysis of NFATc1-c4 in liver revealed that only NFATc3 is significantly up regulated and active during freezing while the remaining NFATs are either unchanged or significantly downregulated (Figure 3.1, 3.3). Interestingly, the addition of glucose or change in temperature did not have any effect on the DNA binding activity of NFATc3 proteins from the 24 hour frozen treatment (Figure 3.5, 3.7). Moreover, the nuclear accumulation of NFATc3 during freezing further confirmed the DNA binding activity results of this transcription factor (Figure 3.3, 3.8). The nuclear accumulation of NFATc3 was further confirmed by the significant decrease in protein levels of GSK3 $\beta$, which functions to re-phosphorylate NFATc3 leading to its nuclear export (Figure 3.10). Furthermore, the activity and nuclear accumulation of NFATc3 correlated strongly with the increase in osteopontin protein levels which in turn correlated with the increase in p-STAT3 (Ser 727) protein levels (Figure 3.11, 3.12b). 
Previous studies have shown that p-STAT3 (Ser 727) binds to the promoter of GSK3 $\beta$ and prevents its gene transcription (Moh et al., 2008). With respect to the data in this chapter, it is highly possible that the increase in p-STAT3 (Ser 727) proteins is responsible for the decrease in GSk3 $\beta$ protein expression (Figure 3.10). Overall, it was demonstrated that NFATc3 signaling may be responsible for inhibiting GSK3 $\beta$ transcription during freezing via osteopontin and p-STAT3 (S727).

Both the total protein levels as well as DNA binding activity of NFATs were also measured in skeletal muscle during the freeze/thaw cycle. Interestingly, NFATs were either significantly downregulated or remained unchanged with no significant increase in DNA binding activity over the freeze/thaw cycle (Figure 3.2, 3.4). This observation might have been a result of the significant decrease detected in calcineurin A, a protein responsible for activating NFATs (Figure 3.9). In addition, varying glucose concentrations did not influence the DNA binding activity of NFATc3 proteins from the 24 hour frozen treatment (Figure 3.6). Unlike liver, the skeletal muscle data obtained showed that NFATc3 protein levels (during 24 hours freezing) and DNA binding levels during the freeze/thaw cycle remained unchanged. These findings also correlate with the constant protein levels of GSK3 $\beta$, which in turn may be the result of constant osteopontin protein levels and the absence of p-STAT3 (S727) proteins (Figure 3.10, 3.11). Overall, this study demonstrated that NFAT signaling exhibited tissue-specific regulation and that NFATs were not active during the freeze/thaw cycle in skeletal muscle as compared to the liver.

\subsection{NFAT signaling during the anoxia/re-oxygenation cycle}

Chapter 4 examined the role of NFATs during the anoxia/re-oxygenation cycle in

liver and skeletal muscle of $R$. sylvatica. Total protein levels of NFATc1-c4 as well as their 
DNA binding activity during the anoxia/re-oxygenation cycle were measured in liver (Figure 4.1, 4.3). This analysis demonstrated that the DNA binding activity of NFATc1-c3 either remained constant or decreased significantly over the anoxia/re-oxygenation cycle (Figure 4.3). NFATc4 on the other hand showed a significant increase in protein levels as well as DNA binding activity after 24 hours of anoxic exposure (Figure 4.1, 4.3). This increase perhaps resulted from the increase in calcineurin A proteins levels which is shown to activate NFATs (Figure 4.6). Furthermore, the increase in NFATc4 activity correlated with the increase in ANP protein levels (Figure 4.7), which has been shown to offer protection to ischemic/perfused liver tissue. Overall, this study demonstrated that NFATc4 signaling was active during the anoxia/re-oxygenation cycle and that it is likely responsible for induction of ANP expression in liver.

Total protein expression levels as well as DNA binding activity of all four NFATs were measured in skeletal muscle (Figure 4.2, 4.4). In correlation with protein expression analysis, anoxia seemed to increase the expression of NFATc3 while leaving the remaining NFATs either constant or significantly down regulated (Figure 4.2). Interestingly, analyzing the DNA binding activity of the same NFATs revealed a different pattern where NFATc1 remained significantly down regulated during anoxic exposure and the remaining NFATs showed no significant change (Figure 4.4). Interestingly, while NFATc1, NFATc3 and NFATc4 DNA binding levels returned to control or remained constant after 4 hours of aerobic recovery, NFATc2 DNA binding levels increased significantly under the same condition (Figure 4.4). The discrepancy between NFATc2, NFATc3 and NFATc4 protein levels and DNA binding activity during the anoxia/re-oxygenation cycle needs to be further examined with the use of phospho-specific anti-NFAT antibodies. As explained previously 
in chapters 3 and chapter 4, NFATs are deactivated by phosphorylation; thus knowing the phosphorylated levels of each NFAT in addition to their total levels (as measured in chapter 3 and 4) would give a better interpretation of how these transcription factors are regulated over the stress/recovery cycle. It is perhaps possible that the antibody used detected both levels of NFATs, active and inactive, therefore providing no correlation between NFAT protein expression and their respective DNA binding levels. To eliminate this confusion, it would be of interest to measure the inactive form of NFATs using phospho-specific antibodies against p-NFATc1 (Ser 172), p-NFATc2 (Ser 168), p-NFATc3 (Ser 163,165) and p-NFATc4 (Ser 168,170). Interestingly, levels of the downstream de-activator of NFATc3, GSK3 $\beta$, also remained unaffected over the anoxia/re-oxygenation cycle which correlates strongly with the DNA binding activity results (Figure 4.5). Moreover, calcineurin A, the upstream activator of NFATs, also showed no change during anoxia but was found to increase significantly after 4 hours of aerobic recovery which correlates with the DNA binding levels of some NFATs (Figure 4.4; 4.6). One possibility is that the increase in calcineurin A protein levels after 4 hours of aerobic recovery is responsible for the significant increase in NFATc2 DNA binding activity (Figure 4.4; 4.6). Moreover, the constant osteopontin expression observed during the anoxia/re-oxygenation cycle highly correlates with the DNA binding levels of NFATc3 (Figure 4.4, 4.8) which further confirms that anoxia does not affect the transcriptional activity of NFATc3. Together, these findings suggest that NFAT transcription factors may not play an essential role in skeletal muscle cells during anoxia and that the basal levels of expression and or down regulation observed may itself be important for promoting cell survival. 


\subsection{Summary}

Overall, this study is the first to demonstrate the effects of the freeze/thaw and anoxia/re-oxygenation cycle on NFAT signalling in $R$. sylvatica liver and skeletal muscle. As seen in chapter 3, NFATc3 was shown to play a role in regulating glucose metabolism during freezing in liver while remaining unchanged in skeletal muscle. Consequently, anoxic activation of NFATc4 in liver but not skeletal muscle is perhaps due to the fact that the liver is more prone to oxidative damage and needs additional protection. The current study showed that NFATs are differentially regulated in a stress and tissue specific manner suggesting the potential importance of these transcription factors in facilitating cell viability and survival during periods of hypometabolism.

\subsection{Future studies}

Various follow-up experiments can be performed to further elucidate the mechanisms of NFAT regulation. To analyze whether NFATs are regulated at the transcriptional level during the stress/recovery cycle, it would be of interest to measure the transcript level of the four NFAT transcription factors using quantitative reverse transcriptase polymerase chain reaction (qRT-PCR) in liver and skeletal muscle exposed to the freeze/thaw and anoxia/re-oxygenation cycle. The increase in transcript levels of these targets would indicate that their respective genes are accessible to the transcriptional machinery; meaning that epigenetic modifications within that region of the wood frog DNA favour an open chromatin structure. The outcome of this analysis will indicate if the protein expression levels seen in chapter 3 and chapter 4 are as a result of transcriptional activity on NFAT genes under the aforementioned conditions. Likewise, since the direct activity of transcription factors can be measured by the transcript levels of the downstream 
target genes, it would be of interest to measure the transcript levels of osteopontin both in liver and skeletal muscle over freeze/thaw and anoxia/re-oxygenation cycle and ANP in liver over the latter cycle. This analysis will show whether the trend seen in osteopontin and ANP transcripts correspond to the trends seen in the transcript and DNA binding activity of NFATc3 and NFATc4 respectively and further confirm that the aforementioned transcription factors are indeed responsible for transcribing the osteopontin and ANP genes.

To understand whether NFATs are regulated at the post-transcriptional level, it would be of interest to measure the transcript levels of specific microRNAs using quantitative PCR (qPCR). MicroRNAs are small non-coding RNAs that bind to their respective mRNA transcripts and cause their degradation. Previous studies have shown that NFATs are targeted by the following microRNAs: NFATc1 (microRNA-124), NFATc2 (microRNA-184), NFATc3 (microRNA-1, 30s) and NFATc4 (microRNA-133a) (Weitzel et al., 2009; Li et al., 2010; Kang et al., 2013; Wu et al., 2015; Yin et al., 2015). Measuring the transcript levels of these microRNAs would add another layer of depth into the analysis of NFATs and would reveal whether these transcription factors are subjected to posttranscriptional controls mediated by microRNAs over the freeze/thaw and anoxia/reoxygenation cycle in liver and skeletal muscle of wood frogs.

Previous studies have shown that post-translational modifications are involved in regulating protein functions under hypometabolic states (Zhang et al., 2013). Analyzing the different post-translational modifications involved would allow for better understanding of NFAT regulation with respect to their DNA binding activity. For example, this study used antibodies raised to detect total NFATs (both active and inactive 
form) in order to determine the protein expression level of these transcription factors over the stress/recovery cycle. As seen in chapter 3 and chapter 4, total NFATc1-c4 protein levels may be contradictory to their DNA binding levels. For this reason, examining the protein levels of deactivated NFATs (p-NFATc1 (Ser 172), p-NFATc2 (Ser 168), pNFATc3 (Ser 163,165) and p-NFATc4 (Ser 168,170) over the course of the stress/recovery cycle will provide further insights into the relationship between the active NFATs and their DNA binding activity. This analysis is crucial as it would shed light on the discrepancy between the protein levels and the respective DNA binding activity measured.

Furthermore, it is possible that other post-translational modifications are involved in regulation NFAT activity. For this reason, it would be of interest to determine whether acetylation, sulfation, biotinylation, nitrosylation, ubiquitination and or glycosylation modifications are involved in regulating NFAT activity. It was shown that these modifications can be detected using matrix-assisted laser desorption/ionization mass spectrometry (MALDI-MS) (Salzano \& Crescenzi, 2005; Parker et al., 2010). To do this, protein extracts from the control, 24 hour frozen, 8 hour thawed, 24 hour anoxic and 4 hour aerobically recovered tissues would be subjected to 2-dimentional gel electrophoresis (2Dgel) separation. This process will help to better identify \& isolate the spots corresponding to NFATc1-NFATc4 prior the mass spectrometry analysis. Analysing the corresponding spots using MALDI-MS would determine two things: whether the aforementioned modifications are applied to NFATs and whether these modifications are stress/tissue specific and are differentially conjugated to NFATs over the freeze/thaw and anoxia/reoxygenation cycle. 
The localization of NFATs may contribute to our understanding of NFAT activation with respect to each tissue and stress. It would be of interest to measure the cytonuclear distribution of all four NFAT proteins over the stress/recovery cycle by western blotting. This information would further confirm the findings obtained from the DNA binding experiments, as levels of nuclear NFATs should theoretically highly correlate with the DNA binding activity of these transcription factors. Altogether, measuring the deactivated levels of NFATs (p-NFATs), other forms of NFAT post-translational modifications along with their cyto-nuclear distribution would confirm the results obtained in this experiment and further improve our understanding of how this family of transcription factors is regulated over the stress/recovery cycles.

Together, this analysis combined with the cyto-nuclear distribution of NFATs would give a better insight into how post-translational modifications regulate NFAT transcriptional activity but either facilitating nuclear important or causing nuclear export. Furthermore, to fully understand NFAT regulation during the freeze/thaw and anoxia/reoxygenation cycle, it is important to look at the downstream regulators of remaining NFATs (NFATc1, NFATc2 and NFATc4). As explained in chapters 3 and 4, JNK is responsible for re-phosphorylating NFATc1 and causing its nuclear exit (Chow et a., 2000). In the same manner, p38 phosphorylates NFATc2 and NFATc4 and which leads to their nuclear export into the cytoplasm (Archo et al., 1999; Yang et al., 2002). In addition, casein kinase I also regulates NFATc2 phosphorylation (Okamura et al., 2004). It would be of interest to measure the protein expression and activity levels of these kinases in liver and skeletal muscle exposed to 24 hours of freezing, 8 hours of thawing, 24 hours of anoxia 
and 4 hours of aerobic recovery. This analysis would give an insight into the regulatory mechanisms involved in expelling NFATs from the nucleus back to the cytoplasm.

Studies have shown that NFATs may interact with co-factors during transcription. For example, Armand et al. (2008) have shown that NFATc3 cooperates with MyoD to induce myogenin expression. NFATc1 cooperates with GATA4 to induce the expression of endothelin-1 in cardiac myocytes (Kakita et al.,2001). Another study showed that the synergistic cooperation NFATc2 and c-Jun induces the expression of interleukin-2 (Walters et al., 2013). It would be of interest to determine whether the aforementioned or other co-regulators are involved in mediating NFAT transcription. Coimmunoprecipitation of NFATc1-c4 from the nuclear fraction of the treated/recovered wood frog tissues (liver and skeletal muscle) followed by mass spectrometry of the obtained complex would identify the different proteins that make physical interaction with each NFAT. Since nuclear NFATs are assumed to be active, it would be safe to assume that the proteins identified in the NFAT complex are co-factors that facilitate and or synergistically increase NFAT transcription.

To understand the broader impact of NFATs on freezing, it is important to consider the three other cellular stresses associated with freezing. As explained earlier, in tolerating freezing, wood frogs have also developed a tolerance for hyperglycemia, anoxia and dehydration. While the role of NFATs over the anoxia/re-oxygenation cycle was examined, there is no information on how this family of transcription factors is regulated in hyperglycemic and dehydrated wood frogs. It would be of interest to measure the total protein levels of NFATs, p-NFATs, calcineurin A, p38, casein kinase I, JNK and GSk3 $\beta$ as well as the DNA binding levels of the four NFATs in each condition. This study found 
that NFATs exhibited tissue-specific regulation, where NFAT activity increased in liver (NFATc3 during freezing and NFATc4 during anoxia) but was found to be supressed or remain constant in skeletal muscle. It would therefore be of interest to measure the aforementioned targets in other tissues (i.e. heart, brain, kidney) under freezing, anoxia, hyperglycemia, and dehydration in wood frogs in order to further examine the tissue specific regulation of this family of transcription factors. Once this analysis is complete, it would be of interest to follow up the downstream effects of active NFATs on their specific target genes (such as osteopontin and ANP to name a few) to see how NFATs facilitate wood frog freezing, anoxia, hyperglycemia and dehydration.

To fully see how NFATs regulate gene expression during freezing and the associated stresses, it is important to look at the specific downstream targets. The recent advancement in technology and molecular methods has provided scientists with a vast array of opportunities to study genome-wide trends in a model system. For example, chromatin immunoprecipitation followed by massive parallel sequencing (ChIP-seq) has been used to study genome-wide DNA-protein interactions (Valouev et al., 2008; Geertz \& Maerkl; 2010). For this reason, ChIP-seq analysis of stresses/recovered liver and skeletal muscle would be performed to generate a genome-wide profile of promoter sites that are occupied by each NFAT. This analysis is initiated by the reversible cross linking of the target protein, in this case NFATs, to the DNA using formaldehyde. The cross-linked protein-DNA complex is then sheared into small fragments (100-500 base pair) and subjected to immunoprecipitation using NFAT-specific antibodies. Once the complex of interest is precipitated and the formaldehyde cross-linking is reversed, the DNA fragments obtained would be subjected to deep sequencing. Normally, the sequences obtained would 
be blasted against the organism's genome to determine the identity of the fragments; however, since the R. sylvatica genome is not sequenced, it is perhaps possible to compare the sequences obtained to other closely related frog genomes such as Xenopus tropicalis and Xenopus laevis to determine the identity of the fragments. While this may require more computation analysis and troubleshooting, the profile obtained would give valuable information about the known and novel genes that are regulated by each NFAT. Further quantification of those genes using qRT-PCR and their respective protein levels by western blotting would generate a genome-wide map of the expression trends of these targets over the stress/recovery cycles in wood frog liver and skeletal muscle. This information can then further be used to study the effect of each downstream target under NFAT regulation in a tissue/stress specific manner and determine its impact on survival and hypometabolism in wood frogs.

Overall, the proposed experiments analyze NFAT regulation at the transcriptional, post-transcriptional and post-translational level in wood frogs exposed to the stress/recovery cycle and elucidate the effect of their signaling on downstream targets. Thoroughly understanding how NFATs are regulated during these conditions, may shed light into potential therapeutics strategies to remedy problems associated with organ cryopreservation, diabetes and ischemic/reperfusion upon stroke in humans. This is plausible since pharmaceutical treatments that modulate NFAT/calcineurin activity are available; making NFAT a potential target for different therapies. 


\section{References}


Arco, P., Martinez-Martinez, S., Maldonado, J., Ortega-Perez, I., Redondo, J. (2000). A Role for the p38 MAP Kinase Pathway in the Nuclear Shuttling of NFATp. The Journal of biological chemistry, 275(18), 13872-13878.

Armand, A., Bourajjaj, M., Martinez-Martinez, S., Azzouzi, H., Martins, P., Hatzis, P., Seidler, T., Redondo, J., Windt, L. (2008). Cooperative Synergy between NFAT and MyoD Regulates Myogenin Expression and Myogenesis. The Journal of biological chemistry, 283(43), 29004-29010.

Baksh, S., DeCaprio, J. A., Burakoff, S. J. (2000). Calcineurin regulation of the mammalian G0/G1 checkpoint element, cyclin dependent kinase. Oncogene, 19(24), 2820-2827.

Baksh, S., Widlund, H. R., Frazer-Abel, A. A., Du, J., Fosmire, S., Fisher, D. E., DeCaprio, J. A., Modiano, J. F., Burakoff, S. J. (2002). NFATc2-mediated repression of cyclin-dependent kinase 4 expression. Molecular cell, 10(5), 1071-1081.

Barbagallo, M., Shan, J., Pang, P. K., Resnick, L. M. (1995). Glucose-induced alterations of cytosolic free calcium in cultured rat tail artery vascular smooth muscle cells. The Journal of Clinical Investigation, 95(2), 763-767.

Bierer, R., Friedman, J., Codianni, S., Frutos, S., Dominguez-Bautista, J., Howard, T., Resta, T., Bosc. L. (2011). NFATc3 is required for chronic hypoxia-induced pulmonary hypertension in adult and neonatal mice. American Journal of Physiology. Lung Cellular and Physiology, 301(6), L872-L880.

Biggar, K. K., and Storey, K. B. (2011). The emerging roles of microRNAs in the molecular responses to metabolic rate depression. Journal of Molecular Cell Biology, 3(3), 167-175.

Bultot, L., Guigas, B., MOellendorff, A., Maisin, L., Vertommen, D., Hussain, N., Beullens, M., Guinovart, J., Foretz, M., Viollet B., Sakamoto, K., Hue, L., Rider, M. (2012). AMP-activated protein kinase phosphorylates and inactivates liver glycogen synthase. The Biochemical Journal, 443(1), 193-203.

Burroughs, J. (1914). The writings of John Burroughs VII, Signs and Seasons, Boston: Houghton Mifflin Co, pg 48-49.

Cai, Q., Greenway, S. C., Storey, K. B. (1997a). Differential regulation of the mitochondrial ADP/ATP translocase gene in wood frogs under freezing stress. Biochimica et Biophysica Acta, 1353(1), 69-78.

Cai, Q. and Storey, K. B. (1997b). Freezing-induced genes in wood frog (Rana sylvatica): fibrinogen upregulation by freezing and dehydration. The American Journal of Physiology, 272(5 pt 2), R1480-R1492.

Cai, Q. and Storey, K. B. (1997c). Upregulation of a novel gene by freezing exposure in the freeze-tolerant wood frog (Rana sylvatica). Gene, 198(1-2), 305-312.

Capote, J., Kramerova, I., Martinez, L., Vetrone, S., Barton, E., Sweeney, H., Miceli, M., Spencer, M. (2016). Osteopontin ablation ameliorates muscular dystrophy by 
shifting macrophages to a pro-regenerative phenotype. Journal of Biological Chemistry, 213(2), 275-288.

Carini, R., Autelli, R., Bellomo, G., Albano, E. (1999). Alteration of cell volume regulation in the development of hepatocyte necrosis. Experimental Cell Research, 248(1), 280-293.

Carini, R., Cesaris, M., Splendore, R., Domenicotti, C., Nitti, M., Pronzota, M., Albano, E. (2003). Mechanisms of hepatocyte protection against hypoxic injury by atrial natriuretic peptide. Hepatology, 37(2), 277-285.

Carmeliet, P., Dor, Y., Herbert, J., Fukumura, D., Brusselmans, K., Dewerchin, M., Neeman, M., Bono, F, Abramovitch, R., Maxwell, P., Koch, C., Ratcliffe, P., Moons, Lieve, Jain, R., Collen, D., Keshet, E. (1998). Role of HIF1-a in hypoxia mediated apoptosis, cell proliferation and tumour angiogenesis. Nature, 394(6692), 485-490.

Cheung, C., and Ko, B. (2013). NFAT5 in cellular adaptation to hypertonic stressregulations and functional significance. The Journal of Molecular Signaling, 8(5).

Cheung, R., Allis, C. D., Sassone-Corsi, P. (2000). Signaling to chromatin through histone modifications. Cell, 103(2), 263-271.

Chow, C. W., Dong, C., Flavell, R. A., Davis, R. J. (2000). C-Jun NH(2)-terminal kinase inhibits targeting of the protein phosphatase calcineurin of NFATc1. Molecular and Cellular Biology, 20(14), 5227-5234.

Churchill, T. A., and Storey, K. B. (1993). Dehydration tolerance in wood frogs: a new perspective on the development of amphibian freeze tolerance. The American Journal of Physiology, 265(6 Pt 2), R1324-R1332.

Taub, R. (2003). Hepatoprotection via the IL-6/STAT3 pathway. The Journal of Clinical Investigation, 112(7), 978-980.

Constanzo, J. P., Bayuk, J. M., Lee, R. E. (1999). Inoculating freezing by environmental ice in the freeze-tolerant wood frog, Rana sylvatica. The Journal of Experimental Zoology, 284(1), 7-14.

Constanzo, J. P., Lee, R. E. (1997). Frogs resorb glucose from urinary bladder. Nature, 389, 343-344.

Costanzo, J. P., Lee, R. E., Ultsch, G. R. (2008). Physiological ecology of overwintering in hatchling turtles. The Journal of Experimental Zoology. Part A, Ecological Genetics and Physiology, 309(6), 297-379.

Costanzo, J. P., Lee, R. E., Lortsz, P. H. (1993). Glucose concentrations regulates freeze tolerance in the wood frog Rana sylvatica. The Journal of Experimental Biology, $181,245-255$.

Costanzo, J. P., and Lee, R. E. (2013). Avoidance and tolerance of freezing in ectothermic vertebrates. The Journal of Experimental Biology, 216(Pt 11), 1961-1967. 
Costanzo, J. P., Amara, M. F., Rosendale, A. J., Lee, R. E. (2013). Hibernation physiology, freezing adaptation and extreme freeze tolerance in a northern population of the wood frog. The Journal of Experimental Biology, 216(Pt 18), 3461-3473.

Cowan, K., and Storey, K. B. (2003). Mitogen-activated protein Kinases: new signaling pathways function in cellular responses to environmental stress. The Journal of Experimental Biology, 206, 1107-1115.

Cowan, K. J., and Storey, K. B. (2001). Freeze-thaw effects on metabolic enzymes in wood frog organs. Cryobiology, 43(1), 32-45.

Cressman, D., GreenBaum, L., DeAngelis, R., Ciliberto, G., Furth, E. E., Poli, V., Taub R. (1996). Liver failure and defective hepatocyte regeneration in interleukin-6 deficient mice. Science, 274(5291), 1279-83.

Cross D., Alessi, D., Cohen, P., Andjelkovich, M., Hemmings, B. (1995). Inhibition of glycogen synthase kinase-3 by insulin mediated by protein kinase B. Nature, 378(6559), 785-689.

Cross, D., Watt, P., Shaw, M., Van der Kaay, J., Downes, C., Holder, J., Cohen, P. (1997). Insulin activates protein kinase B, inhibits glycogen synthase kinse-3 and activates glycogen synthase by rapamycin-insensetive pathways in skeletal muscle and adipose tissue. Federation of European Biochemical Societies Letters, 406(1-2), 211215.

Delling, U., Tureckova, J., Lim, H. W., De, L. J., Rotwein, P., Molkentin, J. D. (2000). A calcineurin-NFATc3-dependent pathway regulates skeletal muscle differentiation and slow myosin heavy-chain expression. Cellular and Molecular Biology, 20(17), 6600-6611.

Dieni, C., and Storey, K. B. (2012). Glycogen synthase kinase-3: cryoprotection and glycogen metabolism in the freeze-tolerant wood frog. The Journal of Experimental Biology, 215(Pt 3), 543-51.

Dolmetsch, R., Xu, K., Lewis, R. (1998). Calcium oscillations increase the efficiency and specificity of gene expression. Nature, 392, 933-936.

Duigliano, D., Geriello, A., Esposito, K., (2008). Glucose metabolism and hyperglycemia. The American Journal of Clinical Nutrition, 87(1), 2175-2225.

Fadda, G. z., and Massry, S. G. (1991). Impaired glucose-induced calcium signaling in pancreatic islets in chronic renal failure. American Journal of Nephrology, 11(6), 475478.

Forsythe, J., Jiang, B., Iyer, N., Agani, F., Leung, S. Koos, R., Semenza. G. (1996). Activation of vascular endothelial growth factor gene transcription by hypoxiainducible factor 1. Molecular and Cellular Biology, 16(9), 4604-4613.

Frutos, S., Spangler, R., Alo, D., Bosc, L. (2007). NFATc3 mediates chronic hypoxiainduced pulmonary arterial remodeling with $\alpha$-actin up-regulation. The Journal of Biological Chemistry, 282(2), 15081-15089. 
Geertz, M., and Maerkl, S. (2010). Experimental strategies for studying transcription factor-DNA binding specificities. Briefings in Functional Genomics, 9(5-6), 362-373.

Gerber, V., Wijenayake, S., Storey, K. B. (2016). Anti-apoptotic response during anoxia and recovery in a freeze-tolerant wood frog (Rana sylvatica). Peer J, 4, e1834.

Gerwig, T., Meibner, H., Bilzer, M., Kiemer, A., Arnholdt, H., Vollmar, A., Gerbes, A. (2003). Atrial Natriuretic peptide preconditioning protects against cell preservation injuty by attenuating necrotic and apoptotic cell death. Journal of Hepatology, 39(3), 341-348.

Graef, I. A., Gastier, J. M., Franche, U., Crabtree, G. R. (2001). Evolutionary relationships among Rel domains indicate functional diversification by recombination. Proceedings of the National Academy of Sciences of the United States of America, 98(10), 5740-5745.

Greenway, S. C., and Storey, K. B. (1999). Discordant response of mitogen-activated protein kinases to anoxia and freezing exposure in hatchling turtles. Journal of Comparative Physiology. B, Biochemical, Systemic, and Environmental Physiology, 169(7), 521-527.

Greenway, S. C., and Storey, K. B. (2000). Mitogen-activated protein kinases and anoxia tolerance in turtles. The Journal of Experimental Zoology, 287(7), 477-284.

Greenway, S. C., and Storey, K. B. (2000). Activation of mitogen-activated protein kinases during natural freezing and thawing in the wood frog. Molecular and Cellular Biochemistry, 209(1-2), 29-37.

Hanger, D. P., Hughes, K., Woodgett, J. R., Brion, J. P., Anderton, B. H. (1992). Glycogen synthase kinase-3 induces Alzheimer's disease-like phosphorylation of taw: generation of paired helical filament epitopes and neuronal localisation of the kinase. Neuroscience Letters, 147(1), 58-62.

Hemmings, S. J., and Storey, K. B. (1993). Alterations in hepatic adrenergic receptor status in Rana sylvatica in response to freezing and thawing: implication to the freezeinduced glycemic responses. Canadian Journal of Physiology and Pharmacology, 72(12), 1552-1560.

Hemmings, S. J., and Storey, K. B. (1996). Characterization of gamaglutamyltranspepidase in the liver of the frog: Responses to freezing and thawing in the freeze-tolerant wood frog, Rana sylvatica. Cellular Biochemistry, 14, 139-148.

Hemmings, S. J., and Storey, K. B. (2001). Characterization of sarcolemma and sarcoplasmic reticulum isolated from skeletal muscle of the freeze tolerant wood frog, Rana sylvatica: the beta(2)-andrenergic receptor and calcium transport system In control, frozen and thawed states. Cellular Biochemistry and Function, 19(2), 143-52.

Herbert, C. V., and Jackson, D. C. (1985). Temperature effects on the response to prolonged submergence in the turtle Chrysemys picta belli. II. Metabolic rate, blood acid-base and ionic changes, and cardiovascular function in aerated and anoxic water. Physiological Zoology, 58(6), 670-681. 
Hirata, A., Masuda, S., Tamura, T., Kai, K., Ojima, K., Fukase, A., Motoyoshi, K., Kamakura, K., Suzuki, Y., Takeda, S. (2003). Expression profiling of cytokines and related genes in regenerating skeletal muscle after cardiotoxin injection. The American Journal of Pathology, 162(1), 203-215.

Ho, I. C., Kim, J. H., Rooney, J. W., Spiegelman, B. M., Glimcher, L. H. (1998). A potential role for the nuclear factor of activated $\mathrm{T}$ cells family of transcriptional regulatory proteins in adipogenesis. Proceedings of the National Academy of Sciences of the United States of America, 95(26), 15537-15541

Hogan, P., Chen, L., Nardone, J., Rao, A. (2003). Transcriptional regulation by calcium, calcineurin, and NFAT. Genes and Development, 17(18), 2205-2232.

Holden C. P., and Storey, K. B. (1997). Second messenger and cAMP-dependent protein kinase responses to dehydration and anoxia stresses in frogs. Journal of Comparative Physiology. B, Biochemical, Systemic and Environmental Physiology, 167(4), 305-312.

Horsley, V., Friday, B. B., Matteson, S., Kegley, K. M., Gephart, J., Pavlath, G. K. (2001). Regulation of the growth of multinucleated muscle cells by an NFATC2dependent pathway. The Journal of Cell Biology, 153(2), 329-38.

Hsieh, I., Yang, R, Fu., W. (2014). Osteopontin upregulates the expression of glucose transporters in osteosarcoma cells. Plos one, 9(10), E109550.

Iniguez, M. A., Martinez-Martinez, S., Punzon, C., Redondo, J. M., Fresno, M. (2000). An essential role of the nuclear factor of activated $T$ cells in the regulation of the expression of the cyclooxygenase- 2 gene in human $\mathrm{T}$ lymphocytes. The Journal of Biological Chemistry, 275(31), 23627- 23635.

Iyer, N., Kotch, L., Agani, F., Leung, S., Laughner, E., Wenger, R., Gassmann, M., Gearhart, J., Lawler, A., Yu, A., Semenza, G. (1998). Cellular and developmental control of $\mathrm{O} 2$ homeostasis by hypoxia-inducible factor 1a. Genes and Development, 12(2), 149-162.

Jackson, D. C., and Ultsch, G. R. (2010). Physiology of hibernation under the ice by turtles and frogs. Journal of Experimental Zoology Part A, 313A (6), 311-327.

Joanisse, D. R., and Storey, K. B. (1996). Oxidative damage and antioxidants in Rana sylvatica, the freeze-tolerant wood frog. American Journal of Physiology, 271(3 Pt 2), R545-R553.

Kakita, T., Hasegawa, K., Iwai-Kanai, E., Adachi, S., Morimoto, T., Wada, H., Kawamura, T., Yanazume, T., Sasayama, S. (2001). Calcineurin Pathways Is Required for Endothelin-1-Mediated Protection Against Oxidant Stress-Induced Apoptosis in Cardiac Myocytes. Circulation Research, 88(12), 1239-1246.

Kaminski M., Schultz, J., Waterstradt, R., Tiedge, M., Lenzen, S., Baltrusch, S. (2013). Glucose-induced association of glucokinase from its regulatory protein in the nucleus of hepatocytes prior to nuclear export. Biochimica et Biophysica Acta-Molecular Cell Research, 1843(3), 554-564. 
Kang, K., Peng, X., Zhang, X., Wang, Y., Zhang, L., Gao, L., Weng, T., Zhang, H., Ramchandran, R., Raj, J., Gou, D., Liu, L. (2013). MicroRNA-124 supresses the transactivation of nuclear factor of activated $\mathrm{T}$ cells by targeting multiple genes and inhibits the proliferation of pulmonary artery smooth muscle cells. The Journal of Biological Chemistry, 288(35), 25412-25427.

Kearney, T., and Dang, C. (2007). Diabetic and endocrine emergencies. Postgraduate Medical Journal, 83(976), 79-86.

Kiemer, A., Gerbes, A., Blizer, M., Vollmar, A. (2002). The atrial natriuretic peptide and cGMP: novel activators of the heat shock response in rat livers. Hepatology. 35(1), 88-94.

Kiemer, A., Vollmar, A, Blizer, M., Gerwig, T., Gerbes, A. (2000). Atrial natriuretic peptide reduces expression of TNF-alpha mRNA during reperfusion of the rate liver upon decreased activation of NF-KappaB and AP-1. Journal of Hepatology, 33(2), 236-246.

King, P., Rosholt, M., Storey, K. (1993). Adaptations of plasma membrane glucose transport facilitates cryoprotectant distribution in freeze-tolerant frogs. The American Journal of Physiology, 265 (5 pt2), R1036-R1042.

Krivoruchko, A., and Storey, K. B. (2010). Molecular mechanisms of turtle anoxia tolerance: A role of NF-kappaB. Gene, 450(1-2), 63-9.

Krivoruchko, A., and Storey, K. B. (2009). Regulation of the heat shock response under anoxia in the turtle, Trachemys scripta elegans. Journal of Comparative Physiology. Part B, Biochemical, Systemic and Environmental Physiology, 180(3), 403-414.

Krivoruchko, A., and Storey, K. B. (2010). Mechanisms of natural anoxia tolerance and potential links to longevity. Oxidative Medicine and Cellular Longevity, 3(3), 186198.

Kuraoka, M., Kimura, E., Nagata, T., Okada, T., Aoki, Y., Tachimori, H., Yonemoto, N., Imamura, M., Takeda, S. (2016). Serum osteopontin as a novel biomarker for muscle regeneration in Duchenne muscular dystrophy. The American Journal of Pathology, 186(5), 1302-1312.

Lawrence, J. C., and Roach, P. J. (1997). New insights into the role of mechanisms of glycogen synthase activation by insulin. Diabetes, 46(4), 541-547.

Lawrence, M., Bhatt, H., Easom, R. (2002). NFAT regulates insulin gene promoter activity in response to synergistic pathways induced by glucose and glucagon-like peptide-1. Diabetes, 51(3), 691-698.

Layne, J. E., Lee, R. E., Heil, T. L. (1989). Freezing-induced changes in the heart rate of wood frogs (Rana sylvatica). The American Journal of Physiology, 257(5 Pt 2), R1046-R1049.

Layne, J. R., Costanzo, J. P., Lee, R. E. (1998). Freeze duration influences post freeze survival in the frog Rana sylvatica. Journal of Experimental Zoology, 280(2), 197-211. 
Layne, J. R., and First, M. C. (1991). Resumption of physiological functions in the wood frog (Rana sylvatica) after freezing. The American Journal of Physiology, 261(1 Pt 2), R134-137.

Layne, J. R., and Lee, R. E. (1995). Adaptations of frogs to survive freezing. Climate Research, 5, 53- 59.

Lazaroski, E. R., Boucher, R. C., Harden, T. K. (2003). Mechanisms of release of nucleotides and integration of their action on $\mathrm{P} 2 \mathrm{X}$ - and $\mathrm{P} 2 \mathrm{Y}$-receptors activating molecules. Molecular Pharmacology, 64(4), 785-795.

Lee, A. S. (2001). The glucose-regulated proteins: stress induction and clinical applications. Trends in Biochemical Sciences, 26(8), 504-510.

Lee, J., and Kim, M. (2007). The role of GSK3 in glucose homeostasis and the development of insulin resistance. Diabetes Research and Clinical Practice, 77 (Suppl 1), S49-S57.

Lee, M. R., Lee, R. E., Strong-Gunderson, J. M., Minges, S. R. (1995). Isolation of ice nucleating activity bacteria from the freeze-tolerant frog, Rana sylvatica. Cryobiology. 32(4), 358-365.

Lee, R. E., Costanzo, J. P., Davidson, E. C., Layne, R. E. (1992). Dynamics of body water during freezing and thawing in a freeze-tolerant frog (Rana sylvatica). Journal of Thermal Biology, 17(4-5), 263-266.

Li, Q., Lin, X., Yang, X., Chang, J. (2010). NFATc4 is negatively regulated in miR133a-mediated cardiomyocyte hypertrophic repression. American Journal of Physiology. Heart and Circulation Physiology, 298(5), H1340-H1347.

Liaw, L., Birk, D., Ballas, C., Whitsitt, J., Davidson, J., Hogan, B. (1998). Altered wound healing in mice lacking a functional osteopontin gene (spp1). Journal of Clinical Investigation. 101(7), 1468-1478.

Liberman, Z., and Eldar-Finkelman, H. (2005). Serine 332 phosphorylation of insulin receptor substrate-1 by glycogen synthase kinase- 3 attenuates insulin signaling. The Journal of Biological Chemistry, 280(6), 4422-4428.

Martof, B. S., and Humphries, R. L. (1959). Geographic variation in the wood frog, Rana sylvatica. The American Midland Naturalist, 61(2), 350-389.

Middle, L. B., and Barnes, B. M. (2001). Overwintering physiology of the wood frog, Rana sylvatica, in Interior Alaska. American Zoologist, 41, 1526-1527.

Millhorn, D., Beitner-Johnson, D., Conforti, L., Conrad, W., Kobayashi, S., Yuan, Y., Rust. R. (2000). Gene regulation during hypoxia in excitable oxygen-sensing cells: depolarization-transcription coupling. Advances in Experimental Medicine and Biology, 475, 131-142.

Moh, A., Zhang, W., Yu, S., Wang, J., Xu, X., Li, J., Fu, X. (2008). STAT3 sensitizes insulin signaling by negatively regulating glycogen synthase kinase 3B. Diabetes, 57(5), 1227-1235. 
Molkentin, J. D., Lu, J. R., Antos, C. L., Markham, B., Richardson, J., Robbins, J., Grant, S. R., Olson, E. N. (1998). A calcineurin-dependent transcriptional pathway for cardiac hypertrophy. Cell, 93(2), 215-228.

Moring, P., and Storey, K. B. (2006). Evidence for a reduced transcriptional state during hibernation in group squirrels. Cryobiology, 53(3), 310-318.

Mottet, D., Michel, G., Renard, P., Ninane, N., Raes, M., Michiels, C. (2003). Role of ERK and calcium in the hypoxia-induced activation of HIF-1. The Journal of Cellular Physiology, 194(1), 30-44.

Mungai, P., Waypa, G., Jairaman, A., Prakiya, M., Dokic, D., Ball, M., Schumacker, P. (2011). Hypoxia Triggers AMPK activation through reactive oxygen speciesmediated activation of calcium release-activated calcium channels. Molecular and Cellular Biology, 31(17), 3531-3545.

Nilsson, G., and Renshaw, G. (2004). Hypoxic survival strategies in two fishes: extreme anoxia tolerant in the North European crucian carp and natural hypoxic preconditioning in a coral-reef shark. Journal of Experimental Biology, 207, 31313139.

Nilsson, J., Nilsson, L., Chen, Y., Molkentin, J., Erlinge, D., Gomez, M. (2006). High glucose activates nuclear factor of activated T cells in Native Vascular Smooth Muscle. Atherosclerosis, Thrombosis and Vascular Biology, 26(4), 794-800.

Nilsson-Berglund, L., Zetterqvist, A., Nilsson-Ohman, J., Sigvardsson, M., Bosc, L., Smith, M., Salehi, A., Agardh, E., Fredrikson, G., Agardh, C., Nilsson, J., Wamhoff, B., Nilsson, A., Gomez, M. (2010). Nuclear Factor of Activated T-cells regulates osteopontin expression in arterial smooth muscle in response to diabetes-induced hyperglycemia. Atherosclerosis, Thrombosis and Vascular Biology, 30(2), 218-224.

Okamura, H., Garcia-Rodriguez, C., Martinson, H., Qin, J., Virshup, D., Rao, A. (2004). A conserved docking motif on CK1 binding control the nuclear localization of NFAT1. Molecular and Cellular Biology, 24(10), 4184-4195.

Overgaard, J., Gesser, H., Wang, T. (2007). Tribute to P. L. Lutz: cardiac performance and cardiovascular regulation during anoxia/hypoxia in fresh water turtles. Journal of Experimental Biology, 2010, 1687-1699.

Parker, C. E., Mocanu, V., Mocanu, M., et al. (2010). Mass Spectrometry for PostTranslational Modifications. Neutoproteomics Boca Raton (FL): NCBI, Chapter 6. http://www.ncbi.nlm.nih.gov/books/NBK56012/

Parodi, J., Flores, C., Aguayo, C., Rudolph, M. I., Casanello, R, Sobrevia, L. (2002). Inhibition of nitrobenzylthioinosine-sensetive adenosine transport by elevated Dglucose involves activation of P2Y2 purinoceptors in human umbilical vein endothelial Cells. Circulation Research, 90, 570-577.

Potts, M. (1994). Desiccation tolerance of prokaryotes. Microbiological Reviews, 58(4), 755-805. 
Rao, A., Luo, C., Hogan, P. G. (1997). Transcription factors of the NFAT family: regulation and function. Annual Review of Immunology, 15, 707-747.

Renault, M. A., Jalv, S., Belloc, I., Pasquet, S., Sena, S., Olive, M., Desgranges, C., Gadeau, A. P. (2003). AP-1 is involved in UTP-induced osteopontin expression in arterial smooth muscle cells. Circulation Research, 93(7), 674-681.

Rider, M., Hussain, N., Horman, S., Dilworth, S., Storey, K. B. (2006). Stress-induced activation of the AMP-activated kinase in the freeze-tolerant frog Rana sylvatica. Cryobiology, 53(3), 297-309.

Rojo, A., Sagarra, M., Cuadrado, A. (2008). GSK-3beta down-regulation the transcription factor Nrf after oxidant damage: relevance to exposure of neuronal cells to oxidative damage. Journal of Neurochemistry, 105(1), 192-202.

Rolfe, D. F., and Brown, G. C., (1997). Cellular energy utilization and molecular origin of standard metabolic rate in mammals. Physiological Reviews, 77(3), 731-758.

Rubinsky, B., Wong, S. T., Hong, J. S., Gilber, J., Roos, M., Storey, K. B. (1994). H ${ }^{1}$ magnetic resonance imaging of freezing and thawing in freeze-tolerant frogs. American Journal of Physiology, 266 (6 Pt2), R1771-R1777.

Ruf, T., and Geiser, F. (2014). Daily torpor and hibernation in birds and mammals. Biological Reviews- Cambridge Philosophical Society, 90(3), 891-926.

Rusnak, F., and Mertz, P. (2000). Calcineurin: form and function. Physiological Reviews, 80(4), 1483-1521.

Russell, E., and Storey, K. B. (1995). Glycogen synthetase and the control of cryoprotectant clearance after thawing in the freeze-tolerant wood frog. CryoLetters, $16,263-266$.

Ryan, H., and Johnson, R. (1998). HIF-1a is required for solid tumor formation and embryonic vascularization. The EMBO Journal, 17(11), 3005-3015.

Salzano, A., and Crescenzi, M. (2005). Mass spectrometry for protein identification and the study of post translational modifications. Annali Dell'Istituto Superiore di Sanita, 41(4), 443-450.

Schmid, W. B. (1982). Survival of frogs in low temperatures. Science, 215(4533), 697698.

Schmid, W. B. (1986). Winter ecology. Ekologiya 6, 29-35

Seagroves, T. N., Ryan, H. E., Lu, H., Wouters, B. G., Knapp, M., Thibault, P., Laderoute, K., Johnson, R. S. (2001). Transcription factor HIF-1 is a necessary mediator of the Pasteur effect in mammalian cells. Molecular and Cellular Biology, 21(10), 3436-3444.

Semenza, G. L. (2000). HIF-1: mediator of physiological and pathophysiological responses to hypoxia. Journal of Applied Physiology, 88(4), 1474-1480. 
Shaw, S. G., Weidmann, P., Hodler, J., Zimmermann, A., Paternostro, A. (1987). Atrial natriuretic peptide protects against acure ischemic renal failure in the rat. Journal of Clinical Investigation, 80(5), 1232-1237.

Sheng, M., McFadden, G., Greenberg, M. E. (1990). Membrane depolarization and calcium induce c-fos transcription via phosphorylation of transcription factor CREB. Neuron, 4(4), 571-82.

Skurat a., and Roac, p. (1996). Multiple mechanisms for the phosphorylation of Cterminal regulatory sites in rabbit muscle glycogen synthase expressed in COS cells. The Biochemical Journal, 313(Pt 1), 45-50.

Smogorzewski, M., Galfayan, V., Massry, S. G. (1998). High glucose concentration causes a rise in $[\mathrm{Ca} 2+] \mathrm{i}$ of cardiac myocytes. Kidney Internationa, 53(5), 1237-43.

Sterner, D. E., and Berger, S. L. (2000). Acetylation of Histones and TranscriptionRelated factors. Microbiology and Molecular Biology Reviews, 64(2), 435-459.

Storey, J. M., and Storey, K. B. (2004a). Functional Metabolism Regulation and Adaptation. Hoboken, New Jersey: John Wiley and Sons Inc. Chapter 17, 473-502.

Storey, K. B., and Storey, J. M. (2004b). Physiology, biochemistry, and molecular biology of vertebrate freeze tolerance: the wood frog. Life in the frozen state. Bocca Raton, Florida: CRC press. Chapter 7, 243-274.

Storey, J. M., and Storey, K. B. (2004c). Functional Metabolism Regulation and Adaptation. Hoboken, New Jersey: John Wiley and Sons Inc. Chapter 15, 415-442.

Storey, J. M., and Storey, K. B. (1985). Triggering of cryoprotectant synthesis by initiation of ice nucleation in the freeze tolerance frogs, Rana sylvatica. Journal of Comparative Physiology B. 156(2),191-195.

Storey, K. B., and Storey, J. M. (1992). Natural freeze tolerance in ectothermic vertebrates. Annual Reviews of Physiology, 54, 619-637.

Storey, K. B., and Storey, J. M. (1988). Freeze tolerance in animals. Physiological Reviews, 68(1), 27-84.

Storey, K. B., and Storey, J. M. (2013). Molecular biology of freezing tolerance. Comprehensive Physiology, 3(3), 1283-1308.

Storey, K. B., and Storey, J. M. (1984). Biochemical adaptations for freezing tolerance in the wood frog, Rana sylvatica. Journal of Comparative Physiology B, 155(1), 2936.

Storey, K. B., and Storey, J. M. (2012). Insect cold hardiness: recent advances in metabolic, gene and protein adaptations. Canadian Journal of Zoology, 90(4), 456-475.

Storey, K. B. (1999). Living in the cold: freeze-induced gene responses in freezetolerant vertebrates. Clinical and Experimental Pharmacology and Physiology, 26(1), $57-63$ 
Storey, K. B. (2007). Anoxia tolerance in turtle Metabolic regulation and gene expression. Comparative Biochemistry and Physiology. Part A, Molecular and Integrative Physiology, 147(2), 263-276.

Storey, K. B., and Storey, J. M. (1986). Freeze-tolerant frogs: cryoprotectants and tissue metabolism during freeze/thaw cycles. Canadian Journal of Zoology, 64(1), 4956.

Storey, K. B. (2006). Reptiles freeze tolerance: Metabolism and gene expression. Cryobiology, 52(1), 1-16.

Storey, K. B. (2015). Regulation of hypometabolism: insights into epigenetic controls. Journal of Experimental Biology, 218, 150-159.

Storey, K. B., and Storey, J. M. (2011). Heat shock proteins and hypometabolism: adaptive strategy for proteome preservation. Dovepress, 2011(2), 57-68.

Storey, K. B., and Storey, J. M. (2007). Tribute to P.L. Lutz: putting life on "pause"molecular regulation of hypometabolism, Journal of Experimental Biology, 201, 17001714.

Suzuki, T., Bridges, D., Nakada, D., Skiniotis, G., Morrison, S., Lin, J., Saltiel, A., Inoki, K. (2013). Inhibition of AMPK catabolic action by Gsk3. Molecular Cell, 50(3), 407-419.

Tabory, O., Boncoeur, E., Martin, R., Pepperkok, R., Clement, A., Schultz, C., Jaquot, J. (2006). Calcium-dependent regulation of NF-(kappa)B activation in cystic fibrosis airway epithelial cells. Cell signalling. 18(5), 652-60.

Tattersall, G. J., and Ultsch, G. F. (2008). Physiology ecology of aquatic overwintering in ranid frogs. Biological Reviews of the Cambridge Philosophical Society, 83(2), 119140.

Uaesoontrachoon, K., Dimuthy, K., Wijesinghe, W., Mackie, E., Pagel, C. (2013). Osteopontin deficiency delays inflammatory infiltration and the onset of muscle regeneration in a mouse model of muscle injury. Disease Models and Mechanisms, 6(1), 197-205.

Uaesoontrachoon, K., Yoo, H., Tudor, E., Pike, R., Mackie, E., Pagel, C. (2008). Osteopontin and skeletal muscle myoblasts: Association with muscle regeneration and regulation of myoblast function in vitro. The International Journal of Biochemistry and Cell Biology, 40(10), 2303-2314.

Ultsch, G.R. (1985). The viability of nearctic freshwater turtles submerged in anoxia and normoxia at 3 and10 degrees C. Comparative Biochemistry and Physiology. A, Comparative Physiology, 81(3), 607-611.

Ultsch, G. R., Carwile, M. E., Crocker, C. E., Jackson, D. (1999). The physiology of hibernation among painted turtles: The Eastern painted turtle Chrysemys picta picta. Physiological and Biochemical Zoology, 72(4), 493-501. 
Ultsch, G. R., and Jackson, D. C. (1982). Long-term submergence at 3 degrees C of the turtle Chrysemys picta bellii in normoxic and severely hypoxic water. III. Effects of changes in ambient PO2 and subsequent air breathing. Journal of Experimental Zoology, 97, 87-99.

Valouev, A., Johnson, D., Sundquist, A., Medina, C., Anton, E., Batzoglou, S., Myers, R., Sidow, A. (2008). Genome-wide Analysis of Transcription Factor Binding Sites based on ChIP-Seq Data. Nature Methods, 5(9), 829-834.

Velden, J., Schols, A., Willems, J., Kelders, M., Langen, R. (2008). Glycogen Synthase Kinase $3 \beta$ Supresses Myogenic Differentiation Though Negative Regulation of NFATc3. Journal of Biological Chemistry, 283(1), 358-366.

Viola, J. P. B., Carvahlo, L. D. S., Fonseca, B. P. F., Teixeira, L. K. (2005). NFAT transcription factors: from cell cycle to tumor development. Brizilian Journal of Medical and Biological Research, 38(3), 335-344.

Walczak-Drzewiecka, A., Ratajewski, M., Wagner, W., Dastych, J. (2008). HIF-1 $\alpha$ is up-regulated in activated mast cells by a process that involved calcineurin and NFAT. Journal of Immunology, 181(3), 1665-1672.

Walters, R., Drullinger, L., Kuge, J., Goodrich, J. (2013). NFATc2 recruits cJun homodimers to an NFAT site to synergistically activate interleukin-2 transcription. Molecular Immunology, 56(1-2), 48-56.

Wang, Q., Zhou, Y., Jackson, L., Johnson, S., Chow, C., Evers, B. (2011). Nuclear factor of activated $\mathrm{T}$ cells (NFAT) signalling regulates PTEN expression and intestinal cell differentiation. Molecular Biology of the Cell, 22(3), 412-420.

Wang, S., Kang, X., Cao, S., Cheng, H., Wang, D., Geng, J. (2010). Calcineurin/NFATc1 pathway contributes to cell proliferation in Hepatocellular Carcinoma. Digestive Diseases and Sciences, 57(12), 3184-3188.

Waypa, G., Marks, J., Mack, M., Boriboun, C., Mungai, P., Schumacker, P. (2002). Mitochondrial reactive oxygen species trigger calcium increases during hypoxia in pulmonary arterial myocytes. Circulation Research, 91(8), 719-726.

Weitzel, R., Lesnieswki, M., Haviernik, P., Kadereit, S., Leahy, P., Greco, N., Laughlin, M. (2009). microRNA-184 regulates expression of NFAT1 in umbilical cord blood CD4 ${ }^{+}$T cells. Blood, 113(26), 6648-6657.

Wellman, G. C., Cartin, L., Eckman, D. M., Stevenson, A. S., Saundry, C. M., Lederer, W. J., Nelson, M. T. (2001). Membrane depolarization, elevated $\mathrm{Ca}(2+)$ entry, and gene expression in cerebral arteries of hypertensive rats. American Journal of Physiology. Heart and Circulatory Physiology, 281(6), H2559-H2567.

Wen, Y., Feng, D., Wu, H., Liu, W., Li, H., Wang, F., Xia, Q., Gao, W., Kong, X. (2015). Defective initiation of liver regeneration in osteopontin deficient mice after partial hepatectomy due to insufficient activation of Il-6/STAT3 pathway. International Journal of Biological Sciences, 11(10), 1236-1247. 
Wharton, D. (1996). Water loss and morphological changes during desiccation of the anhydrobiotic nematode Ditylenchus Dipsaci. Journal of Experimental Biology, 199, 1085-1093.

Woodgett, J. R., and Cohen, P. (1984). Multisite phosphorylation of glycogen synthase. Molecular basis for the substrate specificity of glycogen synthase kinase-3 and casein kinase-ii (Glycogen synthase kinase-5). Biochimica et Biophysica Acta, 788(3), 339347.

Wu, J., Zhang, C., Wang, X., Yun, S., Zhao, Y., Liu, L., Lu, Y., Ye., Y., Zhu, X., Zhang, C., Shi, S., Liu, Z. (2015). MicroRNA-30 family members regulate calcium/calcineurin signaling in podocytes, Journal of Clinical InvestigationI, 125(11), 4091-4106.

Yamada, T., Kotake, Y., Nagata, H., Takeda, J. (2013). Atrial natriuretic peptide reduces hepatic ischemia-reperfusion injury in rabbits. Journal of Anesthesia, 27(6), 901-908.

Yang, T., Suk, H., Yang, X., Olabisi, O., Yu, R., Durand, J., Jelicks, L., Kim, J., Scherer, P., Wang, Y., Feng, Y., Rosetti, L., Graef, I., Crabtree, G., Chow, C. (2006). Role of Transcription Factor NFAT in Glucose and Insulin Homeostasis. Molecular and Cellular Biology, 26(20), 7372-7387.

Yang, T., Xiong, W., Enslen, H., Davis, R., Chow, C. (2002). Phosphorylation of NFATc4 by p38 Mitogen-Activated Protein Kinases. Molecular and Cellular Biology, 22(11), 3892-3904.

Yin, H., Zhao, L., Zhang, S., Zhang, Y., Lei, S. (2015). MicroRNA-1 supresses cardiac hypertrophy by targeting nuclear factor of activated T cells cytoplasmic. Molecular Medicine Reports, 12(6), 8282-8.

Zetterqvist, A., Blanco, F., Ohman, J., Kotova, O., Berglund, L., Garcia, S., Al-Naemi, R., Wigren, M., McGuire, P., Bosc, L., Gomez, M. (2015). Nuclear factor of activated $\mathrm{T}$ cells is activated in endothelium of retinal microvessels in diabetic mice. Journal of Diabetes Research, 2015.

Zhang, J., and Storey, K. B. (2013). Akt signaling and freezing survival in the wood frog, Rana sylvatica. Biochim Biophys Acta, 1830(10), 4818-37.

Zhang, W., DePaoli-Roach A., Roach, P. (1993). Mechanisms of multisite phosphorylation and inactivation of rabbit muscle glycogen synthase. Archives of Biochemistry and Biophysics, 304(1), 219-225.

Zhang, X., Wen, H., Shi, X. (2012). Lysine Methylation: Beyond Histones. Acta Biochimica et Biophysica Sinica, 44(1), 14-27. 
Appendix I: Representative western blots 
Figure S1: Whole image of ECL-detected membrane using the control, 24 hour frozen and 8 hour thawed liver samples probed with anti-NFATc1 antibody.

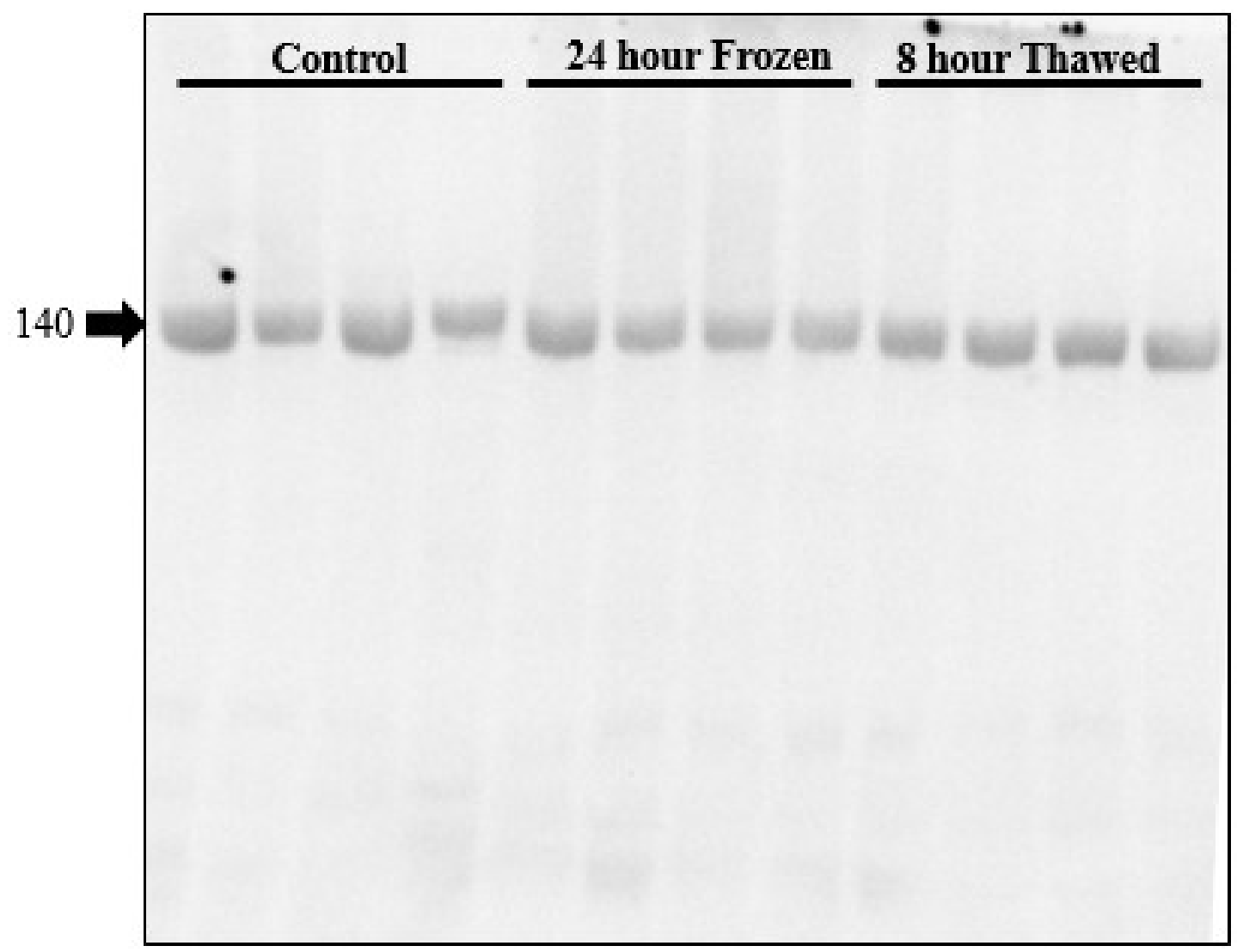


Figure S2: Whole image of ECL-detected membrane using the control, 24 hour frozen and 8 hour thawed skeletal muscle samples probed with anti-GSK3 $\beta$ antibody.

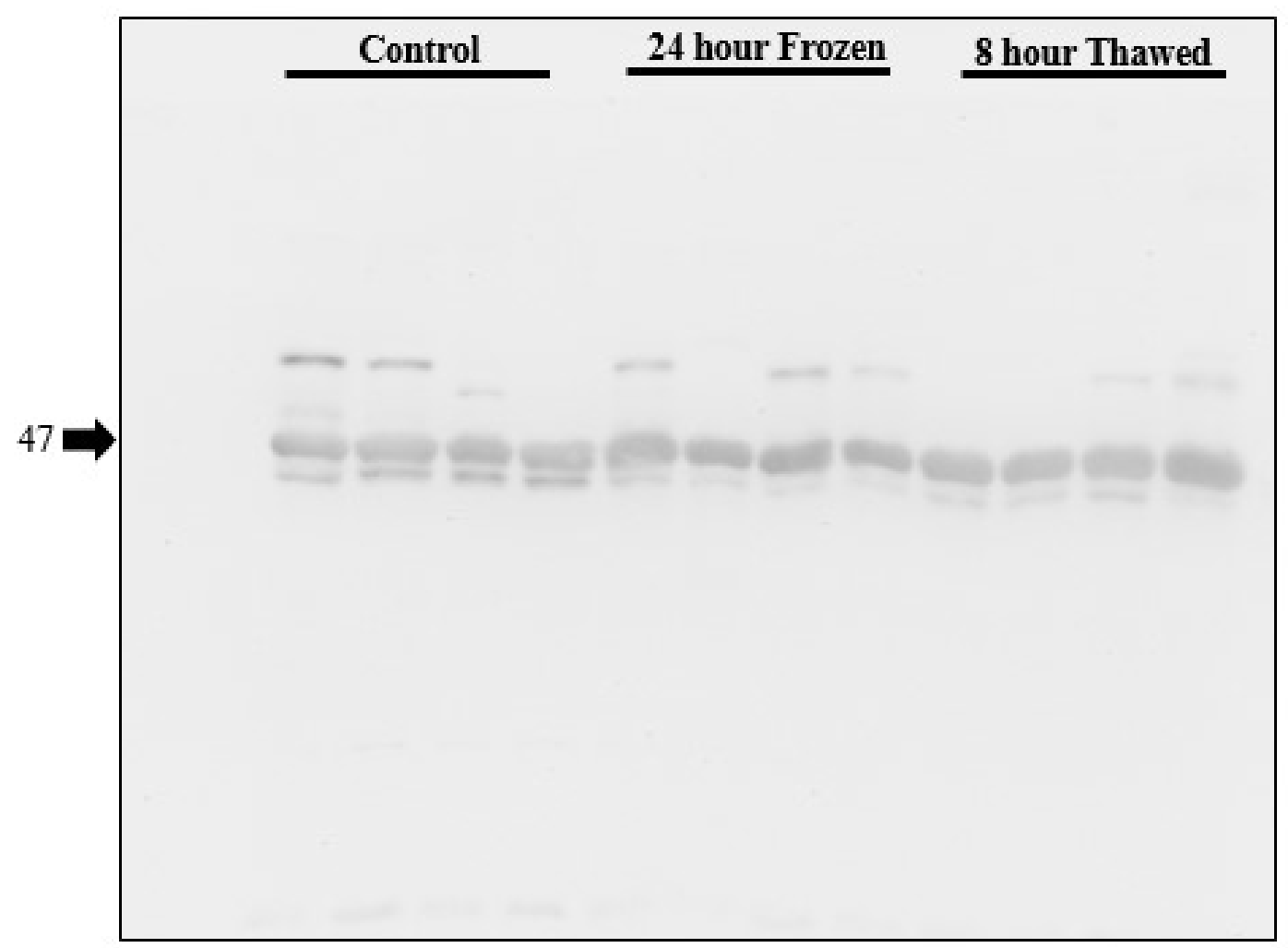


Figure S3: Whole image of ECL-detected membrane using the control, 24 hour frozen and 8 hour thawed liver samples probed with anti-p-STAT3 (Tyr 705).

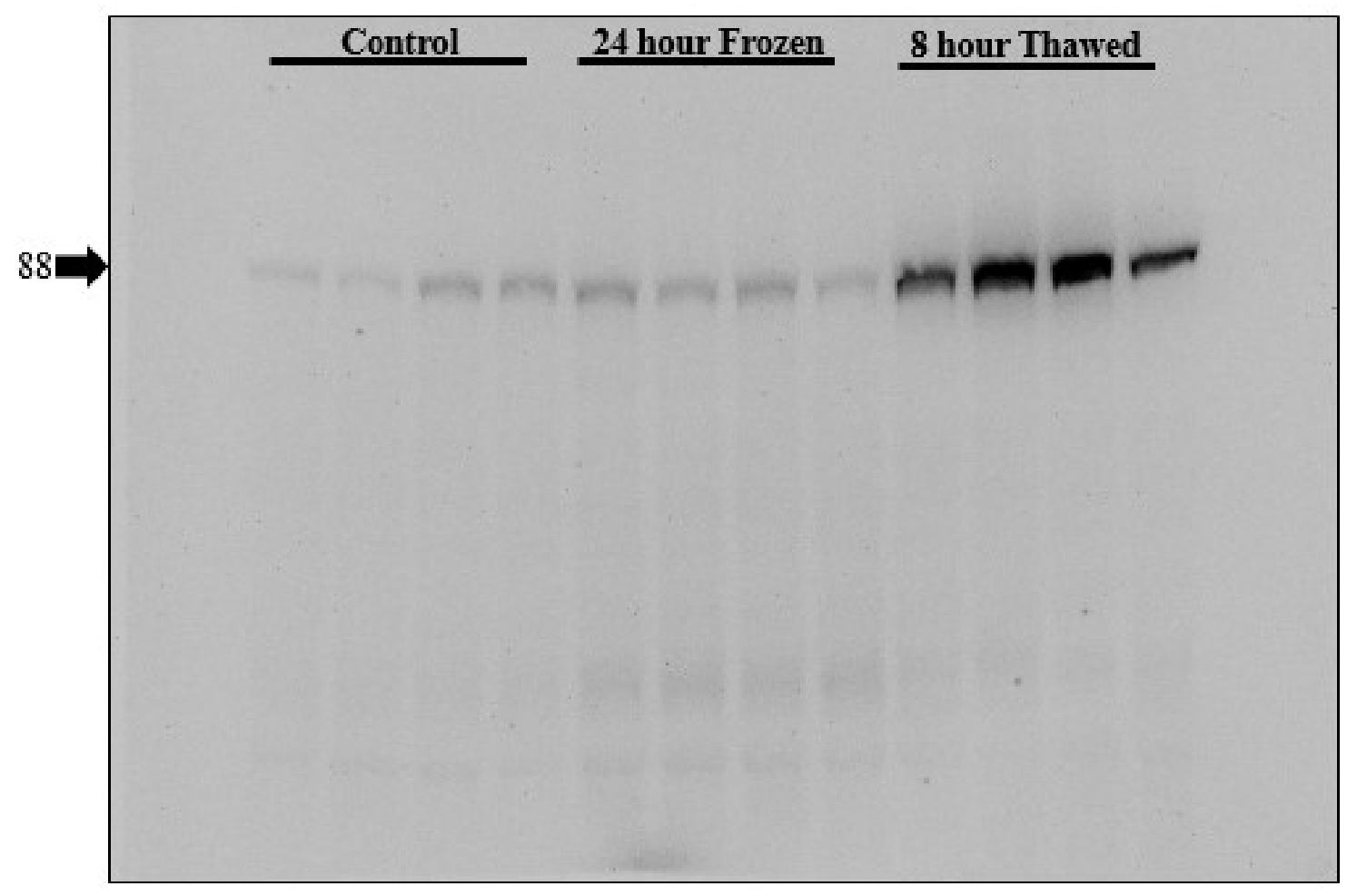


Figure S4: Whole image of ECL-detected membrane using the control, 24 hour anoxic and 4 hour recovery liver samples probed with anti-calcineurin A antibody.

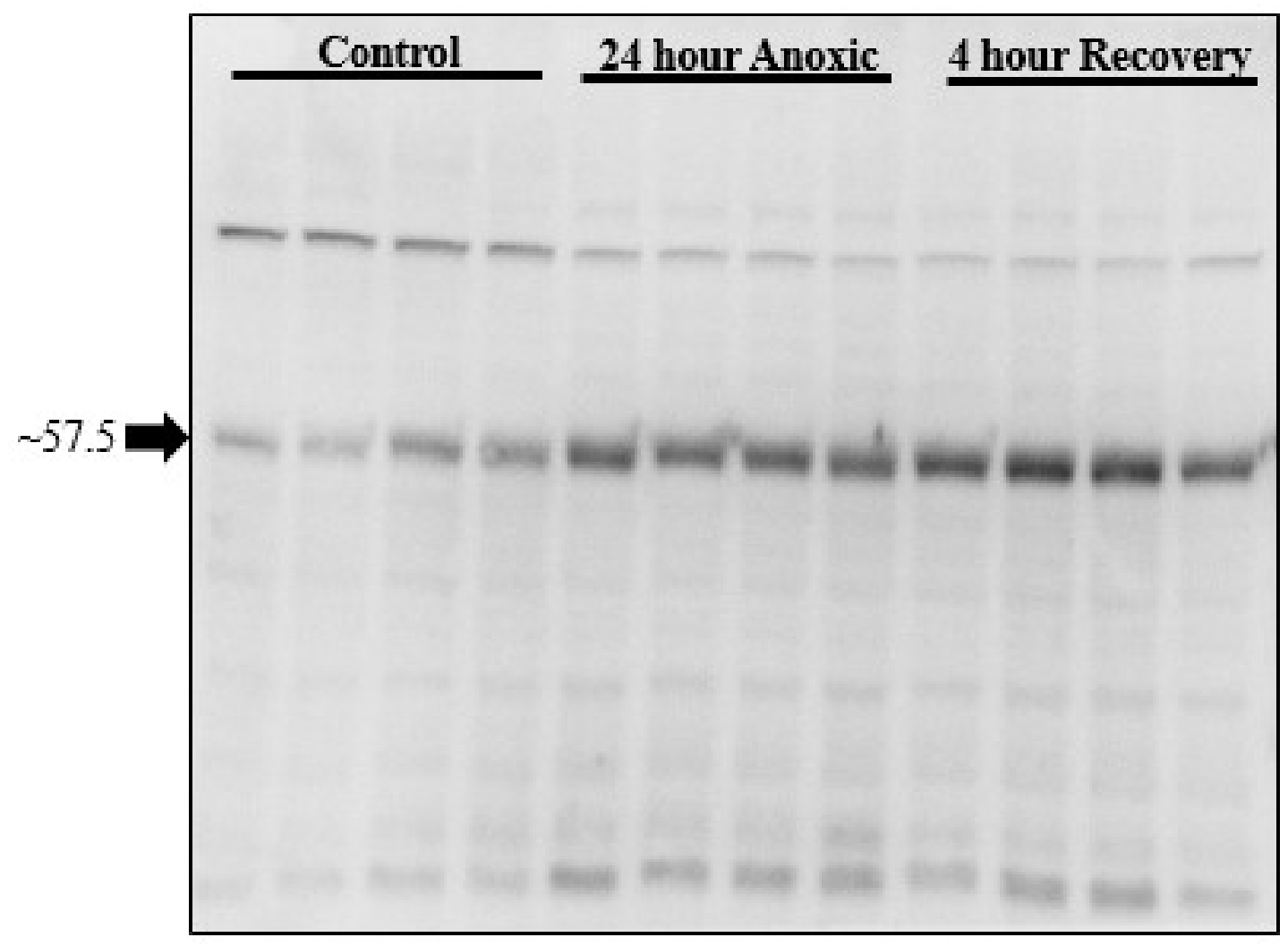


Figure S5: Whole image of ECL-detected membrane using the control, 24 hour anoxic and 4 hour recovery skeletal muscle samples probed with anti-calcineurin A antibody.

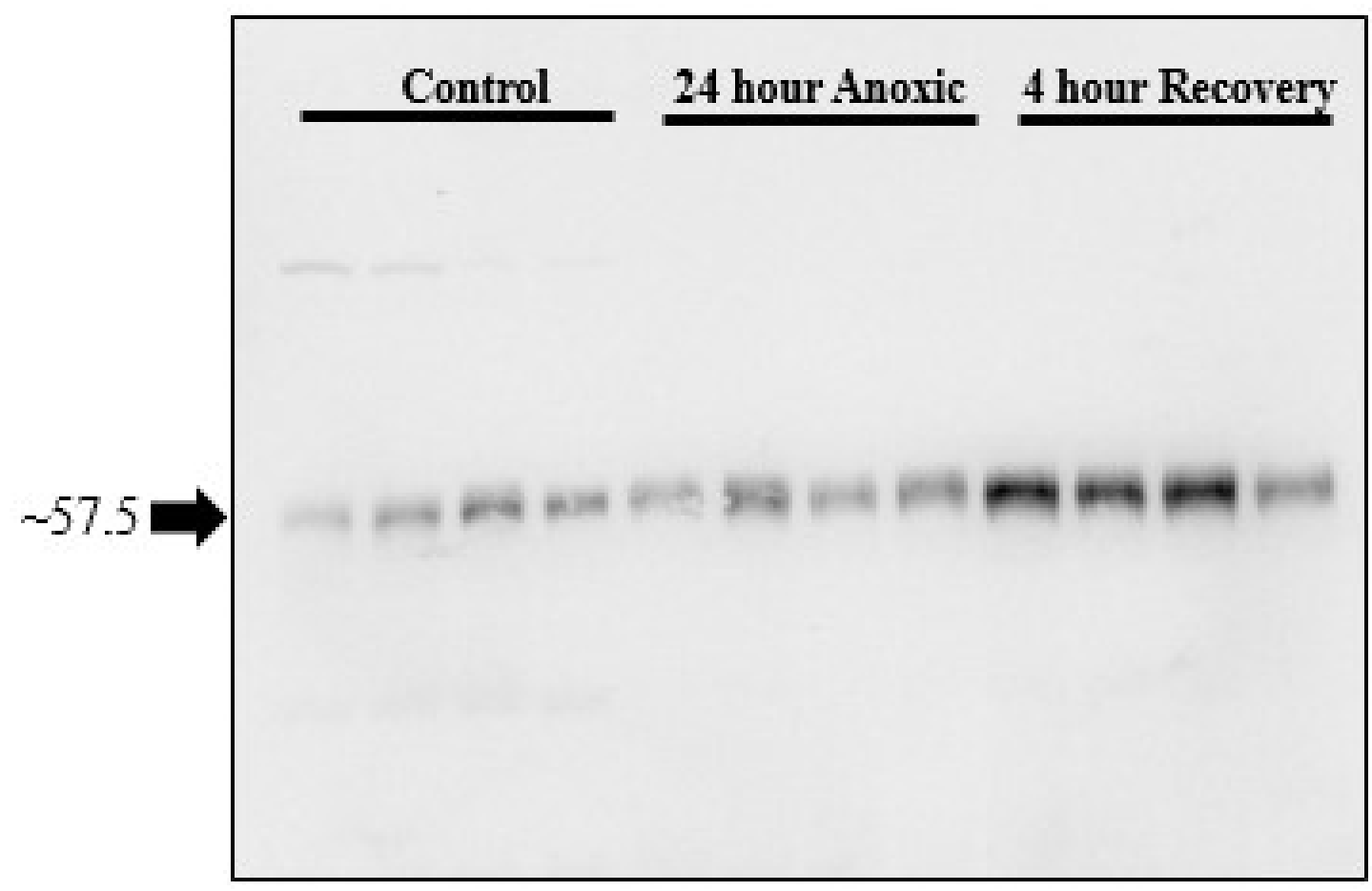

